\title{
Protein phosphorylation in neurodegeneration: friend or foe?
}

\author{
Sandra Tenreiro ${ }^{1}$, Katrin Eckermann ${ }^{2}$ and Tiago F. Outeiro ${ }^{1,3,4}$ * \\ ${ }^{1}$ Cell and Molecular Neuroscience Unit, Instituto de Medicina Molecular, Lisboa, Portugal \\ 2 Department of Neurology, Center for Nanoscale Microscopy and Molecular Physiology of the Brain, University Medical Center Göttingen, Göttingen, Germany \\ ${ }^{3}$ Instituto de Fisiologia, Faculdade de Medicina da Universidade de Lisboa, Lisboa, Portugal \\ ${ }^{4}$ Department of NeuroDegeneration and Restorative Research, Center for Nanoscale Microscopy and Molecular Physiology of the Brain, University Medical Center \\ Göttingen, Göttingen, Germany
}

Edited by:

Jean-Marc Taymans, KU Leuven,

Belgium

Reviewed by:

Baojin Ding, University of

Massachusetts Medical School, USA

Elisa Greggio, University of Padova,

Italy

\section{*Correspondence:}

Tiago F. Outeiro, Department of NeuroDegeneration and Restorative Research University Medical Center Goettingen, Waldweg 33, 37073

Goettingen, Germany

e-mail: tiago.outeiro@

med.uni-goettingen.de
Protein misfolding and aggregation is a common hallmark in neurodegenerative disorders, including Alzheimer's disease (AD), Parkinson's disease (PD), and fronto-temporal dementia (FTD). In these disorders, the misfolding and aggregation of specific proteins occurs alongside neuronal degeneration in somewhat specific brain areas, depending on the disorder and the stage of the disease. However, we still do not fully understand the mechanisms governing protein aggregation, and whether this constitutes a protective or detrimental process. In PD, alpha-synuclein (aSyn) forms protein aggregates, known as Lewy bodies, and is phosphorylated at serine 129. Other residues have also been shown to be phosphorylated, but the significance of phosphorylation in the biology and pathophysiology of the protein is still controversial. In AD and in FTD, hyperphosphorylation of tau protein causes its misfolding and aggregation. Again, our understanding of the precise consequences of tau phosphorylation in the biology and pathophysiology of the protein is still limited. Through the use of a variety of model organisms and technical approaches, we are now gaining stronger insight into the effects of phosphorylation in the behavior of these proteins. In this review, we cover recent findings in the field and discuss how targeting phosphorylation events might be used for therapeutic intervention in these devastating diseases of the nervous system.

\section{Keywords: alpha-synuclein, tau, Parkinson's disease, Alzheimer's disease, phosphorylation, neurodegeneration}

\section{NEURODEGENERATIVE DISORDERS AS PROTEIN AGGREGOPATHIES}

Neurodegenerative disorders, such as Parkinson's disease (PD), Alzheimer's disease (AD) and frontotemporal dementia (FTD), result from the progressive loss of specific neuronal populations leading to the progressive appearance of the clinical symptoms that are characteristic of each disorder. Current treatments for these disorders are palliative rather than curative and their effectiveness is still far from satisfactory. Thus, tremendous efforts are underway to elucidate the causes underlying these disorders and to find a cure. From a molecular perspective, the common hallmark of neurodegenerative disorders is the misfolding and aberrant aggregation of proteins in amyloid-like beta-sheet filaments. This feature is not only characteristic of classic neurodegenerative disorders but also of prion disorders and other amyloidosis inside and outside the central nervous system, suggesting that neurodegenerative disorders are part of a much greater superfamily of protein misfolding disorders, or aggregopathies (Frost and Diamond, 2010).

While it is clear that protein misfolding and aggregation are pathological hallmarks of neurodegenerative disorders, the precise mechanisms linking protein aggregation and neurotoxicity are largely unknown. Protein aggregates are dynamic structures, allowing small soluble species to detach or attach from or to larger protein inclusions relatively easily (Kim et al., 2002). As a result of this dynamism, protein inclusions have variable solubility, stability and size. Big, insoluble protein inclusions inside or outside neurons were initially thought to be neurotoxic. However, current evidence indicates that they might be rather neuroprotective (Arrasate et al., 2004; Bodner et al., 2006), and that the smaller, more soluble oligomers are the ones that exert neurotoxicity. A consensus in this matter remains to be reached but, regardless of the nature of the toxic and non-toxic species, unraveling the mechanisms determining protein aggregation is absolutely necessary for the understanding, diagnosis and treatment of neurodegenerative disorders.

\section{POSTTRANSLATIONAL MODIFICATIONS AS MODULATORS OF PROTEIN FATE}

Protein aggregation can be regulated by various cellular events including different types of stress, molecular crowding, or the local micro-environment. In addition, diverse posttranslational modifications (PTMs), such as phosphorylation, ubiquitination or sumoylation, which alter the conformation and/or biological function of proteins, can also affect protein folding and aggregation, and thereby play a critical role in neurodegenerative disorders. For example, ubiquitination can direct proteins for either degradation by the proteasome or to certain subcellular compartments, and glycosylation is related to the secretion of proteins to the extracellular medium. Both processes could 
therefore influence protein concentration, folding, localization and, ultimately, aggregation. Phosphorylation can also affect protein conformation, function and fate in many different ways: it may be required for proper protein folding; it may induce conformational changes that can result in lower or higher catalytic activity; it may precede or function as a recognition signal for further modifications, such as ubiquitination; it may alter the subcellular localization of the protein; and it may modify protein-protein interactions (Salazar and Hofer, 2009). In the particular case of neurodegenerative and protein misfolding diseases, phosphorylation has been shown to be involved in both protein aggregation and toxicity, as illustrated by the paradigmatic examples described below (Figure 1).

\section{PHOSPHORYLATION IN PARKINSON'S DISEASE AND OTHER SYNUCLEINOPATHIES}

Alpha-synuclein (aSyn) is the main protein component of Lewy bodies (LBs), the typical pathological hallmarks of PD and other disorders collectively known as synucleinopathies. The vast majority of PD cases are sporadic, multiplications and missense mutations in the gene encoding for aSyn have been associated with familial forms of PD (Polymeropoulos et al., 1997; Kruger et al., 1998; Singleton et al., 2003; Chartier-Harlin et al., 2004; Zarranz et al., 2004; Appel-Cresswell et al., 2013; Kiely et al., 2013; Lesage et al., 2013).

Several PTMs have already been identified in aSyn. These include ubiquitination (Shimura et al., 2001), phosphorylation at S129 (Fujiwara et al., 2002), a C-terminal truncation (Li et al., 2005), nitration on tyrosine residues (Giasson et al., 2000), glycosylation, and SUMO modification (Dorval and Fraser, 2006). However, most attention was devoted to phosphorylation at S129 (pS129). While only 4\% of the soluble, monomeric aSyn appears phosphorylated under physiological conditions in vivo, approximately $90 \%$ is phosphorylated in LB lesions (Fujiwara et al., 2002; Anderson et al., 2006), suggesting a close relationship between aSyn phosphorylation at S129 and its aggregation. In particular, pS129 aSyn is found in LBs occurring and other pathogenic inclusions found in substantia nigra of PD patients (Fujiwara et al., 2002; Saito et al., 2003; Anderson et al., 2006) as well as in different brain regions of patients suffering from other synucleinopathies, such as dementia with LBs (DLB), multiple system atrophy (Fujiwara et al., 2002; Kahle et al., 2002; Saito et al., 2003; Nishie et al., 2004; Waxman and Giasson, 2008), Hallervorden-Spatz disease (Fujiwara et al., 2002), pure autonomic failure (Arai et al., 2000b), and LB variant of AD (LBVAD) (Waxman and Giasson, 2008). In addition, aSyn was found to be phosphorylated on S129 in transgenic mice expressing human mutant A30P, A53T, or WT aSyn (Kahle et al., 2002; Freichel et al., 2007; Wakamatsu et al., 2007).

In addition to S129, other three serine, four tyrosine and ten threonine residues are putative sites of phosphorylation (Figure 2). These residues are mostly localized in the C-terminal region of the protein, with the exception of Y39 and S87. Increased levels of phosphorylated S87 (pS87) were also reported in synucleinopathies (Paleologou et al., 2010). Phosphorylation aSyn on tyrosine 39 (pY39) and 125 (pY125) was also reported in human brains but no correlation was established between increased levels of phosphorylation in these residues and the pathological condition (Chen et al., 2009; Mahul-Mellier et al., 2014). Other residues were found to be phosphorylated in vitro but it is unknown if their phosphorylation also occurs in vivo, even if in small extension.

\section{THE ROLE OF PHOSPHORYLATION ON aSYn CYTOTOXICITY AND AGGREGATION}

The phosphorylation status of aSyn clearly influences its aggregation and toxicity, but it is still unclear whether phosphorylation promotes or prevents aggregation and toxicity. To better understand this trinomial relation, would also be important to clearly establish what are the toxic forms of aggregated aSyn, although recent studies suggest that the soluble oligomeric/protofibrillar species may be more toxic than larger aggregated forms of aSyn (Spillantini et al., 1997; Conway et al., 2001; El-Agnaf et al., 2003; Outeiro et al., 2007; Diogenes et al., 2012).

In vitro and in vivo studies, correlating phosphorylation of aSyn in several residues to its aggregation and/or toxicity, resulted in conflicting results (Table 1). Several of these studies employed S129A and S129D/E mutants, to block and mimic phosphorylation, respectively. Other studies modulated the levels of phosphorylation of aSyn by either co-expressing specific kinases or phosphatases, or by using kinase inhibitors (Table 1). Moreover, these studies included three types of assays: (i) in vitro biochemical studies; (ii) single cell models (yeast and mammalian cells); and (iii) animal models of PD (mice or rat models). In these studies the relation between toxicity and aggregation was not always explored (Table $\mathbf{1}$ ).

The genetic mutant that attempts to mimic pS129 (S129D) aSyn was initially associated with pathology in a transgenic Drosophila model (Chen and Feany, 2005; Chen et al., 2009) while aSyn hyperphosphorylation and insolubility were correlated with the disease in transgenic mouse models of PD (Kahle et al., 2002; Freichel et al., 2007). However, opposite results were obtained in yeast, rat and Caenorhabditis elegans models of PD. Namely, S129E had no effect while the mutation S129A increased aSyn toxicity in budding yeast (Fiske et al., 2011; Sancenon et al., 2012). Moreover, in rat models using retrovirus-mediated expression of aSyn in neurons of the substantia nigra, the S129A variant also showed toxicity while the results for S129D were variable, showing either protecting (Gorbatyuk et al., 2008) or no effect (Azeredo Da Silveira et al., 2009). In C. elegans models, S129D aSyn was also protective, reducing neuronal dysfunction, while S129A expression resulted in severe motor dysfunction, growth retardation, and synaptic abnormality by lowering its membrane interaction (Kuwahara et al., 2012).

Similarly, while some reports suggest that pS129 promotes inclusion formation (Fujiwara et al., 2002; Smith et al., 2005; Arawaka et al., 2006; Takahashi et al., 2007; Gorbatyuk et al., 2008; Kragh et al., 2009; Wu et al., 2011a), others suggest that phosphorylation prevents or has no effect on inclusion formation (Lee et al., 2004a; Chen and Feany, 2005; Paleologou et al., 2008; Waxman and Giasson, 2008; Azeredo Da Silveira et al., 2009; Chau et al., 2009; Chen et al., 2009; Fiske et al., 2011; Sancenon et al., 2012) (Table 1). 


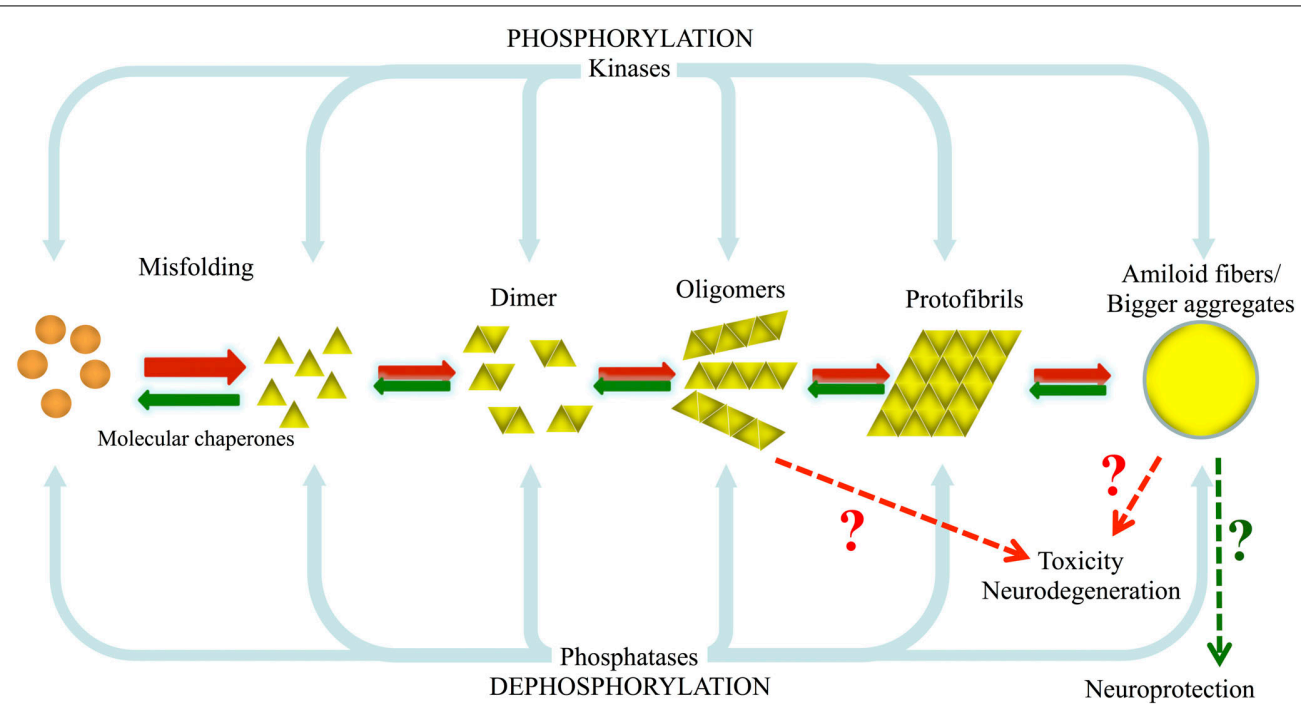

FIGURE 1 | Model of aSyn and tau misfolding and aggregation, and the involvement of kinases and phosphatases on their phosphorylation/dephosphorylation. Under pathological conditions, due to genetic or environmental factors such as exposure to pesticides, normal highly soluble aSyn and tau misfold and are converted into pathological oligomers and larger species that fibrillize and deposit into inclusion bodies as LBs and Lewy neurites and into PHFs and NFTs. In this situation the normal cellular quality-control systems (molecular chaperones, ubiquitin proteasome system (UPS), phagosome/lysosome system) are not able to counteract and prevent or reverse protein misfolding or eliminate proteins that have misfolded or assembled into pathological aggregates and amyloid fibrils.

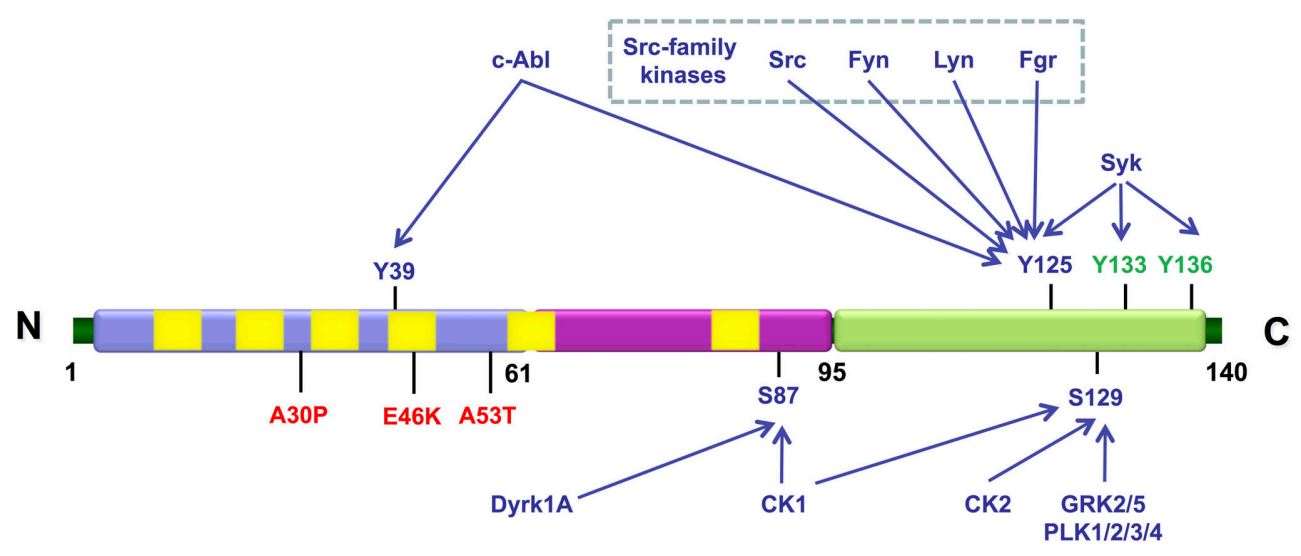

FIGURE 2 | Schematic representation illustrating the various residues in aSyn that can be phosphorylated in vivo (represented in blue) and in vitro (represented in green). The mutations associated with familial PD are shown in red. The $\mathrm{N}$-terminal amphipathic region of the protein is represented in blue, the hydrophobic central region that contains the non-amyloid- $\beta$ component (NAC) domain is represented in purple and the highly acidic C-terminal is represented in green. The imperfect KTKEGV repeats are represented in yellow. The kinases described as being able to phosphorylate each of the indicated residues are also indicated.
In vitro biochemical studies also lead to conflicting results regarding the correlation between pS129 and fibrillization of aSyn. While S129 aSyn phosphorylated by casein kinase (CK)2 was found to form fibrils more readily than unphosphorylated aSyn in vitro (Fujiwara et al., 2002), different studies observed that fibrillization of aSyn is inhibited in purified pS129 S87A aSyn (where phosphorylation at $\mathrm{S} 87$ is blocked) (Paleologou et al., 2008; Waxman and Giasson, 2008), while a more recent study reposted that pS129 aSyn by polo-like kinase (PLK) 2 displays comparable fibrillization kinetics to the $\mathrm{WT}$ protein in vitro (Schreurs et al., 2014).
Studies performed in different cell and animal models are also not consensual regarding the correlation between aSyn pS129 and aggregation. Most studies performed in cell lines associate aSyn pS129 with increased formation of soluble oligomers (Arawaka et al., 2006; Kragh et al., 2009), cytoplasmic and nuclei aggregates (Arawaka et al., 2006; Wu et al., 2011a), and cytoplasmic inclusions (Smith et al., 2005; Takahashi et al., 2007) (Table 1). Toxicity was evaluated only in some of these studies and was interrelated with increased aggregation in one study (Kragh et al., 2009) but was found to be protective in another (Wu et al., 2011a). 
Table 1 | aSyn phosphorylation sites and effects.

\begin{tabular}{|c|c|c|c|c|c|}
\hline $\begin{array}{l}\text { aSyn } \\
\text { residue }\end{array}$ & Kinase & Model & Cytotoxicity & Aggregation & References \\
\hline Y39 & c-Abl & $\begin{array}{l}\text { In vitro biochemical } \\
\text { assay/M17 neuroblastoma } \\
\text { cell lines/ primary cultures of } \\
\text { mouse cortical neurons / } \\
\text { mThy1 aSyn transgenic mice } \\
\text { / Rat model involving viral } \\
\text { delivery }\end{array}$ & $\begin{array}{l}\text { c-Abl inhibition increases } \\
\text { aSyn degradation by } \\
\text { proteasome and autophagy } \\
\text { pathways }\end{array}$ & - & $\begin{array}{l}\text { Mahul-Mellier et al., } \\
2014\end{array}$ \\
\hline \multirow[t]{5}{*}{ S87 } & CK1 & $\begin{array}{l}\text { In vitro biochemical } \\
\text { assay/K293 and PC12 cells }\end{array}$ & - & - & Okochi et al., 2000 \\
\hline & Dyrk1A & $\begin{array}{l}\text { In vitro biochemical } \\
\text { assay/SH-SY5Y and H19-7 } \\
\text { cells }\end{array}$ & $\begin{array}{l}\text { Increased pS87 increases } \\
\text { citotoxicity }\end{array}$ & $\begin{array}{l}\text { Increased pS87 increases } \\
\text { aSyn aggregation in cultured } \\
\text { cells }\end{array}$ & Kim et al., 2006 \\
\hline & CK1 & $\begin{array}{l}\text { In vitro biochemical } \\
\text { assay/SH-SY5Y cells/ } \\
\text { transgenic mice M20 and } \\
\text { M83 }\end{array}$ & - & $\begin{array}{l}\text { pS87 reduce recombinant } \\
\text { aSyn fibril formation }\end{array}$ & $\begin{array}{l}\text { Waxman and } \\
\text { Giasson, } 2008\end{array}$ \\
\hline & CK1 & $\begin{array}{l}\text { In vitro biochemical assay/ } \\
\text { transgenic mouse models of } \\
\text { PD/LBD and MSA }\end{array}$ & - & $\begin{array}{l}\text { S87E or pS87 blocks aSyn } \\
\text { fibrillization }\end{array}$ & $\begin{array}{l}\text { Paleologou et al., } \\
2010\end{array}$ \\
\hline & - & $\begin{array}{l}\text { Rat model involving viral } \\
\text { delivery of WT, S87A, and } \\
\text { S87E aSyn }\end{array}$ & $\begin{array}{l}\text { S87E protects against aSyn } \\
\text { induced toxicity by reducing } \\
\text { dystrophic fibers, and motor } \\
\text { impairment }\end{array}$ & $\begin{array}{l}\text { S87E inhibits aSyn } \\
\text { aggregation }\end{array}$ & Oueslati et al., 2012 \\
\hline \multirow[t]{7}{*}{ Y125 } & Fyn & $\begin{array}{l}\text { In vitro biochemical } \\
\text { assay/COS7 cells }\end{array}$ & - & - & Nakamura et al., 2001 \\
\hline & Src, Fyn & $\begin{array}{l}\text { In vitro biochemical } \\
\text { assay/HEK293T cells }\end{array}$ & - & - & Ellis et al., 2001 \\
\hline & Src-family kinases & COS7 cells & - & - & Nakamura et al., 2001 \\
\hline & Syk, Lyn, Fgr & $\begin{array}{l}\text { In vitro biochemical } \\
\text { assay/SH-N-BE and } \mathrm{CHO} \text { cells }\end{array}$ & - & $\begin{array}{l}\text { Syk-mediated aSyn } \\
\text { phosphorylation decreases } \\
\text { oligomerization }\end{array}$ & Negro et al., 2002 \\
\hline & $\begin{array}{l}\text { kinase shark (Syk } \\
\text { Drosophila } \\
\text { homolog) }\end{array}$ & Drosophila & $\begin{array}{l}\text { Increased } \mathrm{pY} 125 \text { is } \\
\text { protective; } \mathrm{Y} 125 \mathrm{~F} \text { is toxic }\end{array}$ & $\begin{array}{l}\text { Increased pY125 decreases } \\
\text { aSyn oligomerization while } \\
\text { Y125F increases it }\end{array}$ & Chau et al., 2009 \\
\hline & Fyn & In vitro biochemical assay & - & $\begin{array}{l}\text { in vitro pY125 fibrillate } \\
\text { similarly to WT aSyn while } \\
\text { Y125F or Y125E fibrillate } \\
\text { significantly slower than WT } \\
\text { aSyn }\end{array}$ & Schreurs et al., 2014 \\
\hline & c-Abl & $\begin{array}{l}\text { In vitro biochemical } \\
\text { assay/M17 neuroblastoma } \\
\text { cell lines/ primary cultures of } \\
\text { mouse cortical neurons / } \\
\text { mThy1 aSyn transgenic mice } \\
\text { / Rat model involving viral } \\
\text { delivery }\end{array}$ & $\begin{array}{l}\text { c-Abl inhibition increases } \\
\text { aSyn degradation by } \\
\text { proteasome and autophagy } \\
\text { pathways }\end{array}$ & - & $\begin{array}{l}\text { Mahul-Mellier et al., } \\
2014\end{array}$ \\
\hline \multirow[t]{4}{*}{ S129 } & CK1, CK2 & $\begin{array}{l}\text { In vitro biochemical } \\
\text { assay/K293 cells }\end{array}$ & - & - & Okochi et al., 2000 \\
\hline & $\begin{array}{l}\text { CK1, CK2, Grk2, } \\
\text { Grk5 }\end{array}$ & $\begin{array}{l}\text { In vitro biochemical } \\
\text { assay/COS-1 cells }\end{array}$ & - & - & Pronin et al., 2000 \\
\hline & CK2 & In vitro biochemical assay & - & $\begin{array}{l}\text { pS129 increases aSyn } \\
\text { fibrillization in vitro }\end{array}$ & Fujiwara et al., 2002 \\
\hline & PLK2 & $\begin{array}{l}\text { In vitro biochemical } \\
\text { assay/HEK293 cells/Mouse }\end{array}$ & - & - & Inglis et al., 2009 \\
\hline
\end{tabular}


Table 1 | Continued

\begin{tabular}{|c|c|c|c|c|c|}
\hline $\begin{array}{l}\text { aSyn } \\
\text { residue }\end{array}$ & Kinase & Model & Cytotoxicity & Aggregation & References \\
\hline & CK1, CK2 & In vitro biochemical assay & - & $\begin{array}{l}\text { pSer129 inhibits rather than } \\
\text { promotes aSyn fibrillization; } \\
\text { S129A promotes aSyn } \\
\text { aggregation }\end{array}$ & $\begin{array}{l}\text { Paleologou et al., } \\
2008\end{array}$ \\
\hline & PLK2 & In vitro biochemical assay & - & $\begin{array}{l}\text { in vitro pS129, S129A or } \\
\text { S129D fibrillate similarly to } \\
\text { WT aSyn }\end{array}$ & Schreurs et al., 2014 \\
\hline & $\begin{array}{l}\text { Yck1 and Yck2 } \\
\text { yeast CK1 kinases }\end{array}$ & S. cerevisiae & $\begin{array}{l}\text { pS129 by plasma membrane } \\
\text { CK1 kinases correlates with } \\
\text { aSyn toxicity }\end{array}$ & $\begin{array}{l}\text { pS129 by plasma membrane } \\
\text { CK1 kinases correlates with } \\
\text { aSyn inclusion formation }\end{array}$ & Zabrocki et al., 2008 \\
\hline & - & $\begin{array}{l}\text { Schizosaccharomyces pombe } \\
\text { andS. cerevisiae }\end{array}$ & $\begin{array}{l}\text { Neither S129A nor S129D } \\
\text { mutants altered WT aSyn } \\
\text { toxicity }\end{array}$ & $\begin{array}{l}\text { Both S129A and S129D } \\
\text { increased endomembrane } \\
\text { association in S. pombe, but } \\
\text { only S129D decreased } \\
\text { plasma membrane } \\
\text { association in S. cerevisiae }\end{array}$ & Fischer et al., 2009 \\
\hline & CK1 & S. cerevisiae & $\begin{array}{l}\text { Yck1 CK1 yeast ortholog } \\
\text { phosphorylate S129 aSyn and } \\
\text { attenuate aSyn toxicity by an } \\
\text { S129 } \\
\text { phosphorylation-independent } \\
\text { mechanism; S129A increases } \\
\text { aSyn toxicity in a yeast } \\
\text { genetic context-dependent } \\
\text { manner }\end{array}$ & $\begin{array}{l}\text { S129A increases aSyn } \\
\text { inclusion formation a in a } \\
\text { yeast genetic } \\
\text { context-dependent manner; }\end{array}$ & Sancenon et al., 2012 \\
\hline & $\begin{array}{l}\text { PLK1, PLK2, PLK3, } \\
\text { PLK4 }\end{array}$ & $\begin{array}{l}\text { S. cerevisiae, mouse CAD } \\
\text { cathecolaminergic cells and } \\
\text { human } \mathrm{H} 4 \text { neuroglioma cells }\end{array}$ & $\begin{array}{l}\text { PLK2 increased aSyn } \\
\text { cytotoxicity in yeast but by an } \\
\text { S129 } \\
\text { phosphorylation-independent } \\
\text { mechanism phosphorylation }\end{array}$ & $\begin{array}{l}\text { PLK2 promotes aSyn } \\
\text { inclusion formation in yeast } \\
\text { and in mammalian cells by an } \\
\text { S129 } \\
\text { phosphorylation-independent } \\
\text { mechanism }\end{array}$ & Basso et al., 2013 \\
\hline & - & S. cerevisiae & S129A increases aSyn toxicity & $\begin{array}{l}\text { S129A aSyn forms more } \\
\text { inclusions and oligomeric } \\
\text { species with higher molecular } \\
\text { weight than the WT form }\end{array}$ & Tenreiro et al., 2014 \\
\hline & GRK5 & $\begin{array}{l}\text { HEK293, SH-SY5Y cells and } \\
\text { primary neurons from the } \\
\text { cerebral cortex of fetal mice }\end{array}$ & - & $\begin{array}{l}\text { Increased aggregation by } \\
\text { co-expression with GRK5 }\end{array}$ & Arawaka et al., 2006 \\
\hline & CK2 & $\begin{array}{l}\text { 293T, PC-12 and NS20Y cells } \\
\text { stably or transiently } \\
\text { transfected with synphilin-1, } \\
\text { aSyn and/or CKII }\end{array}$ & - & $\begin{array}{l}\text { S129A mutation does not } \\
\text { influence aSyn aggregation } \\
\text { with synphilin-1 }\end{array}$ & Lee et al., 2004a \\
\hline & - & $\begin{array}{l}293 T \text { cells stably transfected } \\
\text { with synphilin-1 } \\
\text { co-expressing aSyn WT or } \\
\text { S129A }\end{array}$ & $\begin{array}{l}\text { S129A mutation does not } \\
\text { influence aSyn toxicity }\end{array}$ & $\begin{array}{l}\text { S129A mutation does not } \\
\text { influence aSyn aggregation }\end{array}$ & Tanaka et al., 2004 \\
\hline & CK2 & SH-SY5Y cells & No toxicity detected & $\begin{array}{l}\text { S129A decreases inclusion } \\
\text { formation while pS129 levels } \\
\text { correlates with inclusion } \\
\text { formation }\end{array}$ & Smith et al., 2005 \\
\hline & $\begin{array}{l}\text { CK2 and other } \\
\text { unidentified } \\
\text { kinases }\end{array}$ & SH-SY5Y cells & $\begin{array}{l}\text { S129D is toxic; S129A does } \\
\text { not affect aSyn toxicity }\end{array}$ & $\begin{array}{l}\text { increased pS129 was not } \\
\text { attend with increased } \\
\text { insoluble aggregates }\end{array}$ & Chau et al., 2009 \\
\hline & CK2 & 3D5 neuroblastoma cell line & - & $\begin{array}{l}\text { pS129 promotes aSyn } \\
\text { oligomerization and inclusion } \\
\text { formation }\end{array}$ & Takahashi et al., 2007 \\
\hline
\end{tabular}


Table 1 | Continued

\begin{tabular}{|c|c|c|c|c|c|}
\hline $\begin{array}{l}\text { aSyn } \\
\text { residue }\end{array}$ & Kinase & Model & Cytotoxicity & Aggregation & References \\
\hline & CK1, CK2 & $\begin{array}{l}\text { In vitro biochemical } \\
\text { assay/SH-SY5Y cells/ } \\
\text { transgenic mice M20 and } \\
\text { M83 }\end{array}$ & - & $\begin{array}{l}\text { pS129 reduced recombinant } \\
\text { aSyn fibril formation }\end{array}$ & $\begin{array}{l}\text { Waxman and } \\
\text { Giasson, } 2008\end{array}$ \\
\hline & - & $\begin{array}{l}\text { Mouse MN9D dopaminergic } \\
\text { cells coexpressing human } \\
\text { aSyn WT or S129D }\end{array}$ & $\mathrm{S} 129 \mathrm{D}$ is protective & $\begin{array}{l}\text { S129D promotes aSyn fibril or } \\
\text { inclusion formation }\end{array}$ & Wu et al., 2011a \\
\hline & $\begin{array}{l}\text { GRK2, GRK5, } \\
\text { PLK2, PLK3 }\end{array}$ & $\begin{array}{l}\text { Human brain neuroglioma } \mathrm{H} 4 \\
\text { cell line }\end{array}$ & - & $\begin{array}{l}\text { S129A increases inclusion } \\
\text { formation }\end{array}$ & $\begin{array}{l}\text { Gonçalves and } \\
\text { Outeiro, } 2013\end{array}$ \\
\hline & CK2 and PLKs & $\begin{array}{l}\text { Rat oligodendroglial cell line } \\
\text { OLN-93 coexpressing human } \\
\text { p25aand aSyn WT or } \\
\text { S129A/D }\end{array}$ & $\begin{array}{l}\text { pS129 increases microtubule } \\
\text { retraction followed by } \\
\text { apoptosis and cell dead; } \\
\text { S129A is protective while } \\
\text { S129D behaves as WT, } \\
\text { whoever with a smooth } \\
\text { phenotype }\end{array}$ & $\begin{array}{l}\text { pS129 promotes aSyn } \\
\text { oligomers formation while } \\
\text { S129A mutagenesis or CK2 } \\
\text { and PLKs kinase inhibitors } \\
\text { prevent it }\end{array}$ & Kragh et al., 2009 \\
\hline & PLK1, PLK2, PLK3 & $\begin{array}{l}\text { HEK293T/HeLa cells/ primary } \\
\text { rat Neurons/ (Thy1)-h[A30P] } \\
\text { aSyn transgenic mice }\end{array}$ & - & - & Mbefo et al., 2010 \\
\hline & $\begin{array}{l}\text { Gprk2 (Grk2 } \\
\text { Drosophila } \\
\text { homolog) }\end{array}$ & Drosophila & $\begin{array}{l}\text { Increased pS129 is toxic; } \\
\text { S129D is toxic; S129A is } \\
\text { protective }\end{array}$ & $\begin{array}{l}\text { pS129 increases soluble } \\
\text { oligomers formation but has } \\
\text { no effect on inclusion } \\
\text { formation }\end{array}$ & $\begin{array}{l}\text { Chen and Feany, } \\
\text { 2005; Chen et al., } \\
2009\end{array}$ \\
\hline & - & $\begin{array}{l}\text { SH-SY5Y cells/ transgenic } C \text {. } \\
\text { elegans }\end{array}$ & $\begin{array}{l}\text { S129D is protective while } \\
\text { S129A is toxic }\end{array}$ & $\begin{array}{l}\text { No insoluble oligomers or } \\
\text { bigger aggregates were } \\
\text { observed }\end{array}$ & Kuwahara et al., 2012 \\
\hline & - & $\begin{array}{l}\text { Rat model involving viral } \\
\text { delivery of WT or S129D/A } \\
\text { aSyn }\end{array}$ & $\begin{array}{l}\text { S129A is toxic while S129D is } \\
\text { protective }\end{array}$ & $\begin{array}{l}\text { S129D promotes inclusion } \\
\text { formation while S129A } \\
\text { reduce it }\end{array}$ & Gorbatyuk et al., 2008 \\
\hline & - & $\begin{array}{l}\text { Rat model involving viral } \\
\text { delivery of WT or A30P aSyn } \\
\text { with S129D/A mutations }\end{array}$ & $\begin{array}{l}\text { S129A is toxic while S129D } \\
\text { has no effect }\end{array}$ & $\begin{array}{l}\text { S129A increases aggregates } \\
\text { formation while S129D forms } \\
\text { fewer but larger aggregates }\end{array}$ & $\begin{array}{l}\text { Azeredo Da Silveira } \\
\text { et al., } 2009\end{array}$ \\
\hline & $\begin{array}{l}\text { CK1, CK2, PLK1, } \\
\text { PLK2, PLK3 }\end{array}$ & $\begin{array}{l}\text { In vitro biochemical assay / } \\
\text { QBI } 293 \text { cells transfected with } \\
\text { WT aSyn and treated with } \\
\text { recombinant aSyn fibrils to } \\
\text { induce the formation of } \\
\text { aggregates, treated with } \\
\text { kinases inhibitors or } \\
\text { co-expressing kinases }\end{array}$ & - & $\begin{array}{l}\text { Results obtained with } \\
\text { different kinases suggest that } \\
\text { phosphorylation of aSyn is } \\
\text { independent of aSyn } \\
\text { aggregate formation }\end{array}$ & $\begin{array}{l}\text { Waxman and } \\
\text { Giasson, } 2011\end{array}$ \\
\hline & PLK2 & $\begin{array}{l}\text { HEK239T cells co transfected } \\
\text { with aSyn and WT PLK2 or } \\
\text { the kinase dead mutant (DM) } \\
\text { PLK2; treated or not with } \\
\text { PLK2 inhibitor / Rat model } \\
\text { involving viral delivery of aSyn } \\
\text { with either PLK2 WT or KDM }\end{array}$ & $\begin{array}{l}\text { Increased pS129 aSyn by } \\
\text { PLK2 reduces aSyn } \\
\text { accumulation, suppresses } \\
\text { dopaminergic } \\
\text { neurodegeneration, and } \\
\text { reverses hemiparkinsonian } \\
\text { motor impairments by } \\
\text { promoting aSyn autophagic } \\
\text { clearence }\end{array}$ & - & Oueslati et al., 2013 \\
\hline Y133 & Syk & $\begin{array}{l}\text { In vitro biochemical } \\
\text { assay/SH-N-BE and } \mathrm{CHO} \text { cells }\end{array}$ & - & $\begin{array}{l}\text { Syk-mediated aSyn } \\
\text { phosphorylation decreases } \\
\text { oligomerization }\end{array}$ & Negro et al., 2002 \\
\hline Y136 & Syk & $\begin{array}{l}\text { In vitro biochemical } \\
\text { assay/SH-N-BE and } \mathrm{CHO} \text { cells }\end{array}$ & - & $\begin{array}{l}\text { Syk-mediated aSyn } \\
\text { phosphorylation decreases } \\
\text { oligomerization }\end{array}$ & Negro et al., 2002 \\
\hline
\end{tabular}


In yeast cells, S129A aSyn is more toxic and forms more inclusions and oligomeric species of higher molecular weight than S129E or WT forms of aSyn (Sancenon et al., 2012; Tenreiro et al., 2014). Consistently, higher toxicity of the S129A variant is also associated with an increase in the generation of small, more soluble aggregates in rats (Azeredo Da Silveira et al., 2009).

To explain the discrepancies between the results obtained in different cell and animal models, several ideas have been put forward. One possibility is that the predominance of pS129 aSyn in LBs is not caused by its inherent propensity to aggregate but could be more related to the presence or absence of additional factors in the different models employed. Namely, the distinct results obtained in rat models could be eventually associated to dosedependent interactions between rat aSyn and virally expressed mutant human aSyn, altering the aggregation properties of the protein, as has been demonstrated in vitro for mixtures of mouse and human aSyn (Rochet et al., 2000). On the other hand, in SHSY5Y cells, co-expression of aSyn S129A with synphilin-1, an aSyn interacting protein that is also present in LBs, resulted in the formation of fewer inclusions than WT aSyn (Smith et al., 2005). In a Drosophila model, the obvious differences in the complexity of the nervous system and the absence of an aSyn homolog might explain the differences observed (Goedert, 2001; Hamilton, 2004).

Recently, it was also suggested that the discrepancies observed in the various studies might be due to different efficiencies of the different kinases in phosphorylating either S129 or other residues, as well as their differential pattern of expression in the different models (Oueslati et al., 2013; Schreurs et al., 2014). The conflicting results might also be due to differences in the dephosphorylation machinery involved in the dephosphorylation of aSyn, a process that is still understudied.

Another hypothesis is that phosphorylation could be an indirect cause of aSyn pathology, namely due to the impairment of the proteolytic machinery (Azeredo Da Silveira et al., 2009). There are several examples of proteins where phosphorylation works as a signal for protein degradation. If this is also the case for aSyn, then phosphorylated aSyn could accumulate in LBs due to proteasomal impairment (McNaught and Jenner, 2001; Shimura et al., 2001; Tanaka et al., 2001; Snyder et al., 2003; Grunblatt et al., 2004) leading to its accumulation and consequent aggregation.

Phosphorylation of aSyn in inclusions may be partially due to the intrinsic properties of aggregated aSyn to act as substrate for kinases but not phosphatases, as indicated by in vitro studies, suggesting that fibril and inclusion formation occur prior to phosphorylation and that this modification becomes more pronounced with disease progression (Waxman and Giasson, 2008; Mbefo et al., 2010; Paleologou et al., 2010; Waxman and Giasson, 2011).

In addition to S129, there are other phosphorylation sites in aSyn that may be relevant to aggregation and toxicity in synucleinopathies. This could either be due to a direct effect of the phosphorylation, or due to an effect on the cross-talk that likely occurs between phosphorylated states of these different residues. For example, phosphorylation of tyrosine residues Y125, Y133, and Y136 in the C-terminal segment of aSyn suppresses eosininduced oligomerization (Negro et al., 2002). Phosphorylation at
Y125 (pY125) has opposing effects to phosphorylation of S129 on aSyn neurotoxicity and soluble oligomer formation in a transgenic Drosophila model (Chen et al., 2009). Although pY125 does not directly affect the pS129 or vice versa, tyrosine phosphorylation is possibly acting downstream of pS129, as increasing pY125 levels rescued the neurotoxicity of a phospho-mutant S129D (Chen et al., 2009). This could be easily explained considering that different kinases are involved in the two phosphorylation events, which in turn can have behind completely different regulation pathways and physiological roles. Phosphorylation at Y125 diminishes with aging and is reduced in cortical tissue of DLB patients indicating a neuroprotective role (Chen et al., 2009). However, another recent study did not observe any significant differences in the levels of pY125 between PD brains and controls (Mahul-Mellier et al., 2014). In fact, phosphorylation at this residue was not detected in LBs of patients with DLB, in PD patients carrying the A53T mutation, nor in MSA cases (Anderson et al., 2006). This might be due to an increased sensitivity of Y125 to be dephosphorylated post mortem (Chen et al., 2009). Additionally, it could not be completely excluded that the observed effect on reduced oligomerization and concomitant toxicity was exclusively due to pY125, as the degree of Y133 and Y136 phosphorylation was not evaluated in this study performed in a Drosophila PD model (Chen et al., 2009). In fact, studies using recombinant aSyn demonstrated that the single phosphorylation of Y125 by Lyn and Fgr kinases does not affect oligomerization while the phosphorylation of all residues Y125, Y133 and Y136 by Syk prevents it (Negro et al., 2002). Recently, a new residue was detected as being phosphorylated in human brain tissues, the Y39, but without significant differences in the levels of pY39 between PD brains and controls (Mahul-Mellier et al., 2014). Importantly, in this same study, phosphorylation at Y39 and Y125 was found to play an important role in regulating aSyn clearance through proteasome and autophagy pathways (Mahul-Mellier et al., 2014).

S87 is, in addition to Y39, the only other residue outside the C-terminal region reported to undergo phosphorylation (pS87) in vivo (Paleologou et al., 2010). pS87 was found to be increased in brains of rat and mice models of synucleinopathies as well as in human brains from AD, LBD, and MSA patients (Paleologou et al., 2010) contradicting previous studies where phosphorylation of aSyn at this residue was not detected in either human brain samples or a transgenic mouse model of synucleinopathies (Fujiwara et al., 2002; Anderson et al., 2006; Waxman and Giasson, 2008). Again, results obtained using different systems were contradicting. pS87 may promote aSyn inclusion formation and decrease cell viability in SH-SY5Y and H19-7 cell lines (Kim et al., 2006). On the other hand, in vitro phosphorylation at this site inhibits aSyn fibril formation (Waxman and Giasson, 2008; Paleologou et al., 2010). Moreover, immunofluorescence staining of LBs isolated from fresh human brains using a specific anti-pS87 antibody allowed its detection and suggested that this phosphorylation occurs throughout the life span of LB development (Paleologou et al., 2010). More recently, S87E was found to inhibit aggregation and to protect against aSyn induced toxicity in vivo, namely by reducing aSyn aggregates, dystrophic fibers, and motor impairment in a rat model of $\mathrm{PD}$ where viral 
delivery was used to overexpress WT, S87A, and S87E aSyn in the substantia nigra (Oueslati et al., 2012).

Another aspect that might explain the discrepancies observed in the different studies is the employment of aSyn phosphorylation mutants. While several studies reported consistent results using in parallel genetic or pharmacological methods to alter aSyn phosphorylation status (Chen and Feany, 2005; Smith et al., 2005; Chen et al., 2009), other studies indicate that phospho-mutants may not fully recapitulate the real phosphorylation/unphosphorylation states of aSyn (Paleologou et al., 2008; Schreurs et al., 2014). In particular, it was shown that S129A and S129D/E mutations themselves could have effects on aSyn aggregation properties independent of their effects on phosphorylation, with the S129A mutation stimulating fibril formation while S129D/E mutations do not reproduce the effect of phosphorylation on the structural and aggregation properties of aSyn in vitro (Paleologou et al., 2008). However, in yeast we observed that S129G and S129A mutations, both blocking aSyn phosphorylation, were more toxic and resulted in increased inclusion formation excluding that the observed phenotypes were due to specific structural consequences of S129A mutation on aSyn (Tenreiro et al., 2014). Moreover, in this yeast model, S129E aSyn exhibited the same phenotype of toxicity and inclusion formation as the WT protein that is strongly phosphorylated on S129 by endogenous kinases (Tenreiro et al., 2014). Despite the inherent caveats, the use of aSyn phospho-mutants still remains as a unique and powerful means to interrogate the effects of phosphorylation. Regarding the use of phosphomimic mutants of other residues, S87E was shown to behave as pS87, at least with respect to its effects on aSyn aggregation, while the S87A mutant exhibited similar secondary structure and similar membrane binding and aggregation properties as the WT protein (Waxman and Giasson, 2008; Paleologou et al., 2010; Oueslati et al., 2012).

Mutants that abolish phosphorylation at tyrosine residues of aSyn (by replacing tyrosine by phenylalanine residues) were used in several in vitro and in vivo studies (Chen et al., 2009; MahulMellier et al., 2014). However, there are no mutants that mimic the phosphorylated state of a tyrosine residue, restricting the use of mutants that attempt to mimic tyrosine phosphorylation.

\section{PHYSIOLOGICAL AND PATHOLOGICAL IMPLICATIONS OF aSyn PHOSPHORYLATION}

Initial studies suggested aSyn might be predominantly unphosphorylated under physiological conditions (Okochi et al., 2000; Fujiwara et al., 2002). It was hypothesized that changes in aSyn phosphorylation could represent a response to biochemical events associated with PD pathogenesis. Among these, mitochondrial complex I dysfunction, oxidative stress and proteasome dysfunction are processes that are known to be involved in synucleinopathies (Lee and Trojanowski, 2006; Lashuel et al., 2013). Increased levels of pS129 aSyn were observed upon proteasome inhibition or oxidative stress in SH-SY5Y cells over-expressing aSyn. In the case of proteasomal impairment, this seems to result in pS129 aSyn accumulation through an increase in the activity of the kinase(s) involved, a decrease in protein turnover and, ultimately, in increased cell death (Waxman and Giasson, 2008; Chau et al., 2009). The kinases involved were not fully characterized but CK2 was found to be one of them. On the other hand, it is known that aggregation of aSyn itself leads to proteasome impairment (Tanaka et al., 2001; Snyder et al., 2003; Lindersson et al., 2004), which in turn could lead to CK2 activation and eventually to increased levels of pS129. It is important to note that phosphorylation of S129 appears not to be a general response to cellular stress, as inhibition of complex I had little effect on pS129 aSyn levels (Waxman and Giasson, 2008; Chau et al., 2009).

The low levels of pS129 aSyn under physiological conditions as well as the absence of other phosphorylated residues such as pY39, pS87 and pY125 (Okochi et al., 2000; Fujiwara et al., 2002; Anderson et al., 2006) could also be related to a faster degradation of this form under normal conditions. In fact, the phosphorylation status of aSyn was recently correlated with clearance mechanisms (Oueslati et al., 2013; Mahul-Mellier et al., 2014). Namely, blocking S129 phosphorylation in a yeast model lead to impaired aSyn clearance by autophagy (Tenreiro et al., 2014). In line with this observation increased levels of pS129 by overexpression of PLK2 suppress dopaminergic neurodegeneration, and reverse hemiparkinsonian motor impairments in a rat model of PD by promoting aSyn autophagic degradation (Oueslati et al., 2013). Moreover, phosphorylation at Y39 and Y125 by c-Abl kinase protects aSyn against its degradation via the autophagy and proteasome pathways in cortical neurons (Mahul-Mellier et al., 2014).

Phosphorylation also seems to alter the subcellular localization of aSyn. While pS129 aSyn was found to be preferentially localized in the nuclei of dopaminergic neurons in rat and mouse models of synucleinopathy (Yamada et al., 2004; Wakamatsu et al., 2007), in other studies using PD rat models the phosphoresistant S129A was found to be localized in the nucleus at higher levels than the S129D form, and was found to correlate with enhanced toxicity (Gorbatyuk et al., 2008; Azeredo Da Silveira et al., 2009). Our group demonstrated that S129 phosphorylation modulates the shuttling of aSyn between nucleus and cytoplasm in human neuroglioma cells, using photoactivatable green fluorescent protein as a reporter. Moreover, we also found that co-expression of aSyn with different kinases altered the translocation dynamics of the protein. While G protein-coupled receptor kinase 5 (GRK5) promotes the nuclear localization of aSyn, PLK2 and 3 modulate the shuttling of the protein between the nucleus and cytoplasm (Gonçalves and Outeiro, 2013). This difference might reflect different aSyn phosphorylation patterns in S129 and/or other residues, or phosphorylation of other targets besides aSyn. Very recently, G51D aSyn was found to exhibit enhanced nuclear localization and to be hyperphosphorylated on S129 in primary neurons (Fares et al., 2014). Although the function of aSyn in the nucleus is still unclear, it seems this is related with a pathological role that is independent of aSyn aggregation. In particular, nuclear localization of aSyn increases under oxidative stress conditions (Xu et al., 2006; Monti et al., 2010; Siddiqui et al., 2012). Nuclear aSyn interacts with histones, inhibits acetylation and promotes neurotoxicity (Goers et al., 2003; Kontopoulos et al., 2006). Moreover, aSyn might act as a transcriptional regulator, binding promoters such as PGC1-alpha, a master regulator of mitochondrial gene expression (Siddiqui et al., 2012). 
Phosphorylation at S129 reduces the affinity of aSyn for lipids (Okochi et al., 2000; Pronin et al., 2000; Fujiwara et al., 2002; Yamada et al., 2004). Also pS87 was described to significantly reduce aSyn binding to lipid vesicles (Paleologou et al., 2010). Therefore, the phosphorylation status of aSyn might regulate its role in synaptic vesicle dynamics in physiological conditions and might contribute to its pathological role in abnormal dopamine neurotransmission (Lundblad et al., 2012; Scott and Roy, 2012).

It was also reported that aSyn inhibits tyrosine hydroxylase activity, a rate-limiting enzyme in dopamine biosynthesis, in dopaminergic MN9D cells, while the phosphomimic mutant of aSyn, S129D, relieves this inhibition and results in an increase of dopamine content in cells (Wu et al., 2011a). Recently, it was also observed that membrane-associated aSyn enhances dopamine uptake capacity in dopaminergic SH-SY5Y cells by the dopamine transporter through GRKs-mediated S129 phosphorylation (Hara et al., 2013).

The phosphorylation status of aSyn could also modulate its protein-protein interactions. The unphosphorylated form of S129 associates mainly with mitochondrial electron transport proteins while pS129 associates with cytoskeletal, vesicular trafficking proteins and enzymes involved in protein serine phosphorylation (McFarland et al., 2008). Phosphorylation also appears to have an important role in the regulation of aSyn axonal transport as the S129D mutation significantly reduces its rate of transport in neurons, likely due to the modulation of the interaction of aSyn with motor and/or accessory proteins involved in this process (Saha et al., 2004). Moreover, the interplay between the different phosphorylated residues could also contribute to increase the diversity in the possible protein interactors. In fact, several differences were observed in the set of proteins that were found to interact with S129 or Y125-phosphorylated forms of aSyn (McFarland et al., 2008). Both, S129 and Y125 residues are localized in the Cterminal region of aSyn which has been implicated in the majority of aSyn interactions with proteins (Jensen et al., 1999; Giasson et al., 2003a; Fernandez et al., 2004) reinforcing the relevance that phosphorylation in these residues could modulate the biological role of aSyn.

The C-terminus of the protein was also implicated in aSyn interactions with metal ions (Paik et al., 1999; Brown, 2007). These interactions influence the structure and propensity for aggregation of aSyn in vitro and in cell culture models of synucleinopathies (Paik et al., 1999; Brown, 2007; Wright et al., 2009). Interestingly, a recent study showed that pY125 and pS129 alter the binding sites of metal ions and increase the binding affinity of $\mathrm{Cu}(\mathrm{II}), \mathrm{Pb}(\mathrm{II})$, and $\mathrm{Fe}(\mathrm{II})$, but not $\mathrm{Fe}(\mathrm{III})$, a feature that could modulate aSyn function as well as aggregation (Lu et al., 2011).

Phosphorylation at S87 could also modulate protein-protein interactions, as some proteins were found to interact via the non-amyloid component (NAC) region, in which this residue is located. As an example, it is possible that S87 phosphorylation alters the interaction with phospholipase D (PLD) 2, an enzyme involved in lipid-mediated signaling cascades and vesicle trafficking (Outeiro and Lindquist, 2003; Payton et al., 2004).

Fyn and Src kinases are able to phosphorylate aSyn at Y125, suggesting phosphorylation in this residue might also modulate spatial learning and synaptic plasticity, due to the role these kinases play in these processes (Zhao et al., 2000). On the other hand, Fyn and Src are non-receptor-type PTKs activated by extracellular factors like neurotrophic factors and growth factors, suggesting that the phosphorylation state of aSyn can be regulated by extracellular signaling molecules, such as neurotrophins, cytokines, and cell adhesion molecules (Nakamura et al., 2001). Recently, a new connection between tyrosine phosphorylation of aSyn and synaptic plasticity was established with the identification of $\mathrm{Y} 39$ as the main target of phosphorylation by c-Abl protein tyrosine kinase (Mahul-Mellier et al., 2014), a kinase that plays an important role in the development of the central nervous system (CNS) and in neuronal plasticity (Moresco and Koleske, 2003; Moresco et al., 2003). Interestingly, c-Abl is upregulated in PD brains (Ko et al., 2010; Hebron et al., 2013a) as well as in other neurodegenerative diseases (Schlatterer et al., 2011). This tyrosine kinase is activated by increased levels of aSyn and, in turn, increased c-Abl activity leads to aSyn accumulation (Hebron et al., 2013a,b) by increasing pY39 and, to a lesser extent pY125, thereby affecting clearance pathways (Mahul-Mellier et al., 2014). Thus, phosphorylation of aSyn at tyrosine residues could be relevant in the context of the alterations of synaptic functions observed in PD and other synucleinopathies.

It remains unclear how familial mutations of aSyn might alter the phosphorylation of the protein, but it is likely that different mutations may influence phosphorylation in different residues. In transgenic mice expressing either E46K or A53T aSyn, inclusions were found to be strongly phosphorylated at S129 (Emmer et al., 2011). In HEK cells, S129 phosphorylation by GRK6 or PLK2 is equally efficient in WT or in G51D aSyn, although pS129 enhanced nuclear localization of G51D compared to WT aSyn (Fares et al., 2014). Moreover, while the A53T mutant shows similar phosphorylation levels to WT aSyn in SH-SY5Y cells (Smith et al., 2005), and slower in vitro phosphorylation kinetics by CK2 (Ishii et al., 2007), it was observed that detergentinsoluble aSyn from patients carrying the A53T mutation was hyper-phosphorylated at S129 (Anderson et al., 2006). In any case, additional studies on the interplay between aSyn mutations and phosphorylation are needed.

\section{KINASES INVOLVED IN aSyn PHOSPHORYLATION}

Several kinases have been implicated in aSyn phosphorylation (Table 1). S129 can be phosphorylated by G-protein coupled receptor kinases (GRK1, GRK2, GRK5 and GRK6) (Pronin et al., 2000; Arawaka et al., 2006; Sakamoto et al., 2009), casein kinases 1 and 2 (CK1, CK2) (Okochi et al., 2000; Smith et al., 2005; Ishii et al., 2007; Takahashi et al., 2007; Wakamatsu et al., 2007; Waxman and Giasson, 2008; Zabrocki et al., 2008), and the pololike kinases (PLKs) (Inglis et al., 2009). The leucine-rich repeat kinase 2 (LRRK2) was also shown to phosphorylate aSyn at S129 (Qing et al., 2009), but this remains highly controversial as no other studies were able to confirm this, despite the existence of a clear interaction between the two proteins (Qing et al., 2009; Guerreiro et al., 2013).

Recent studies revealed that, in addition to phosphorylating agonist-occupied G protein-coupled receptors (GPCRs), GRKs may also phosphorylate non-receptor substrates, including the four members of the synuclein family (aSyn, 
beta-, gamma-synuclein and synoretin) (Pronin et al., 2000). Overexpression of GRK2 or GRK5 in COS-1 cells showed that these kinases phosphorylate aSyn at S129 (Pronin et al., 2000). Phosphorylation of aSyn at S129 by endogenous GRKs was also demonstrated in HEK293 cells and it was observed that GRK3 and GRK6 play the main role in this modification (Sakamoto et al., 2009).

GRK5 was found to colocalize with aSyn in the LBs of the substantia nigra of PD patients, but was not detected in cortical LBs of DLB, or in the glial cytoplasmic inclusions of MSA (Arawaka et al., 2006). Overexpression of aSyn increased GRK5 protein expression in both, SH-SY5Y cells and in brain extracts of transgenic mice expressing human aSyn (Liu et al., 2010). A genetic association study performed in the Japanese population revealed a haplotypic association of the GRK5 gene with susceptibility to sporadic PD (Arawaka et al., 2006). However, another genetic association study performed in Southern Italy failed to correlate GRK5 polymorphisms with sporadic PD (Tarantino et al., 2011). The knockdown of endogenous GRK5 in SH-SY5Y cells fails to suppress phosphorylation of aSyn (Liu et al., 2010) confirming the involvement of other kinases in this phosphorylation.

CK1 and CK2 also phosphorylate aSyn at S129 in yeast (Zabrocki et al., 2008), in mammalian cells (Okochi et al., 2000; Waxman and Giasson, 2008) and in rat primary cortical neurons (Ishii et al., 2007).

CK1-mediated phosphorylation at S129 may counteract aSyn toxicity by attenuating vesicular trafficking defects and restoring synaptic transmission in some extension (Sancenon et al., 2012). However, higher levels of aSyn could result in protein mislocalization in other compartments, ultimately leading to defects in synaptic vesicle homeostasis and neurotransmission. In addition, excess aSyn may form inclusions that sequester CK1, depleting CK1 activity and exacerbating synaptic defects, generating a toxic vicious cycle. CK1 was also found to phosphorylate aSyn at S87 (Okochi et al., 2000), and to colocalize with pS87 in transgenic mice and in LB-like structures in LBD/PD diseased brains (Paleologou et al., 2010). $\beta$ subunits of CK2 were also found to colocalize with $\mathrm{LBs}$ in $\mathrm{PD}$ brains (Ryu et al., 2008). Interestingly, oxidative stress imposed by iron overload causes upregulation of CK2 which, in turn, leads to increased pS129 aSyn with a concomitant increase in oligomerization and inclusion formation (Takahashi et al., 2007). In SH-SY5Y cells, the increase in aSyn phosphorylation under oxidative stress is mediated by CK2 and correlates with enhancement of inclusion formation (Smith et al., 2005).

In vitro studies, employing kinase assays, showed that PLK1, PLK2 and PLK3 are also capable of phosphorylating aSyn at S129 (Inglis et al., 2009; Mbefo et al., 2010). The PLKs comprise a family of conserved Ser/Thr protein kinases that are known to play critical roles on cell cycle regulation, cellular response to stress and carcinogenesis (Ng et al., 2006). PLK2 and PLK3 are expressed in response to synaptic activation and appear to be involved in synaptic plasticity, remodeling and homeostasis (Kauselmann et al., 1999; Seeburg et al., 2005, 2008), suggesting these kinases could be important actors in modulating the normal physiology of aSyn.
PLK2 and PLK3 partially colocalize with pS129 aSyn in primary hippocampal neurons as well as in cortical brain areas of aSyn transgenic mice, reinforcing the idea that S129 phosphorylation by the PLKs might also occur in human brain (Mbefo et al., 2010). Consistently, PLK2 levels are elevated in brains of patients with $\mathrm{AD}$ and $\mathrm{DLB}$, and correlate with the increased levels of pS129 aSyn, further supporting a role for this kinase in disease (Mbefo et al., 2010). PLK2 is also involved in the phosphorylation of aggregated aSyn in vitro (Mbefo et al., 2010) and in cell culture (Waxman and Giasson, 2011). A prominent role of PLK2 as a regulator of aSyn turnover was recently described (Oueslati et al., 2013). Importantly, PLK2-mediated pphosphorylation at S129 of aSyn is protective in a rat model of $\mathrm{PD}$, by promoting aSyn autophagic degradation (Oueslati et al., 2013). Recently, we also described that PLK2 mediates aSyn inclusion formation in yeast and in mammalian cells by a S129 phosphorylation-independent mechanism (Basso et al., 2013).

Only CK1 and the dual specificity tyrosine regulated kinase $1 \mathrm{~A}$ (Dyrk1A) were found to phosphorylate aSyn at S87, and this was based on in vitro kinase assays and cells culture models (Okochi et al., 2000; Waxman and Giasson, 2008). CK1 colocalizes with pS87 in neuronal inclusions in a PD mouse model and in LB-like structures in LBD/PD diseased brains (Paleologou et al., 2010).

Several tyrosine kinases phosphorylate aSyn. The Y125 residue is target of phosphorylation by Fyn (Nakamura et al., 2001), Syk (Negro et al., 2002), Lyn (Negro et al., 2002), c-Frg (Negro et al., 2002), Src (Ellis et al., 2001) and c-Abl (Mahul-Mellier et al., 2014). Syk also phosphorylates Y133 and Y136 (Negro et al., 2002), and c-Abl also phosphorylates Y39 aSyn (Mahul-Mellier et al., 2014).

An emerging concept is that certain phosphorylation events might promote or prevent subsequent phosphorylation events in other residues (Negro et al., 2002; Mbefo et al., 2010). In fact, the double mutation of Y133 and Y136 to phenylalanines, designed to prevent phosphorylation in these residues, augments Y125 phosphorylation by Lyn (Negro et al., 2002). Phosphorylation or binding of c-Abl at Y125 was also found to decrease the propensity of this kinase to phosphorylate aSyn at Y39 (Mahul-Mellier et al., 2014).

\section{TAU PHOSPHORYLATION IN ALZHEIMER'S DISEASE AND OTHER TAUOPATHIES}

The "amyloid cascade hypothesis" was formulated after an amyloid precursor protein (APP) mutation was reported in a family with AD-typical histology and proposes that accumulation of an APP cleavage product, beta amyloid (A $\beta)$, induces the biochemi$\mathrm{cal}$, histologic, and clinical changes $\mathrm{AD}$ patients manifest (Hardy and Higgins, 1992). Later, A $\beta$ oligomers were suggested to trigger neurotoxicity in AD probably via tau phosphorylation. Glycogen

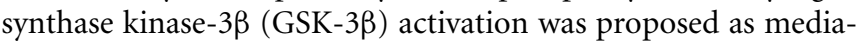
tor of $A \beta 42$ oligomer-induced effects on tau phosphorylation in P301L mice (Selenica et al., 2013).

\section{THE ROLE OF PHOSPHORYLATION ON TAU CYTOTOXICITY AND AGGREGATION}

Tau, in its longest isoform, contains 35 threonine, 45 serine, and 5 tyrosine residues meaning that nearly $20 \%$ of the tau protein 
has the potential to be phosphorylated. Early studies revealed that tau is more efficient at promoting microtubules (MT) assembly in a more unphosphorylated state (Lindwall and Cole, 1984). A few years later, tau was demonstrated to make up the pairedhelical filaments (PHFs) which form the neurofibrillary tangles (NFTs) found in AD brain and to be abnormally phosphorylated in these structures (Grundke-Iqbal et al., 1986; Goedert et al., 1988; Kosik et al., 1988; Wischik et al., 1988). Further analyses revealed that PHF-tau is phosphorylated at "pathological" sites, which was assumed to contribute to pathological processes in $\mathrm{AD}$. Enhanced immunoreactivity in human AD tissue was observed with the phosphorylation-dependent antibodies AT8 (epitope pS199/pS202/pT205), PHF-1 (epitope pS396/pS404), and pS262 (Gu et al., 2013a; Mondragon-Rodriguez et al., 2014). Hyperphosphorylation of tau was shown to be involved in tau aggregation and cytotoxicity (Table 2) (Kosik and Shimura, 2005; Noble et al., 2013).

Abnormal high levels of intracellular tau are frequently observed in $\mathrm{AD}$ patients and may be directly implicated in tau aggregation, PHF formation, and neuron loss (Gomez-Isla et al., 1997). It was speculated that the hyperphosphorylation of tau precedes NFT pathology and, more important, is a key event for the integration of tau into fibrils (Bancher et al., 1991). The staging of AD-related neurofibrillary pathology using a silver stain technique was revised using immunostaining for hyperphosphorylated tau at the AT8 epitope (Braak et al., 2006). Several studies addressed the question whether the pattern of tau hyperphosphorylation correlates with the progression of neuronal cytopathology and the formation of higher order tau species in $\mathrm{AD}$. Brain tissue was classified into pre-NFTs, intra-neuronal NFTs and extra-neuronal NFTs, and was examined regarding the most prominent staining of phosphorylation-dependent tau antibodies. Epitopes that were associated with pretangle, non-fibrillar tau include pS199, pS202, pT231, pS262, pT153, and S409. Intraneuronal fibrillar structures were stained with antibodies recognizing pS46, pT175/pT181, pT231, pS262/pS356 (12E8 epitope), pS396, pS422, and pS214. Epitopes associated with extracellular filamentous tau include AT8, AT100 (pT212/pS214), and PHF-1 (Morishima-Kawashima et al., 1995b; Kimura et al., 1996; Augustinack et al., 2002). Notably, with progression of the disease, tau is phosphorylated at pathological multiple-site epitopes (AT8, AT100, AT180, PHF-1, 12E8). Tau inclusions were observed in other neurodegenerative disorders such as MSA (Giasson et al., 2003b), familial and sporadic PD (Ishizawa et al., 2003; Rajput et al., 2006), and in Down syndrome (Flament et al., 1990; Mondragon-Rodriguez et al., 2014). Elevated levels of AT180 (pT231/pS235)-phosphorylated tau were detected in the cerebrospinal fluid (CSF) of patients with mild cognitive impairment who later went on to develop AD (Arai et al., 2000a).

Several animal models were generated to recapitulate hyperphosphorylation of tau and the formation of NFTs as key aspects of tauopathies (Ribeiro et al., 2013). Some studies showed that the overexpression of human mutant tau in transgenic mice led to increased phosphorylation of tau and the formation of tau inclusions, aggregates, and fibrils. Phosphorylation of tau was detected at the well-known disease-related epitopes S202, T205, S212, S216, T231, S262, S356, S422, AT100 (Kohler et al., 2013;
Nilsen et al., 2013; Sahara et al., 2013). Likewise, overexpression of LRRK2 or p25/Cyclin-dependent kinase-5 (Cdk5) in mice resulted in hyperphosphorylation of tau, tau aggregation into NFT-like structures, and neuronal death (Cruz et al., 2003; Noble et al., 2003; Bailey et al., 2013). Other models took advantage of the co-expression of other disease-associated proteins such as APP and presenilin 1 (Oddo et al., 2003; Grueninger et al., 2010), or made use of the injection of A $\beta$ fibrils (Gotz et al., 2001).

Almost all currently available animal models in $\mathrm{AD}$ are based on the over-expression of pathogenic mutant tau forms. Therefore, it debatable how well these models recapitulate AD cases where there are no mutations in either tau or APP. However, the first models of tauopathy, based on the overexpression of either 3-repeat or 4-repeat human WT tau, presented tau hyperphosphorylation but no NFT formation. Expression of tau-P301L, often in conjunction with other disease-associated proteins, is the most widely used and most successful approach to recapitulate key aspects of $\mathrm{AD}$ such as tau hyperphosphorylation, aggregation, and filament formation as well as neuron death. In these models, it is often not clear what drives tau hyperphosphorylation. In vitro studies may help to decipher the impact of specific pathogenic mutations on tau phosphorylation but existing data are not consistent. The well-known FTDP-17associated missense tau mutations R406W, V337M, G272V, and P301L were shown to make tau a more favorable substrate for phosphorylation by rat brain kinases, in comparison to WT tau protein (Alonso Adel et al., 2004). In another study, the same mutations were shown to promote or inhibit phosphorylation at specific sites (Han et al., 2009). In vitro phosphorylation by recombinant GSK-3b exerted reduced phosphorylation of the R406W mutation, probably through long-range conformational changes. Conversely, P301L and V337M mutations had no effect (Connell et al., 2001). Similar results were obtained in cell culture (Dayanandan et al., 1999). In contrast, several other studies using cell culture models and human brain tissue indicate that the R406W mutation reduces tau phosphorylation, not only at the neighboring PHF1 epitope but at several positions (Miyasaka et al., 2001; Deture et al., 2002; Tackenberg and Brandt, 2009; Gauthier-Kemper et al., 2011). However, depending on the cellular context, R406W was also shown to increase phosphorylation, and other mutations, such as V337M, reduced phosphorylation of tau at specific sites (Deture et al., 2002; Krishnamurthy and Johnson, 2004). Alterations in the phosphorylation state can have tremendous effects on the structural properties, function, and pathology of tau as discussed below.

In vitro data imply that phosphorylation of tau at certain epitopes directly impacts on local structural properties or the global conformation of tau which in turn may affect its assembly into PHFs. Different sites were suggested to be important for the aggregation propensity and filament formation of tau including AT8, AT100, AT180, PHF-1, and S305 upstream of the PHF6-hexapeptide motif which is known to be important for tau fibrillization (Sun and Gamblin, 2009; Bibow et al., 2011; Inoue et al., 2012). Some studies suggested that the compaction of the paperclip conformation of tau becomes tighter or looser depending on phosphorylation at the AT8, PHF-1, and AT100 epitopes (Jeganathan et al., 2008; Bibow et al., 2011). Likewise, 
Table 2 | Tau phosphorylation sites and effects.

\begin{tabular}{|c|c|c|c|c|c|}
\hline Tau residue & Kinase & Model & Cytotoxicity & Aggregation & References \\
\hline & GSK-3 $\beta$ & $\begin{array}{l}\text { In vitro biochemical } \\
\text { assay }\end{array}$ & - & $\begin{array}{l}\text { Pre-assembled pS199/pT205 tau } \\
\text { filaments form large tangle-like } \\
\text { structures }\end{array}$ & Rankin et al., 2008 \\
\hline & GSK-3 $\beta$ & Rat hippocampal slices & $\begin{array}{l}\text { NMDA receptor activation } \\
\text { induces } \mathrm{pS} 199 / \mathrm{pS} 202 \text { and } \\
\text { facilitates LTD induction }\end{array}$ & - & $\begin{array}{l}\text { Mondragon-Rodriguez } \\
\text { et al., } 2012\end{array}$ \\
\hline & - & $\begin{array}{l}\text { TPR50 tau transgenic } \\
\text { mice }\end{array}$ & $\begin{array}{l}\text { pS202/pT205 increased with } \\
\text { age, MT hyperdynamics, } \\
\text { impaired axonal transport, } \\
\text { cognitive deficits earlier than } \\
\text { aggregates }\end{array}$ & $\begin{array}{l}\text { Tau insolubility and intracellular } \\
\text { accumulation }\end{array}$ & Onishi et al., 2014 \\
\hline & GSK-3 $\beta$ & $\begin{array}{l}\text { pR5 tau transgenic } \\
\text { mice }\end{array}$ & - & $\begin{array}{l}\text { Increased pS202/pT205 is } \\
\text { associated with fibrillar tau } \\
\text { pathology }\end{array}$ & Kohler et al., 2013 \\
\hline & LRRK2 & $\begin{array}{l}\text { LRRK2/TauP301L } \\
\text { transgenic mice }\end{array}$ & - & $\begin{array}{l}\text { LRRK2 expression increases } \\
\text { pS199/pS202/pT205 of insoluble } \\
\text { tau }\end{array}$ & Bailey et al., 2013 \\
\hline & - & $\begin{array}{l}\text { rTg4510 tau transgenic } \\
\text { mice }\end{array}$ & - & $\begin{array}{l}\text { pS202/pT205 in TBS-extractable } \\
\text { tau which consists of granular } \\
\text { aggregates and short filaments }\end{array}$ & Sahara et al., 2013 \\
\hline & - & $\begin{array}{l}\text { IHC on paraffin- } \\
\text { sections } A D \text { brain }\end{array}$ & - & $\begin{array}{l}\text { Enhanced pS199/pS202/pT205 in } \\
\text { mature NFTs }\end{array}$ & $\begin{array}{l}\text { Mondragon-Rodriguez } \\
\text { et al., } 2014\end{array}$ \\
\hline & - & $\begin{array}{l}\text { homogenates from } A D \\
\text { brain tissue, } A D \\
\text { synaptosomes }\end{array}$ & - & $\begin{array}{l}\text { Oligomers positive for } \\
\text { pS202/pT205 accumulate at } \\
\text { synapses in AD }\end{array}$ & $\begin{array}{l}\text { Henkins et al., 2012; } \\
\text { Lasagna-Reeves et al., } \\
\text { 2012; Tai et al., } 2012\end{array}$ \\
\hline \multirow[t]{2}{*}{$\begin{array}{l}\text { S262/S356 } \\
\text { (12E8 epitope) }\end{array}$} & MARK2 & $\begin{array}{l}\text { In vitro biochemical } \\
\text { assay }\end{array}$ & - & $\begin{array}{l}\text { Acetylation on S262/S356 inhibits } \\
\text { its phosphorylation and tau } \\
\text { aggregation }\end{array}$ & $\begin{array}{l}\text { Schwalbe et al., 2013; } \\
\text { Cook et al., } 2014\end{array}$ \\
\hline & MARK4 & $\begin{array}{l}\text { rat primary } \\
\text { hippocampal neurons }\end{array}$ & $\begin{array}{l}\text { Increased pS262/pS356 is } \\
\text { associated with decrease in } \\
\text { synaptic markers, loss of } \\
\text { spines and synapses }\end{array}$ & - & Yu et al., 2012 \\
\hline
\end{tabular}


Table 2 | Continued

\begin{tabular}{|c|c|c|c|c|c|}
\hline Tau residue & Kinase & Model & Cytotoxicity & Aggregation & References \\
\hline & - & $\begin{array}{l}\text { rTg4510 tau transgenic } \\
\text { mice }\end{array}$ & - & $\begin{array}{l}\text { pS262/pS356 in TBS-extractable } \\
\text { tau which consists of granular } \\
\text { aggregates and short filaments }\end{array}$ & Sahara et al., 2013 \\
\hline \multirow[t]{4}{*}{ S262 } & DAPK1 & HEK293,N2a cells & $\begin{array}{l}\text { Tau expression antagonizes } \\
\text { DAPK } 1 \text { induced apoptosis } \\
\text { with simultaneous pS262, } \\
\text { no up-regulation of kinases }\end{array}$ & - & Duan et al., 2013 \\
\hline & PKA & $\begin{array}{l}\text { Rat hippocampal } \\
\text { neurons }\end{array}$ & $\begin{array}{l}\text { pS262 mediates toxicity via } \\
\text { MT instability; accelerated } \\
\text { degradation of } \\
\text { synaptophysin }\end{array}$ & - & Qureshi et al., 2013 \\
\hline & Par-1 & Drosophila & $\begin{array}{l}\text { pS262 contributes to } \\
\text { tau-mediated } \\
\text { neurodegeneration }\end{array}$ & - & lijima-Ando et al., 2012 \\
\hline & $\begin{array}{l}\text { MARK2 } \\
\text { MARK4 }\end{array}$ & $\begin{array}{l}\text { Paraffin sections } A D \\
\text { brain }\end{array}$ & - & $\begin{array}{l}\text { MARK-tau interactions and pS262 } \\
\text { correlate with Braak stages }\end{array}$ & Gu et al., 2013a \\
\hline \multirow[t]{5}{*}{$\begin{array}{l}\text { T231/S235 } \\
\text { (AT180,PHF-6 } \\
\text { epitopes) }\end{array}$} & - & $\begin{array}{l}\text { In vitro NMR } \\
\text { measurements }\end{array}$ & - & $\begin{array}{l}\text { pT231/pS235 has a helix stabilizing } \\
\text { role, potentially affecting tau } \\
\text { function and aggregation }\end{array}$ & Sibille et al., 2011 \\
\hline & DAPK1 & HEK293,N2a cells & $\begin{array}{l}\text { tau expression antagonizes } \\
\text { DAPK1 induced apoptosis } \\
\text { with simultaneous } \mathrm{pT} 231 \text {, } \\
\text { no up-regulation of kinases }\end{array}$ & - & Duan et al., 2013 \\
\hline & - & $\begin{array}{l}\text { rTg } 4510 \text { tau transgenic } \\
\text { mice }\end{array}$ & - & $\begin{array}{l}\text { pT231/pS235 in TBS-extractable } \\
\text { tau which consists of granular } \\
\text { aggregates and short filaments }\end{array}$ & Sahara et al., 2013 \\
\hline & GSK-3 $\beta$ & SAMP8 mice & $\begin{array}{l}\text { GSK-3 } \beta \text { antisense treatment } \\
\text { decreases } \mathrm{pT} 231 / \mathrm{pS} 235 ; \\
\text { reduced oxidative stress, } \\
\text { improved learning and } \\
\text { memory }\end{array}$ & - & Farr et al., 2013 \\
\hline & - & $\begin{array}{l}\text { Homogenates from } A D \\
\text { brain tissue }\end{array}$ & - & $\begin{array}{l}\text { Identification of pT231-positive } \\
\text { oligomers at early AD stages }\end{array}$ & $\begin{array}{l}\text { Lasagna-Reeves et al., } \\
2012\end{array}$ \\
\hline \multirow[t]{3}{*}{$\begin{array}{l}\text { S396/S404 } \\
\text { (PHF-1, AD2, } \\
\text { PHF-13 epitopes) }\end{array}$} & MARK2 & $\begin{array}{l}\text { In vitro biochemical } \\
\text { assay }\end{array}$ & - & $\begin{array}{l}\text { Acetylation on S396/S404 inhibits } \\
\text { its phosphorylation and tau } \\
\text { aggregation }\end{array}$ & Cook et al., 2014 \\
\hline & - & $\begin{array}{l}\text { In vitro biochemical } \\
\text { assay }\end{array}$ & - & $\begin{array}{l}\text { S396E/S404E affects MT binding, } \\
\text { MT polymerization and aggregation } \\
\text { of tau }\end{array}$ & $\begin{array}{l}\text { Sun and Gamblin, } \\
\text { 2009; Bibow et al., } 2011\end{array}$ \\
\hline & GSK-3 $\beta$ & $\begin{array}{l}\text { In vitro biochemical } \\
\text { assay }\end{array}$ & - & $\begin{array}{l}\text { pre-assembled pS396/pS404 tau } \\
\text { filaments form large tangle-like } \\
\text { structures }\end{array}$ & Rankin et al., 2008 \\
\hline
\end{tabular}


Table 2 | Continued

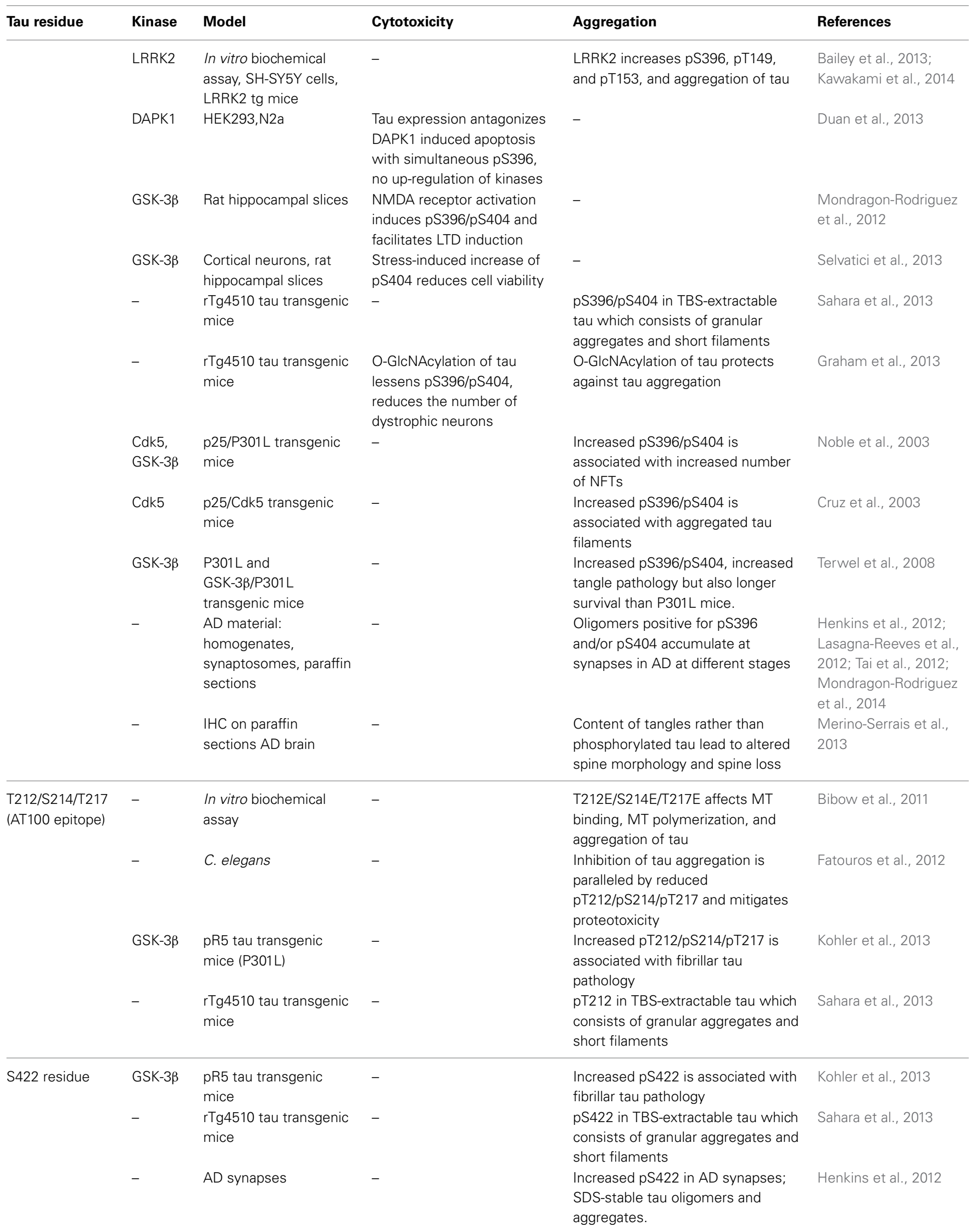


phosphorylation within the repeat region, particularly at KXGS motifs, induced specific conformational changes that altered the MT binding properties of tau (Fischer et al., 2009). In other cases, structural changes were localized in the proximity of the phosphorylation sites without affecting the global conformation (Schwalbe et al., 2013).

Despite intensive research in the field, the contribution of phosphorylation to the formation of tau aggregates is still controversial (Table 2). Recent results from in vitro experiments, showing that recombinant unphosphorylated tau induced fibril formation similar to $\mathrm{AD}$-derived PHFs, questioned the necessity of tau phosphorylation for the fibrillization process (Morozova et al., 2013). Furthermore, altered spine morphology and spine loss in tissue of $\mathrm{AD}$ cases were attributed to the content of tangles rather than to the amount of phosphorylated tau (Merino-Serrais et al., 2013). In a study using PS19 mice (tauP301S mutation), synthetic tau fibrils induced NFT pathology in the absence of tau hyperphosphorylation (Iba et al., 2013). The introduction of "pro-" and "anti-" aggregation mutations revealed that hexapeptide motifs of tau may function as a core to form local $\beta$-sheet structure and, subsequently, to induce PHF formation (Von Bergen et al., 2000; Eckermann et al., 2007). Enhanced tau levels, via stabilization of tau mRNA, may contribute to tau pathology independent of tau phosphorylation (Qian et al., 2013).

Other PTMs of tau might interfere with its phosphorylation, thereby influencing the structure, function and regulation of the protein, but the data are not consistent. KXGS motifs were found to be hypoacetylated and hyperphosphorylated in patients with $\mathrm{AD}$, consistent with in vitro data showing that the acetylation of tau prevents its phosphorylation and inhibits tau aggregation (Irwin et al., 2013; Cook et al., 2014). In contrast, acetylation of tau at K280 was associated with phosphorylation at the AT8 epitope in tau aggregates of tau transgenic mice, and detected in post-mortem tissue of cases with $\mathrm{AD}$ or other tauopathies (Min et al., 2010; Cohen et al., 2011; Irwin et al., 2012). Recent evidence was provided that tau itself possesses acetyltransferase activity, and is capable of catalyzing self-acetylation (Cohen et al., 2013). In vitro, O-linked $\beta-\mathrm{N}$-acetylglucosaminylation (O-GlcNAcylation) at S400 was inversely correlated with tau phosphorylation at S396 (Smet-Nocca et al., 2011). However, treatment of tau transgenic mice with an O-GlcNAcase inhibitor increased tau O-GlcNAcylation, hindered the formation of tau aggregates, and slowed neurodegeneration without affecting the phosphorylation of tau (Yuzwa et al., 2012; Graham et al., 2013).

Phosphorylation of tau at several residues mediates cellular toxicity (Table 2). Many data implicate that phosphorylation of tau needs to be well balanced. It was hypothesized that the detachment of tau from MTs results in impaired MT stability and excess amount of unbound hyperphosphorylated tau in the cytosol, thereby contributing to toxic insult. In vitro experiments provided evidence that phosphorylation of tau at S262, T231, and S214 is necessary for the full detachment of tau from MTs (Illenberger et al., 1998; Sengupta et al., 1998). Consistently, enhanced phosphorylation at S262 and T231 resulted in MT instability and cytotoxicity in cell and animal models (Steinhilb et al., 2007; Qureshi et al., 2013). Moreover, pathological processes were rescued by overexpression and activation of microtubule-affinity-regulating kinases (MARKs) that phosphorylate tau at KXGS motifs of the repeat domains (Mandelkow et al., 2004; Thies and Mandelkow, 2007). Aberrant phosphorylation of tau at pathological sites may result in altered tau-MT binding, thereby affecting the organization and dynamics of MT networks. This in turn may compromise axoplasmic flow and proper neuronal function, and ultimately cause cell death. The phosphorylation within KXGS motifs, especially at S262, and GSK-3 $\beta$ seem to take key roles among the phosphorylation sites and tau kinases, respectively.

Mitochondrial dysfunction and oxidative stress are both intimately associated with cell death in neurodegeneration. Mitochondrial oxidative stress in superoxide dismutase 2deficient and APP expressing mice exacerbated amyloid burden and the hyperphosphorylation of tau at S396. Treatment with high doses of antioxidants prevented from tau hyperphosphorylation and neuropathology (Melov et al., 2007). Triple AD mice expressing mutant tau, APP and presenilin 1 developed tangles and $A \beta$ plaques, and displayed deregulation of several mitochondrial proteins suggesting synergistic effects of $A \beta$ and tau in perishing mitochondria (Rhein et al., 2009).

Undoubtedly, tau hyperphosphorylation is an important phenomenon in $\mathrm{AD}$ and other tauopathies and parallels the appearance of tau aggregates and NFTs, but despite great efforts, the underlying mechanisms that ultimately lead to toxicity and neurodegeneration remain elusive (Papanikolopoulou et al., 2010; Ambegaokar and Jackson, 2011). In recent years, it was hypothesized that the segregation of tau in intracellular aggregates is an escape route for the cell from excess amount of protein. Instead, tau oligomers were considered as toxic species that harm the cell and, ultimately, lead to cell death (Sahara and Avila, 2014).

Accumulation of phosphorylated (AT8, PHF-1, S422) tau oligomers was detected at human AD synapses concomitant with dysfunction of the UPS (Henkins et al., 2012; Tai et al., 2012). Use of a tau oligomer-specific antibody in human $\mathrm{AD}$ brain samples revealed that tau oligomers appear at early stages in $\mathrm{AD}$, either before or after the manifestation of tau phosphorylation at specific epitopes (Lasagna-Reeves et al., 2012). Thus, aggregation of the hyperphosphorylated forms of tau into PHF structures could be neurotoxic by sequestering important cellular proteins, but it could also be neuroprotective by avoiding accumulation of toxic oligomeric tau.

\section{PHYSIOLOGICAL AND PATHOLOGICAL IMPLICATIONS OF TAU PHOSPHORYLATION}

At normal levels of phosphorylation, tau contains 2-3 moles phosphate/mole of protein and is a soluble cytosolic protein (Khatoon et al., 1992). From the overall 85 phosphorylatable residues, approximately 30 residues are phosphorylated in normal tau proteins (Morishima-Kawashima et al., 1995a; Hanger et al., 2009a). Most of the tau phosphorylation sites are clustered in the proline-rich region, the microtubule binding repeats (MTBR) or MTBR-flanking domains.

Tau expression and phosphorylation are developmentally regulated. A single tau isoform is expressed in fetal human brain whereas six isoforms are expressed in adult human brain, with fetal tau corresponding to the shortest adult tau isoform. The degree of tau phosphorylation decreases during embryogenesis 
(Mawal-Dewan et al., 1994), which might be related to increasing neuronal plasticity in the early developmental process (Brion et al., 1993; Hanger et al., 2009a). PHF-tau contains 3-4 fold phosphates over the normal adult tau (Khatoon et al., 1992; Iqbal et al., 2013). In immature brain, as in PHFs, tau is phosphorylated at a large number of sites (Kenessey and Yen, 1993; Morishima-Kawashima et al., 1995b). However, as in adult brain, the phosphorylation in fetal tau is only partial. Phosphorylation of tau in PHFs is denominated as "hyperphosphorylation" which takes into account that other sites than the physiological ones are phosphorylated. This state is also referred to as "abnormal" or "pathological" phosphorylation.

MT dynamics are dependent on a balanced ratio between tau molecules and MT tracks. Either excess or poor binding of tau molecules, e.g., through dysregulation of the tau phosphorylation state, results in destabilization and breakdown of MT networks. This has a direct impact on MT function in the formation of the cytoskeletal architecture and as track for axonal and organelle transport, and is resumed in the "Tau-microtubule hypothesis" (Alonso et al., 1994).

Early studies clearly demonstrated that tau plays an important role in the establishment of neuronal polarity and axonal outgrowth (Caceres and Kosik, 1990). Neurite extension and retraction may be regulated by MARK and GSK-3 $\beta$-mediated tau phosphorylation (Biernat et al., 2002; Sayas et al., 2002). It was speculated that phosphorylation of tau within the MTBR is necessary for appropriate neurite outgrowth whereas phosphorylation at SP and TP motifs within flanking domains retards neuronal differentiation (Biernat and Mandelkow, 1999). Tau, a cargo of kinesin, may displace other kinesin-based cargo indicating that the development and stabilization of axons are dependent on a balance of cytoskeletal elements (Dubey et al., 2008).

Overexpression of tau is known to compromise MTdependent axonal transport in a phosphorylation-dependent manner (Sato-Harada et al., 1996). Co-expression of constitutively active GSK-3 $\beta$ exacerbated, whereas GSK-3 $\beta$ inhibition rescued vesicle aggregation and locomotor dysfunction in a Drosophila model (Mudher et al., 2004; Cowan et al., 2010b). Phosphorylation of tau at Y18 by the Fyn kinase was suggested to prevent the activation of the GSK-3 $\beta$ signaling cascade, thereby counteracting tau's inhibitory effect on anterograde fast axonal transport (Kanaan et al., 2012). These data suggest that the pathological over-activation of GSK-3 $\beta$ inhibits axonal transport through hyperphosphorylation of tau. In contrast, other studies showed that the inhibition of tau phosphorylation by GSK-3 $\beta$ inhibitors was associated with decreased mitochondrial transport and motility and increased mitochondrial clustering in cells (Tatebayashi et al., 2004; Llorens-Martin et al., 2011). Tau may control intracellular trafficking by affecting the frequencies of attachment and detachment of motors, in particular kinesin, to the MT tracks (Trinczek et al., 1999; Morfini et al., 2007). It was speculated that excess tau acts as transport block for vesicles and organelles which is reversed by removal of tau through MARK-mediated tau phosphorylation and subsequent detachment of tau from MTs (Thies and Mandelkow, 2007). However, detachment of tau from MT may also contribute to axonal transport blockage and neurodegeneration (Iijima-Ando et al., 2012). Dephosphorylation and phosphorylation cycles of tau, through the interplay of tau kinases and phosphatases, may serve as general mechanism to regulate tau's function to maintain a dynamic MT network for neurite outgrowth and axonal transport (Fuster-Matanzo et al., 2012; Mandelkow and Mandelkow, 2012). Interestingly, improper distribution of overexpressed tau in the somatodendritic compartment was shown to result in more numerous and densely packed MTs in axons and dendrites. Phosphomimic mutations of the AT8 epitope caused expansion of the space between MTs and may thereby contribute to axonal transport and mitochondrial movement defects (Thies and Mandelkow, 2007; Shahpasand et al., 2012). Furthermore, phosphorylated tau may sequester normal tau in neurites away from MTs leading to disruption of the microtubular cytoskeleton and demise of axonal transport (Niewiadomska et al., 2005; Cowan et al., 2010a; Iqbal et al., 2013).

Extracellular $A \beta$, shown to exacerbate the hyperphosphorylation of tau and NFT formation, was also suggested to modulate Nmethyl-D-aspartate receptor (NMDAR) function and to induce excitotoxicity (Lauren et al., 2009). However, among the plethora of known $A \beta$-interacting molecules, the specific $A \beta$ target and the intracellular propagation of the signal remain elusive. Prion protein was proposed as binding partner of $A \beta$ but there is still controversy about the significance of this interaction (Balducci et al., 2010; Kessels et al., 2010; Chen et al., 2013a). A $\beta$ induces the activation of Fyn which, in turn, increases the phosphorylation of a subunit of NMDARs dependent on the status of tau phosphorylation and tau localization at the post-synapse. After an initial increase, the number of surface NMDARs declined which resulted in dendritic spine loss and excitotoxicity (Um et al., 2012). The interaction of Fyn and tau, both forming a complex together with NMDAR, seems to modulate synaptic plasticity and to sensitize synapses to glutamate excitoxicity in AD (Ittner et al., 2010).

Phosphorylation of tau was also linked to altered turnover and proteolysis. The detection of ubiquitin immunoreactivity in tau inclusions was interpreted as failure of the ubiquitin proteasome system (UPS) to proteolytically degrade excess tau (Bancher et al., 1989). Proteasomal inhibition resulted in the accumulation of particularly hyperphosphorylated tau species (Shimura et al., 2004) and disruption of neuritic transport (Agholme et al., 2013). Inhibition of autophagy in neurons resulted in 3-fold accumulation of phosphomimic tau over wild type tau indicating that both, autophagic and proteasomal pathways, are responsible for the clearance of phosphorylated tau species (Rodriguez-Martin et al., 2013). Biochemical and morphological analysis of AD cortices revealed that tau becomes hyperphosphorylated and misfolded at presynaptic and postsynaptic terminals, in association with an increase in ubiquitinated substrates and proteasome components (Tai et al., 2012).

Many other mechanisms were suggested for the implication of tau hyperphosphorylation in tauopathies. Cell death was accompanied by expression of cell-cycle regulatory proteins in aged mice expressing human tau isoforms on a knockout background (Andorfer et al., 2003). Inappropriate re-entry to the cell cycle plays a role in $\mathrm{AD}$ and might be linked to hyperphosphorylation of tau via activation of cell-cycle relevant kinases (Delobel et al., 2002; Absalon et al., 2013). Abnormal interaction 
with the mitochondrial fission protein Drp1 might be causative for mitochondrial dysfunction and neuronal damage (Manczak and Reddy, 2012). DNA damage resulted in the activation of the checkpoint kinases Chk1 and 2, subsequent tau phosphorylation at $\mathrm{AD}$-related sites, and enhancement of tau-induced neurodegeneration in human tau expressing Drosophila (IijimaAndo et al., 2010). Immunohistochemical analysis of AD brains revealed that tau is truncated at D421, and that this cleavage occurs after conformational changes detected by the Alz-50 antibody but precedes cleavage at E391 (Guillozet-Bongaarts et al., 2005). Accumulation of D421 and E391-truncated species occurs early in the disease and correlates with the progression in $\mathrm{AD}$ (Basurto-Islas et al., 2008). In transgenic mice, truncation of tau was shown to drive pre-tangle pathology (McMillan et al., 2011). In cells, hyperphosphorylation of tau at several residues and cleavage of tau at D421, the preferential cleavage site of caspase3 , enhanced the secretion of tau. This was suggested as potential mechanisms for the propagation of tau pathology in the brain and tau accumulation in the CSF (Plouffe et al., 2012).

\section{KINASES INVOLVED IN TAU PHOSPHORYLATION}

Similar to the pattern of tau hyperphosphorylation, the idea of a distinct signature-specific pattern of tau kinase activation emerged (Duka et al., 2013). Several attempts were done to identify the responsible kinases and the corresponding phosphorylation sites of tau (Table 2). However, most of the kinases phosphorylate several residues of tau, and most tau phosphorylation sites are targets of more than one kinase (Figure 3). In addition, the existence of priming, meaning that the phosphorylation at one site facilitates phosphorylation at another site, and feedback events to regulate the overall level of tau phosphorylation, hamper the assignment of a specific phosphorylation site to a particular (dys-)function of tau (Bertrand et al., 2010; Kiris et al., 2011).

Numerous kinases, including more than 20 serine/threonine kinases, were shown to phosphorylate tau in vitro but their relevance in AD is still under investigation (Hanger et al., 2009b; Cavallini et al., 2013).

The proline-directed kinase GSK-3 $\beta$ was particularly associated with the formation of PHFs and NFTs and proposed as key mediator in the pathogenesis of AD (Hooper et al., 2008; Terwel et al., 2008; Ma, 2014; Medina and Avila, 2014). GSK-3 $\beta$ targets tau at SP/TP sites, including the epitopes PHF-1, AT8, AT180, AT100, S404 and S413 (Pei et al., 1999; Medina and Avila, 2014). Alterations in GSK-3 $\beta$ levels were associated with changes in tau phosphorylation in several cell and animal models (Hernandez et al., 2013). Stress stimuli such as mitochondrial toxins or oxidative stress to mimic conditions in neurodegenerative disorders resulted in increased GSK-3 $\beta$-mediated phosphorylation of tau, reduced cell metabolic activity and MT destabilization (Hongo et al., 2012; Selvatici et al., 2013). Other studies position GSK-3 $\beta$ as prominent player in the pathogenesis of $\mathrm{AD}$ beyond its role as tau phosphorylating kinase. Tau-P301Lx GSK-3 $\beta$ mice developed severe forebrain tauopathy with tangles in the majority of neurons but in the absence of tau hyperphosphorylation (Muyllaert et al., 2006). In a Drosophila model, co-expression of a GSK-3 $\beta$ homolog and human tau led to increased toxicity more likely due to the fact that GSK-3 $\beta$ is a pro-apoptotic protein than due to increased tau phosphorylation (Jackson et al., 2002).

The serine/threonine kinase Cdk5 plays important roles in neuronal development and migration, neurite outgrowth, and synaptic transmission, and is implicated in the pathogenesis of AD (Cheung and Ip, 2012; Shukla et al., 2012). Immunoreactivity of Cdk5 in several brain regions in $\mathrm{AD}$ was associated with pretangle and early NFT stages, and colocalized with AT8-positive tau in a subset of neurons (Pei et al., 1998; Augustinack et al., 2002). Cdk5 activity was found to be higher in AD than control cases probably due to the conversion of the Cdk5 activator p35 into the constitutive active form p25 (Lee et al., 1999; Patrick et al., 1999; Shukla et al., 2012).

Mice overexpressing human p25/Cdk5 displayed enhanced Cdk5 activity, hyperphosphorylation of tau, and cytoskeletal disorganization (Ahlijanian et al., 2000). The activation of Cdk5 along with overexpression of mutant tau was associated with tau hyperphosphorylation and tangle formation (Noble et al., 2003). APPswe mice showed increased Cdk5 activity due to increases in p25 levels, and substantial phosphorylation of tau at AT8 and PHF-1 epitopes linking $\mathrm{A} \beta$ pathology to tau hyperphosphorylation via increased Cdk5 activity (Otth et al., 2002). Furthermore, Cdk5 was suggested to be linked to GSK-3 $\beta$. Mice expressing human p25 showed elevated A $\beta$ levels but decreased phosphotau levels and reduced GSK-3 $\beta$ activity. Administration of Cdk5 inhibitors reduced $A \beta$ production but did not alter the phosphorylation of tau suggesting that Cdk5 predominantly regulates APP processing, whereas GSK-3 $\beta$ plays a dominant role in tau phosphorylation (Wen et al., 2008; Engmann and Giese, 2009). The crosstalk between Cdk5 and mitogen-activated protein kinase (MAPK) pathways suggests a connection with neuronal apoptosis and survival signaling (Sharma et al., 2002; Zheng et al., 2007). Dysregulation of the MAPK signaling pathways, comprising the three signaling cascades extracellular signal regulated kinase (ERK), p38, and c-Jun N-terminal kinase (JNK), was suggested to be implicated in $\mathrm{AD}$ and other neurodegenerative disorders (Kim and Choi, 2010). In the course of AD, ERK and JNK are activated throughout all stages, and p38 in mild to severe cases (Braak stages III to VI) (Pei et al., 2001; Zhu et al., 2001). p38 and JNK immunoreactivity were associated with neurons containing neuritic plaques, neuropil threads, and NFTs, structures that were also recognized by antibodies raised against phosphorylated PHF-tau (Hensley et al., 1999; Atzori et al., 2001).

The kinases MARK1-4 are non-proline directed kinases that are involved in the establishment of neuronal polarity and the regulation of neurite outgrowth (Biernat et al., 2002; Matenia and Mandelkow, 2009; Reiner and Sapir, 2014). MARKs are named after their ability to regulate the affinity of tau to MTs through phosphorylation (Drewes et al., 1997). Importantly, MARKs phosphorylate tau within the KXGS motifs, particularly at S262, which phosphorylation is detected early in the course of AD. Expression of MARK2 and MARK4, as well as the interactions of these kinases with tau, were significantly enhanced in $\mathrm{AD}$ brains, correlated with the Braak stages of the disease, and were associated with NFTs (Chin et al., 2000; Gu et al., 2013a).

In transgenic Drosophila, overexpression of the Drosophila homolog Par-1 was associated with increased phosphorylation 


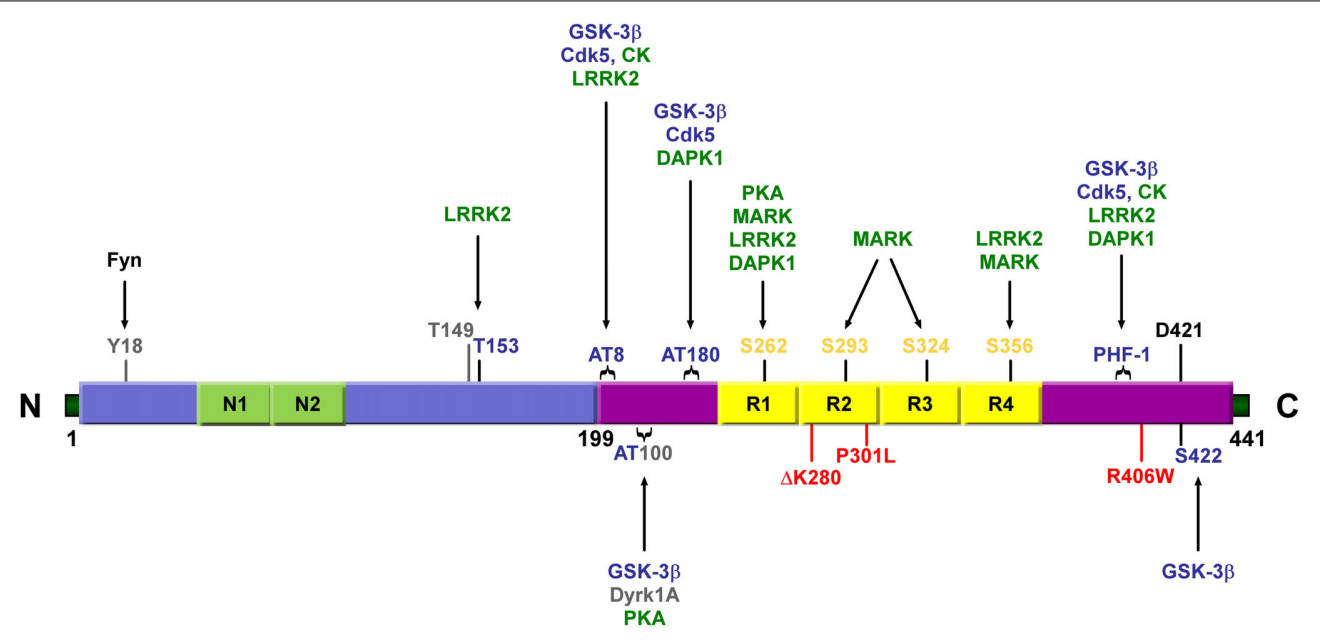

FIGURE 3 | Schematic representation illustrating the various residues in the longest isoform of tau that can be phosphorylated. SP/TP motifs (represented in blue), KXGS motifs (represented in yellow), and other sites (represented in gray) can be phosphorylated by proline-directed kinases (represented in blue) and non-proline directed Ser/Thr kinases (represented in green). Antibody epitopes AT8, AT100, AT180, and PHF-1 comprise dual and triple serine/threonine residues (indicated by brackets). Some mutations associated with FTDP-17 are shown in red. Alternative splicing of N1, N2, and R2 generates the six different isoforms of tau. N1, N2, N-terminal inserts 1 and 2; R1-R4,MT binding repeats 1-4; GSK-3 $\beta$, Glycogen synthase kinase $3 \beta$; Cdk5, Cyclin-dependent kinase 5; CK, casein kinase; MARK, microtubule affinity-regulating kinase; LRRK2, leucine-rich repeat kinase 2; DAPK, Death-associated protein kinase; Dyrk1A, dual-specificity protein kinase. and enhanced toxicity of human tau. Loss of Par-1 function and mutation of tau at the Par-1 directed phosphorylation sites (S262, S356) rescued from tau-induced toxicity. Interestingly, Par-1 phosphorylation of tau was a prerequisite for downstream phosphorylation through GSK-3 $\beta$ and Cdk5, and the generation of disease-associated phosphorylation epitopes (Nishimura et al., 2004). Activation of MARK2 rescued from synaptic decay caused by overexpression and improper distribution of tau in the somatodendritic compartment (Mandelkow et al., 2004; Thies and Mandelkow, 2007). However, overexpression of MARK4 resulted in tau hyperphosphorylation and loss of spines, which also manifested after $A \beta$ treatment. Therefore, MARKs may have regulatory functions in spine morphology and synaptic transmission, but may also act as critical mediators in $\mathrm{A} \beta$-induced toxicity on synapses and dendritic spines (Zempel et al., 2010; Hayashi et al., 2011; Yu et al., 2012). Furthermore, the phosphorylation of tau by MARK was suggested to inhibit tau's assembly into PHFs (Schneider et al., 1999), contradictory to the hypothesis that the pool of hyperphosphorylated, MT-unbound tau assembles into PHFs. Phosphorylation of tau at SP/TP sites has low impact on the tau-MT binding and is observed in $\mathrm{AD}$, dissociating the detachment of tau from MTs from the likability to assemble into PHFs. GSK-3 $\beta$ was shown to phosphorylate MARK2 at two different sites, the activatory T208 and the inhibitory S212, thereby modulating the phosphorylation of tau, particularly at S262 (Kosuga et al., 2005; Timm et al., 2008). MARK1/2 activity was also regulated by the death domain of DAPK. DAPK activated MARK and promoted the phosphorylation of tau but also seems to act via MARK-independent pathways on T231, S262, and S396 of tau (Wang et al., 2010; Duan et al., 2013). Moreover, DAPK induced rough eye and loss of photoreceptor neurons in a Drosophila model, in part through the activation of the Drosophila ortholog Par-1 (Wu et al., 2011b). PKC was described as negative regulator of MARK2, playing an important role in neuronal polarity (Chen et al., 2006).

$\mathrm{CK} 1$ and $\mathrm{CK} 2$ are serine/threonine-selective protein kinases. Overall CK2 immunoreactivity is reduced in the brain of $\mathrm{AD}$ cases although NFTs stain very strong with anti-CK2 antibodies (Iimoto et al., 1990). CK-1 $\delta$ is upregulated in AD brain, correlating with the degree of regional pathology. CK- $1 \delta$ colocalizes with NFTs, neuropil threads and dystrophic neurites (Yasojima et al., 2000). In cells, CK $1 \delta$ inhibition reduced the phosphorylation of tau at S396/S404 by more than 70\%. Exogenous expression of CK1 $\delta$ increased tau phosphorylation at S202/T205 and S396/S404 and reduced tau-MT binding (Lee and Leugers, 2012).

Several sites in PHF-tau are targeted by CK1 in concert with other kinases such as GSK-3 $\beta$ and protein kinase A (PKA). Moreover, three sites, S113, S238, and S433, were phosphorylated only by the action of CK1 $\delta$ suggesting a relevant role of this kinase in tau pathology (Hanger et al., 2007). Synthetic A $\beta$ was reported to stimulate the activities of CK1 and CK2 and to mediate phosphorylation of the substrate casein in vitro (Chauhan et al., 1993). A $\beta$ production was increased in cells with exogenous expression of constitutively active CK1 and reduced by CK1 specific inhibition (Flajolet et al., 2007).

Dyrk1A is upregulated in AD, Down's syndrome, and Pick's disease. Dyrk1A immunoreactivity was observed in the cytoplasm and nucleus of scattered neurons, and detected in sarkosylinsoluble PHF fractions. Overexpression of Dyrk1A in transgenic mice led to increased tau levels in the brain and accumulation in NFTs (Wegiel et al., 2008). Direct phosphorylation of tau at T212 by Dyrk1A still lacks evidence in vivo.

LRRK2, a putative kinase, gained interest in recent years due to its genetic association with both, inherited and sporadic PD, 
and a possible overlap to $\mathrm{AD}$ (Zhao et al., 2011; Ujiie et al., 2012). The first hints for an involvement of LRRK2 in tau pathology were given in transgenic mice expressing mutant LRRK2. These animals showed increased tau phosphorylation at T149, T153, and the AT8, CP13, 12E8 and PHF-1 epitopes, tau mislocalization in cell bodies and the neuropil, and tau aggregation (Li et al., 2009, 2010; Melrose et al., 2010; Bailey et al., 2013). Correspondingly, phosphorylation of tau at the AT8 epitope was decreased in LRRK2 knock-out mice (Gillardon, 2009). Several studies imply that LRRK2 phosphorylates and activates other kinases and signal transduction pathways, thereby contributing to enhanced tau phosphorylation, mislocalization, and dendritic degeneration (Gloeckner et al., 2009; Lin et al., 2010; Chen et al., 2012).

Several other kinases may be implicated in the pathology of $\mathrm{AD}$, anticipated from their aberrant activity in human brain (Martin et al., 2013). In general, dysregulation of kinases is likely to be responsible for the hyperphosphorylation of tau, abnormal tau-MT binding, tau mislocalization, and tau assembly into PHFs. However, it is still not known, which phosphorylation sites of tau are the most critical ones, which kinases are the main players, and how these processes are mechanistically linked to toxicity in $\mathrm{AD}$ and other neurodegenerative disorders.

\section{PHOSPHORYLATION AS A TARGET FOR THERAPEUTIC INTERVENTION}

Our current lack of understanding of the precise molecular mechanisms underlying neurodegenerative disorders has limited our ability to develop effective therapeutic strategies. Targeting phosphorylation of aSyn and tau can impact on several mechanisms associated with the pathogenesis of $\mathrm{AD}, \mathrm{PD}$ and other neurodegenerative disorders. Thus, reducing aberrant protein phosphorylation and protein levels, preventing protein aggregation, eliminating amyloidogenic species and preventing spreading of pathology are all potentially beneficial and will be discussed below.

\section{KINASE INHIBITION}

Although the precise consequences of aSyn phosphorylation remain to be fully understood, it is evident that pS129 correlates with disease progression, is present in the pathological hallmark lesions of synucleinopathies and can have detrimental functional consequences. Thus, inhibition of the relevant kinases might constitute a possible therapeutic strategy. Inhibitors of PLKs have been developed for oncology indications and tested in vivo. A PD mouse model of subject to a treatment with the specific PLK inhibitor BI2356 presented reduced pS129 aSyn (Inglis et al., 2009). However, the long-term safety of such strategy is currently unclear, as the kinases that phosphorylate aSyn have ubiquitous distribution and because there is evident redundancy in the types of kinases phosphorylating same residues in aSyn. In the particular case of PLK2, recent data suggest that enhancing the kinase activity, instead of inhibiting, might also prove worth investigating further, as PLK2 suppresses aSyn toxicity in vivo by promoting autophagy-mediated degradation of pS129 aSyn (Oueslati et al., 2013).
The pharmacological inhibition of c-Abl is also emerging as an attractive therapeutic strategy, as it was found to be neuroprotective in animal models of PD (Ko et al., 2010; Imam et al., 2011, 2013; Hebron et al., 2013a; Mahul-Mellier et al., 2014), by promoting aSyn degradation (Hebron et al., 2013a,b; MahulMellier et al., 2014). Interestingly, c-Abl inhibition also targets hyperphosphorylated tau for degradation (Hebron et al., 2013a) and inhibits $\beta$-amyloid production in rat neuronal primary cultures and in guinea pig brains (Netzer et al., 2003). Therefore, this kinase is a promising target for the treatment of both, PD and AD.

Inhibition of GSK-3 $\beta$ activity by chemical compounds, antisense RNAs and kinase-dead mutations or reduction of GSK$3 \beta$ levels were the most promising attempts to decrease the phosphorylation of tau at critical residues. This was shown to counteract neuronal death, reduce oxidative stress, and improve learning and memory (Hernandez et al., 2013; Medina and Avila, 2014). GSK-3 $\beta$ was suggested as missing link between $A \beta$ and tau pathology. Small molecule inhibitors of GSK$3 \beta$ might be potent to reduce $A \beta$-induced tau hyperphosphorylation (Noh et al., 2013; Ye et al., 2013). Given the contribution of other kinases to tau hyperphosphorylation, effective treatment may require multiple kinase targeting (Mazanetz and Fischer, 2007; Tell and Hilgeroth, 2013; Pinsetta et al., 2014).

\section{IMMUNOLOGICAL TARGETING OF PHOSPHORYLATED PROTEINS}

The consequences of loss of aSyn function in PD are not completely clarified. Some studies suggest that a substantial reduction in the levels of aSyn could have potential harmful effects in the CNS. In fact, aSyn knockout mice show some loss of dopaminergic nigrostriatal terminals with aging (Al-Wandi et al., 2010). Moreover, aSyn seems to play an important role holding together the SNARE complex, suggesting that excessive reduction of this abundant protein in the nervous system could lead to deleterious effects. Nevertheless, therapeutic strategies involving immunization or promoting clearance of aSyn excess are attractive and have been recently considered. Studies exploring immunization as a potential therapeutic were performed in mice models of PD and achieved promising results (Masliah et al., 2005, 2011). However, to our knowledge, the use of phospho-specific antibodies against aSyn was not explored so far.

Targeting specific phospho-tau sites through passive immunization may be useful to slow, or even reverse, the progression of a disease. Antibody uptake resulted in reduced tau phosphorylation, and clearance of pathological tau protein in brain slices up to significantly improved cognitive performance in Thy-Tau22 transgenic mice (Troquier et al., 2012; Gu et al., 2013b). However, repeated immunization of mice with phospho-tau peptides may cause neuroinflammation (Rozenstein-Tsalkovich et al., 2013).

\section{ACTIVATION OF PHOSPHATASES}

Another possible therapeutic strategy could involve restoring or increasing the activity of specific phosphatases. Although phosphatases are thought to be less appealing drug targets, since they are considered less specific than kinases, increasing evidence suggests that they might be "druggable" proteins. On the other hand, the lower level of redundancy may be seen as an advantage. 
In fact, pharmacological induction of the phosphoprotein phosphatase 2A (PP2A) by eicosanoyl-5-hydroxytryptamide resulted in dephosphorylation of aSyn at S129, inhibition of aSyn aggregation with concomitant improved neuronal integrity, reduction in inflammation and amelioration of behavioral deficits in an aSyn transgenic mouse model, (Lee et al., 2011).

Dysregulated phosphatase activity also seems to be partially responsible for tau pathology. A number of pharmacological agents, such as the FDA-approved drug memantine, prevented okadaic acid or calyculin-induced PP2A inhibition and tau phosphorylation (Li et al., 2004; De Los Rios et al., 2010; Kickstein et al., 2010; Yang et al., 2011).

\section{MODULATION OF PROTEIN CLEARANCE VIA PHOSPHORYLATION}

The induction of aSyn degradation through clearance pathways is also seen as an attractive therapeutic strategy. aSyn can be degraded by direct proteolysis, by the UPS, by chaperonemediated autophagy, or by general autophagy (Lashuel et al., 2013). As discussed earlier, phosphorylation of Y39 by c-Abl impairs aSyn degradation by autophagy and proteasome (MahulMellier et al., 2014), while PLK2 phosphorylation at S129 promotes selective autophagic aSyn clearance (Oueslati et al., 2013). Likewise, inhibiting c-Abl and enhancing PLK2 activity are two promising therapeutic approaches.

Several studies indicate that the reduction of tau phosphorylation was paralleled by an overall decrease in protein levels. Moreover, targeting unphosphorylated tau protein had deleterious effects since tau is a normal component of the cytoskeleton (Rosenmann et al., 2006). Additionally, reduced protein levels were achieved through interference with the UPS and the lysosomal / autophagic pathways. Immunization using phosphospecific antibodies against tau epitopes resulted in reduced levels of tau protein and clearance of tau aggregates (Asuni et al., 2007; Boimel et al., 2010; Boutajangout et al., 2010, 2011). Interestingly, memantine that inhibited the phosphorylation of tau at some epitopes in hippocampal slices also reduced tau aggregation ( $\mathrm{Li}$ et al., 2004). The small molecule IU1, a potent and selective inhibitor of the deubiquitinating enzyme ubiquitin specific peptidase 14 (USP14), enhanced the degradation of tau (Lee et al., 2010). The underlying mechanisms are not clear because USP14deficient mice showed no alterations in tau degradation and actually increased amounts of phosphorylated tau (Jin et al., 2012). Chronic treatment with lithium chloride, a direct inhibitor of GSK-3 $\beta$, reduced tau pathology by promoting ubiquitination (Nakashima et al., 2005).

Positive lysosomal modulation was described for several factors and may be an attempt of cells to clear amyloidogenic species such as tau and aSyn oligomers (Lee et al., 2004b; Butler et al., 2006; Bahr et al., 2012). Methylene blue (MB) was shown to induce autophagy and to reduce total and phosphorylated levels of tau. Although MB administration improved cognitive performance in tau transgenic mice, a reversal of already existing NFTs was disputed (Congdon et al., 2012; Spires-Jones et al., 2014). Interestingly, MB was the first identified direct tau aggregation inhibitor (Duff et al., 2010). Modified versions of this substance with greater tolerability and better absorption are underway in clinical trials (Wischik et al., 2013). Lithium chloride prevented tau aggregation in cultured neurons probably through decreased tau protein levels as outlined above (Rametti et al., 2008). In recent studies, pre-filamentous aSyn and tau oligomers rather than aSyn fibrils and NFTs were considered as toxic species questioning the usefulness of aggregation inhibitors (Castillo-Carranza et al., 2013; Crowe et al., 2013; Lesne, 2013). Furthermore, at higher doses, some of the in vitro tested substances showed severe side effects on the normal biology of tau and its MT stabilization in cell culture and brain slices (Duff et al., 2010).

\section{MODULATION OF PATHOLOGY SPREADING VIA PHOSPHORYLATION}

Recent studies strongly suggest that disease progression in $A D$, $\mathrm{PD}$, and other neurodegenerative disorders may, at least in part, be due to cell-to-cell transmission of amyloidogenic species. Thus, the elimination of these toxic species may help to slow or contain neurodegeneration.

The mechanisms behind the spreading of aSyn are not fully understood. However, aSyn secreted by neurons could strongly contribute to cell-to-cell propagation (Marques and Outeiro, 2012; Eisbach and Outeiro, 2013). The relationship between the phosphorylated status of aSyn and its secretion are currently unknown and require investigation, but if correlation exists then phosphorylation might be targeted to prevent the spreading of aSyn pathology.

Immunization with cell-penetrating phospho-tau antibodies was already discussed as a therapeutic approach to clear from toxic tau species. Similarly, antibodies that remain in the extracellular space may inhibit spreading and this includes both, anti-tau and anti-A $\beta$ antibodies (Giacobini and Gold, 2013; Liu et al., 2014). Lowering the intracellular amyloid burden through RNA interference or by drugs may entail reduced secretion of $A \beta$ and thereby lessen tau pathology (Chen et al., 2013b; Spilman et al., 2013). However, some of these treatments failed in clinical trials (Doody et al., 2014). Importantly, extracellular soluble tau was also shown to initiate spread of tau pathology and may be a plausible target for treatment (Michel et al., 2014).

\section{CONCLUSIONS AND FUTURE PERSPECTIVES}

While it is clear that phosphorylation of aSyn and tau is relevant in the context of their aggregation and toxicity, there is still no final consensus on the precise contribution this type of PTM has toward the disease process. For example, there is still no consensus on whether aSyn phosphorylation is a cause or a consequence of aggregation, or whether phosphorylation is neurotoxic or neuroprotective. Furthermore, only a few phosphorylation sites have been confirmed in human tissue so far, so there may be other sites relevant to human pathology that remain to be identified. Tau phosphorylation regulates tau's function in many ways while abnormal phosphorylation of tau is neurotoxic. The relationship between tau phosphorylation and aggregation is clearly complex with evidence that tau phosphorylation precedes, prevents or is irrelevant to its aggregation. It will also be important to explore the cross-talk between different PTMs, as this will likely have a strong impact on our understanding of the biology/pathobiology of different proteins associated with neurodegeneration. In addition, the identification of the kinases and phosphatases involved 
in the phosphorylation/dephosphorylation of aSyn and tau will certainly open novel possibilities for pharmacological intervention. Ultimately, solving the problems and inconsistencies surrounding the phosphorylation of these important players in $\mathrm{AD}$ and PD will be essential for advancing the development of novel therapeutic strategies.

\section{ACKNOWLEDGMENTS}

We thank Dr. Federico Herrera for his critical reading of the manuscript and insightful comments. Sandra Tenreiro is supported by FCT (SFRH/BPD/35767/2007). Katrin Eckermann is supported by the DFG Center for Nanoscale Microscopy and Molecular Physiology of the Brain (CNMPB). Tiago F. Outeiro is currently funded by the DFG Center for Nanoscale Microscopy and Molecular Physiology of the Brain (CNMPB) and was funded by Fundação para a Ciência e Tecnologia, Portugal (Grants PTDC/BIA-BCM/117975/2010 and PTDC/SAU-NEU/105215/2008).

\section{REFERENCES}

Absalon, S., Kochanek, D. M., Raghavan, V., and Krichevsky, A. M. (2013). MiR-26b, upregulated in Alzheimer's disease, activates cell cycle entry, tauphosphorylation, and apoptosis in postmitotic neurons. J. Neurosci. 33, 14645-14659. doi: 10.1523/JNEUROSCI.1327-13.2013

Agholme, L., Nath, S., Domert, J., Marcusson, J., Kagedal, K., and Hallbeck, M. (2013). Proteasome inhibition induces stress kinase dependent transport deficits - Implications for Alzheimer's disease. Mol. Cell. Neurosci. 58C, 29-39. doi: 10.1016/j.mcn.2013.11.001

Ahlijanian, M. K., Barrezueta, N. X., Williams, R. D., Jakowski, A., Kowsz, K. P., McCarthy, S., et al. (2000). Hyperphosphorylated tau and neurofilament and cytoskeletal disruptions in mice overexpressing human p25, an activator of cdk5. Proc. Natl. Acad. Sci. U.S.A. 97, 2910-2915. doi: 10.1073/pnas.040 577797

Alonso, A. C., Zaidi, T., Grundke-Iqbal, I., and Iqbal, K. (1994). Role of abnormally phosphorylated tau in the breakdown of microtubules in Alzheimer disease. Proc. Natl. Acad. Sci. U.S.A. 91, 5562-5566. doi: 10.1073/pnas.91.12.5562

Alonso Adel, C., Mederlyova, A., Novak, M., Grundke-Iqbal, I., and Iqbal, K. (2004). Promotion of hyperphosphorylation by frontotemporal dementia tau mutations. J. Biol. Chem. 279, 34873-34881. doi: 10.1074/jbc.M405131200

Al-Wandi, A., Ninkina, N., Millership, S., Williamson, S. J., Jones, P. A., and Buchman, V. L. (2010). Absence of alpha-synuclein affects dopamine metabolism and synaptic markers in the striatum of aging mice. Neurobiol. Aging 31, 796-804. doi: 10.1016/j.neurobiolaging.2008.11.001

Ambegaokar, S. S., and Jackson, G. R. (2011). Functional genomic screen and network analysis reveal novel modifiers of tauopathy dissociated from tau phosphorylation. Hum. Mol. Genet. 20, 4947-4977. doi: 10.1093/hmg/ddr432

Anderson, J. P., Walker, D. E., Goldstein, J. M., De Laat, R., Banducci, K., Caccavello, R. J., et al. (2006). Phosphorylation of Ser-129 is the dominant pathological modification of alpha-synuclein in familial and sporadic Lewy body disease. J. Biol. Chem. 281, 29739-29752. doi: 10.1074/jbc.M600933200

Andorfer, C., Kress, Y., Espinoza, M., De Silva, R., Tucker, K. L., Barde, Y. A., et al. (2003). Hyperphosphorylation and aggregation of tau in mice expressing normal human tau isoforms. J. Neurochem. 86, 582-590. doi: 10.1046/j.14714159.2003.01879.x

Appel-Cresswell, S., Vilarino-Guell, C., Encarnacion, M., Sherman, H., Yu, I., Shah, B., et al. (2013). Alpha-synuclein p.H50Q, a novel pathogenic mutation for Parkinson's disease. Mov. Disord. 28, 811-813. doi: 10.1002/mds.25421.

Arai, H., Ishiguro, K., Ohno, H., Moriyama, M., Itoh, N., Okamura, N., et al. (2000a). CSF phosphorylated tau protein and mild cognitive impairment: a prospective study. Exp. Neurol. 166, 201-203. doi: 10.1006/exnr.2000.7501

Arai, K., Kato, N., Kashiwado, K., and Hattori, T. (2000b). Pure autonomic failure in association with human alpha-synucleinopathy. Neurosci. Lett. 296, 171-173. doi: 10.1016/S0304-3940(00)01623-2

Arawaka, S., Wada, M., Goto, S., Karube, H., Sakamoto, M., Ren, C. H., et al. (2006). The role of G-protein-coupled receptor kinase 5 in pathogenesis of sporadic
Parkinson's disease. J. Neurosci. 26, 9227-9238. doi: 10.1523/JNEUROSCI.034106.2006

Arrasate, M., Mitra, S., Schweitzer, E. S., Segal, M. R., and Finkbeiner, S. (2004). Inclusion body formation reduces levels of mutant huntingtin and the risk of neuronal death. Nature 431, 805-810. doi: 10.1038/nature02998

Asuni, A. A., Boutajangout, A., Quartermain, D., and Sigurdsson, E. M. (2007). Immunotherapy targeting pathological tau conformers in a tangle mouse model reduces brain pathology with associated functional improvements. J. Neurosci. 27, 9115-9129. doi: 10.1523/JNEUROSCI.2361-07.2007

Atzori, C., Ghetti, B., Piva, R., Srinivasan, A. N., Zolo, P., Delisle, M. B., et al. (2001). Activation of the JNK/p38 pathway occurs in diseases characterized by tau protein pathology and is related to tau phosphorylation but not to apoptosis. J. Neuropathol. Exp. Neurol. 60, 1190-1197.

Augustinack, J. C., Sanders, J. L., Tsai, L. H., and Hyman, B. T. (2002). Colocalization and fluorescence resonance energy transfer between $c \mathrm{dk} 5$ and AT8 suggests a close association in pre-neurofibrillary tangles and neurofibrillary tangles. J. Neuropathol. Exp. Neurol. 61, 557-564.

Azeredo Da Silveira, S., Schneider, B. L., Cifuentes-Diaz, C., Sage, D., Abbas-Terki, T., Iwatsubo, T., et al. (2009). Phosphorylation does not prompt, nor prevent, the formation of alpha-synuclein toxic species in a rat model of Parkinson's disease. Hum. Mol. Genet. 18, 872-887. doi: 10.1093/hmg/ddn417

Bahr, B. A., Wisniewski, M. L., and Butler, D. (2012). Positive lysosomal modulation as a unique strategy to treat age-related protein accumulation diseases. Rejuvenation Res. 15, 189-197. doi: 10.1089/rej.2011.1282

Bailey, R. M., Covy, J. P., Melrose, H. L., Rousseau, L., Watkinson, R., Knight, J., et al. (2013). LRRK2 phosphorylates novel tau epitopes and promotes tauopathy. Acta Neuropathol. 126, 809-827. doi: 10.1007/s00401-013-1188-4

Balducci, C., Beeg, M., Stravalaci, M., Bastone, A., Sclip, A., Biasini, E., et al. (2010). Synthetic amyloid-beta oligomers impair long-term memory independently of cellular prion protein. Proc. Natl. Acad. Sci. U.S.A. 107, 2295-2300. doi: 10.1073/pnas.0911829107

Bancher, C., Brunner, C., Lassmann, H., Budka, H., Jellinger, K., Wiche, G., et al. (1989). Accumulation of abnormally phosphorylated tau precedes the formation of neurofibrillary tangles in Alzheimer's disease. Brain Res. 477, 90-99.

Bancher, C., Grundke-Iqbal, I., Iqbal, K., Fried, V. A., Smith, H. T., and Wisniewski, H. M. (1991). Abnormal phosphorylation of tau precedes ubiquitination in neurofibrillary pathology of Alzheimer disease. Brain Res. 539, 11-18. doi: 10.1016/0006-8993(91)90681-K

Basso, E., Antas, P., Marijanovic, Z., Goncalves, S., Tenreiro, S., and Outeiro, T. F. (2013). PLK2 modulates alpha-synuclein aggregation in yeast and mammalian cells. Mol. Neurobiol. 48, 854-862. doi: 10.1007/s12035-013-8473-z

Basurto-Islas, G., Luna-Munoz, J., Guillozet-Bongaarts, A. L., Binder, L. I., Mena, R., and Garcia-Sierra, F. (2008). Accumulation of aspartic acid421- and glutamic acid391-cleaved tau in neurofibrillary tangles correlates with progression in Alzheimer disease. J. Neuropathol. Exp. Neurol. 67, 470-483. doi: 10.1097/NEN.0b013e31817275c7

Bertrand, J., Plouffe, V., Senechal, P., and Leclerc, N. (2010). The pattern of human tau phosphorylation is the result of priming and feedback events in primary hippocampal neurons. Neuroscience 168, 323-334. doi: 10.1016/j.neuroscience.2010.04.009

Bibow, S., Ozenne, V., Biernat, J., Blackledge, M., Mandelkow, E., and Zweckstetter, M. (2011). Structural impact of proline-directed pseudophosphorylation at AT8, AT100, and PHF1 epitopes on 441-residue tau. J. Am. Chem. Soc. 133 , 15842-15845. doi: 10.1021/ja205836j

Biernat, J., and Mandelkow, E. M. (1999). The development of cell processes induced by tau protein requires phosphorylation of serine 262 and 356 in the repeat domain and is inhibited by phosphorylation in the proline-rich domains. Mol. Biol. Cell 10, 727-740. doi: 10.1091/mbc. 10.3.727

Biernat, J., Wu, Y. Z., Timm, T., Zheng-Fischhofer, Q., Mandelkow, E., Meijer, L., et al. (2002). Protein kinase MARK/PAR-1 is required for neurite outgrowth and establishment of neuronal polarity. Mol. Biol. Cell 13, 4013-4028. doi: 10.1091/mbc.02-03-0046

Bodner, R. A., Outeiro, T. F., Altmann, S., Maxwell, M. M., Cho, S. H., Hyman, B. T., et al. (2006). Pharmacological promotion of inclusion formation: a therapeutic approach for Huntington's and Parkinson's diseases. Proc. Natl. Acad. Sci. U.S.A. 103, 4246-4251. doi: 10.1073/pnas.05112 56103 
Boimel, M., Grigoriadis, N., Lourbopoulos, A., Haber, E., Abramsky, O., and Rosenmann, H. (2010). Efficacy and safety of immunization with phosphorylated tau against neurofibrillary tangles in mice. Exp. Neurol. 224, 472-485. doi: 10.1016/j.expneurol.2010.05.010

Boutajangout, A., Ingadottir, J., Davies, P., and Sigurdsson, E. M. (2011). Passive immunization targeting pathological phospho-tau protein in a mouse model reduces functional decline and clears tau aggregates from the brain. J. Neurochem. 118, 658-667. doi: 10.1111/j.1471-4159.2011.07337.x

Boutajangout, A., Quartermain, D., and Sigurdsson, E. M. (2010). Immunotherapy targeting pathological tau prevents cognitive decline in a new tangle mouse model. J. Neurosci. 30, 16559-16566. doi: 10.1523/JNEUROSCI.4363-10.2010

Braak, H., Alafuzoff, I., Arzberger, T., Kretzschmar, H., and Del Tredici, K. (2006). Staging of Alzheimer disease-associated neurofibrillary pathology using paraffin sections and immunocytochemistry. Acta Neuropathol. 112, 389-404. doi: 10.1007/s00401-006-0127-z

Brion, J. P., Smith, C., Couck, A. M., Gallo, J. M., and Anderton, B. H. (1993). Developmental changes in tau phosphorylation: fetal tau is transiently phosphorylated in a manner similar to paired helical filament-tau characteristic of Alzheimer's disease. J. Neurochem. 61, 2071-2080.

Brown, D. R. (2007). Interactions between metals and alpha-synuclein-function or artefact? FEBS J. 274, 3766-3774. doi: 10.1111/j.1742-4658.2007.05917.x

Butler, D., Nixon, R. A., and Bahr, B. A. (2006). Potential compensatory responses through autophagic/lysosomal pathways in neurodegenerative diseases. Autophagy 2, 234-237.

Caceres, A., and Kosik, K. S. (1990). Inhibition of neurite polarity by tau antisense oligonucleotides in primary cerebellar neurons. Nature 343, 461-463. doi: 10.1038/343461a0

Castillo-Carranza, D. L., Lasagna-Reeves, C. A., and Kayed, R. (2013). Tau aggregates as immunotherapeutic targets. Front. Biosci. (Schol. Ed.) 5, 426-438.

Cavallini, A., Brewerton, S., Bell, A., Sargent, S., Glover, S., Hardy, C., et al. (2013). An unbiased approach to identifying tau kinases that phosphorylate tau at sites associated with Alzheimer disease. J. Biol. Chem. 288, 23331-23347. doi: 10.1074/jbc.M113.463984

Chartier-Harlin, M. C., Kachergus, J., Roumier, C., Mouroux, V., Douay, X., Lincoln, S., et al. (2004). Alpha-synuclein locus duplication as a cause of familial Parkinson's disease. Lancet 364, 1167-1169. doi: 10.1016/S01406736(04)17103-1

Chau, K. Y., Ching, H. L., Schapira, A. H., and Cooper, J. M. (2009). Relationship between alpha synuclein phosphorylation, proteasomal inhibition and cell death: relevance to Parkinson's disease pathogenesis. J. Neurochem. 110, 1005-1013. doi: 10.1111/j.1471-4159.2009.06191.x

Chauhan, A., Chauhan, V. P., Murakami, N., Brockerhoff, H., and Wisniewski, H. M. (1993). Amyloid beta-protein stimulates casein kinase I and casein kinase II activities. Brain Res. 629, 47-52. doi: 10.1016/0006-8993(93)90479-7

Chen, C. Y., Weng, Y. H., Chien, K. Y., Lin, K. J., Yeh, T. H., Cheng, Y. P., et al. (2012). (G2019S) LRRK2 activates MKK4-JNK pathway and causes degeneration of SN dopaminergic neurons in a transgenic mouse model of PD. Cell Death Differ. 19, 1623-1633. doi: 10.1038/cdd.2012.42

Chen, L., and Feany, M. B. (2005). Alpha-synuclein phosphorylation controls neurotoxicity and inclusion formation in a Drosophila model of Parkinson disease. Nat. Neurosci. 8, 657-663. doi: 10.1038/nn1443

Chen, L., Periquet, M., Wang, X., Negro, A., McLean, P. J., Hyman, B. T., et al. (2009). Tyrosine and serine phosphorylation of alpha-synuclein have opposing effects on neurotoxicity and soluble oligomer formation. J. Clin. Invest. 119, 3257-3265. doi: 10.1172/JCI39088

Chen, R. J., Chang, W. W., Lin, Y. C., Cheng, P. L., and Chen, Y. R. (2013a). Alzheimer's amyloid-beta oligomers rescue cellular prion protein induced tau reduction via the Fyn pathway. ACS Chem. Neurosci. 4, 1287-1296. doi: $10.1021 / \mathrm{cn} 400085 \mathrm{q}$

Chen, S., Ge, X., Chen, Y., Lv, N., Liu, Z., and Yuan, W. (2013b). Advances with RNA interference in Alzheimer's disease research. Drug. Des. Devel. Ther. 7, 117-125. doi: 10.2147/DDDT.S40229

Chen, Y. M., Wang, Q. J., Hu, H. S., Yu, P. C., Zhu, J., Drewes, G., et al. (2006). Microtubule affinity-regulating kinase 2 functions downstream of the PAR-3/PAR-6/atypical PKC complex in regulating hippocampal neuronal polarity. Proc. Natl. Acad. Sci. U.S.A. 103, 8534-8539. doi: 10.1073/pnas.05099 55103

Cheung, Z. H., and Ip, N. Y. (2012). Cdk5: a multifaceted kinase in neurodegenerative diseases. Trends Cell Biol. 22, 169-175. doi: 10.1016/j.tcb.2011.11.003
Chin, J. Y., Knowles, R. B., Schneider, A., Drewes, G., Mandelkow, E. M., and Hyman, B. T. (2000). Microtubule-affinity regulating kinase (MARK) is tightly associated with neurofibrillary tangles in Alzheimer brain: a fluorescence resonance energy transfer study. J. Neuropathol. Exp. Neurol. 59, 966-971.

Cohen, T. J., Friedmann, D., Hwang, A. W., Marmorstein, R., and Lee, V. M. (2013). The microtubule-associated tau protein has intrinsic acetyltransferase activity. Nat. Struct. Mol. Biol. 20, 756-762. doi: 10.1038/nsmb.2555

Cohen, T. J., Guo, J. L., Hurtado, D. E., Kwong, L. K., Mills, I. P., Trojanowski, J. Q., et al. (2011). The acetylation of tau inhibits its function and promotes pathological tau aggregation. Nat. Commun. 2, 252. doi: 10.1038/ncomms 1255

Congdon, E. E., Wu, J. W., Myeku, N., Figueroa, Y. H., Herman, M., Marinec, P. S., et al. (2012). Methylthioninium chloride (methylene blue) induces autophagy and attenuates tauopathy in vitro and in vivo. Autophagy 8, 609-622. doi: 10.4161/auto. 19048

Connell, J. W., Gibb, G. M., Betts, J. C., Blackstock, W. P., Gallo, J., Lovestone, S., et al. (2001). Effects of FTDP-17 mutations on the in vitro phosphorylation of tau by glycogen synthase kinase 3beta identified by mass spectrometry demonstrate certain mutations exert long-range conformational changes. FEBS Lett. 493, 40-44. doi: 10.1016/S0014-5793(01)02267-0

Conway, K. A., Rochet, J. C., Bieganski, R. M., and Lansbury, P. T. Jr. (2001). Kinetic stabilization of the alpha-synuclein protofibril by a dopamine-alpha-synuclein adduct. Science 294, 1346-1349. doi: 10.1126/science. 1063522

Cook, C., Carlomagno, Y., Gendron, T. F., Dunmore, J., Scheffel, K., Stetler, C., et al. (2014). Acetylation of the KXGS motifs in tau is a critical determinant in modulation of tau aggregation and clearance. Hum. Mol. Genet. 23, 104-116. doi: $10.1093 / \mathrm{hmg} / \mathrm{ddt} 402$

Cowan, C. M., Bossing, T., Page, A., Shepherd, D., and Mudher, A. (2010a). Soluble hyper-phosphorylated tau causes microtubule breakdown and functionally compromises normal tau in vivo. Acta Neuropathol. 120, 593-604. doi: 10.1007/s00401-010-0716-8

Cowan, C. M., Chee, F., Shepherd, D., and Mudher, A. (2010b). Disruption of neuronal function by soluble hyperphosphorylated tau in a Drosophila model of tauopathy. Biochem. Soc. Trans. 38, 564-570. doi: 10.1042/BST0380564

Crowe, A., James, M. J., Lee, V. M., Smith, A. B. 3rd, Trojanowski, J. Q., Ballatore, C., et al. (2013). Aminothienopyridazines and methylene blue affect Tau fibrillization via cysteine oxidation. J. Biol. Chem. 288, 11024-11037. doi: 10.1074/jbc.M112.436006

Cruz, J. C., Tseng, H. C., Goldman, J. A., Shih, H., and Tsai, L. H. (2003). Aberrant Cdk5 activation by p25 triggers pathological events leading to neurodegeneration and neurofibrillary tangles. Neuron 40, 471-483. doi: 10.1016/S08966273(03)00627-5

Dayanandan, R., Van Slegtenhorst, M., Mack, T. G., Ko, L., Yen, S. H., Leroy, K., et al. (1999). Mutations in tau reduce its microtubule binding properties in intact cells and affect its phosphorylation. FEBS Lett. 446, 228-232. doi: 10.1016/S0014-5793(99)00222-7

De Los Rios, C., Egea, J., Marco-Contelles, J., Leon, R., Samadi, A., Iriepa, I., et al. (2010). Synthesis, inhibitory activity of cholinesterases, and neuroprotective profile of novel 1,8-naphthyridine derivatives. J. Med. Chem. 53, 5129-5143. doi: 10.1021/jm901902w

Delobel, P., Flament, S., Hamdane, M., Mailliot, C., Sambo, A. V., Begard, S., et al. (2002). Abnormal Tau phosphorylation of the Alzheimer-type also occurs during mitosis. J. Neurochem. 83, 412-420. doi: 10.1046/j.1471-4159.2002.01143.x

Deture, M., Ko, L. W., Easson, C., and Yen, S. H. (2002). Tau assembly in inducible transfectants expressing wild-type or FTDP-17 tau. Am. J. Pathol. 161, 1711-1722. doi: 10.1016/S0002-9440(10)64448-3

Diogenes, M. J., Dias, R. B., Rombo, D. M., Vicente Miranda, H., Maiolino, F., Guerreiro, P., et al. (2012). Extracellular alpha-synuclein oligomers modulate synaptic transmission and impair LTP via NMDA-receptor activation. J. Neurosci. 32, 11750-11762. doi: 10.1523/JNEUROSCI.0234-12.2012

Doody, R. S., Thomas, R. G., Farlow, M., Iwatsubo, T., Vellas, B., Joffe, S., et al. (2014). Phase 3 trials of solanezumab for mild-to-moderate Alzheimer's disease. N. Engl. J. Med. 370, 311-321. doi: 10.1056/NEJMoa1312889

Dorval, V., and Fraser, P. E. (2006). Small ubiquitin-like modifier (SUMO) modification of natively unfolded proteins tau and alpha-synuclein. J. Biol. Chem. 281, 9919-9924. doi: 10.1074/jbc.M510127200

Drewes, G., Ebneth, A., Preuss, U., Mandelkow, E. M., and Mandelkow, E. (1997). MARK, a novel family of protein kinases that phosphorylate microtubuleassociated proteins and trigger microtubule disruption. Cell 89, 297-308. doi: 10.1016/S0092-8674(00)80208-1 
Duan, D. X., Chai, G. S., Ni, Z. F., Hu, Y., Luo, Y., Cheng, X. S., et al. (2013). Phosphorylation of tau by death-associated protein kinase 1 antagonizes the kinase-induced cell apoptosis. J. Alzheimers Dis. 37, 795-808. doi: 10.3233/JAD130377

Dubey, M., Chaudhury, P., Kabiru, H., and Shea, T. B. (2008). Tau inhibits anterograde axonal transport and perturbs stability in growing axonal neurites in part by displacing kinesin cargo: neurofilaments attenuate taumediated neurite instability. Cell Motil. Cytoskeleton 65, 89-99. doi: 10.1002/ cm. 20243

Duff, K., Kuret, J., and Congdon, E. E. (2010). Disaggregation of tau as a therapeutic approach to tauopathies. Curr. Alzheimer Res. 7, 235-240. doi: 10.2174/156720510791050885

Duka, V., Lee, J. H., Credle, J., Wills, J., Oaks, A., Smolinsky, C., et al. (2013). Identification of the sites of tau hyperphosphorylation and activation of tau kinases in synucleinopathies and Alzheimer's diseases. PLOS ONE 8:e75025. doi: 10.1371/journal.pone.0075025

Eckermann, K., Mocanu, M. M., Khlistunova, I., Biernat, J., Nissen, A., Hofmann, A., et al. (2007). The beta-propensity of Tau determines aggregation and synaptic loss in inducible mouse models of tauopathy. J. Biol. Chem. 282, 31755-31765. doi: 10.1074/jbc.M705282200

Eisbach, S. E., and Outeiro, T. F. (2013). Alpha-synuclein and intracellular trafficking: impact on the spreading of Parkinson's disease pathology. J. Mol. Med. (Berl.) 91, 693-703. doi: 10.1007/s00109-013-1038-9

El-Agnaf, O. M., Salem, S. A., Paleologou, K. E., Cooper, L. J., Fullwood, N. J., Gibson, M. J., et al. (2003). Alpha-synuclein implicated in Parkinson's disease is present in extracellular biological fluids, including human plasma. FASEB J. 17, 1945-1947. doi: 10.1096/fj.03-0098fje

Ellis, C. E., Schwartzberg, P. L., Grider, T. L., Fink, D. W., and Nussbaum, R. L. (2001). alpha-synuclein is phosphorylated by members of the Src family of protein-tyrosine kinases. J. Biol. Chem. 276, 3879-3884. doi: 10.1074/jbc.M010316200

Emmer, K. L., Waxman, E. A., Covy, J. P., and Giasson, B. I. (2011). E46K human alpha-synuclein transgenic mice develop Lewy-like and tau pathology associated with age-dependent, detrimental motor impairment. J. Biol. Chem. 286, 35104-35118. doi: 10.1074/jbc.M111.247965

Engmann, O., and Giese, K. P. (2009). Crosstalk between Cdk5 and GSK3beta: implications for Alzheimer's disease. Front. Mol. Neurosci. 2:2. doi: 10.3389/neuro.02.002.2009

Fares, M. B., Bouziad, N. A., Dikiy, I., Mbefo, M. K., Jovicic, A., Kiely, A., et al. (2014). The Novel Parkinson's disease linked mutation G51D attenuates in vitro aggregation and membrane binding of alpha-synuclein, and enhances its secretion and nuclear localization in cells. Hum. Mol. Genet. doi: 10.1093/hmg/ddu165. [Epub ahead of print].

Farr, S. A., Ripley, J. L., Sultana, R., Zhang, Z., Niehoff, M. L., Platt, T. L., et al. (2013). Antisense oligonucleotide against GSK-3beta in brain of SAMP8 mice improves learning and memory and decreases oxidative stress: involvement of transcription factor Nrf2 and implications for Alzheimer disease. Free Radic. Biol. Med. 67C, 387-395. doi: 10.1016/j.freeradbiomed.2013.11.014

Fatouros, C., Pir, G. J., Biernat, J., Koushika, S. P., Mandelkow, E., Mandelkow, E. M., et al. (2012). Inhibition of tau aggregation in a novel Caenorhabditis elegans model of tauopathy mitigates proteotoxicity. Hum. Mol. Genet. 21, 3587-3603. doi: $10.1093 / \mathrm{hmg} / \mathrm{dds} 190$

Fernandez, C. O., Hoyer, W., Zweckstetter, M., Jares-Erijman, E. A., Subramaniam, V., Griesinger, C., et al. (2004). NMR of alpha-synuclein-polyamine complexes elucidates the mechanism and kinetics of induced aggregation. EMBO J. 23, 2039-2046. doi: 10.1038/sj.emboj.7600211

Fischer, D., Mukrasch, M. D., Biernat, J., Bibow, S., Blackledge, M., Griesinger, C., et al. (2009). Conformational changes specific for pseudophosphorylation at serine 262 selectively impair binding of tau to microtubules. Biochemistry 48 , 10047-10055. doi: 10.1021/bi901090m

Fiske, M., Valtierra, S., Solvang, K., Zorniak, M., White, M., Herrera, S., et al. (2011). Contribution of alanine-76 and serine phosphorylation in alphasynuclein membrane association and aggregation in yeasts. Parkinsons Dis. 2011, 392180. doi: 10.4061/2011/392180

Flajolet, M., He, G., Heiman, M., Lin, A., Nairn, A. C., and Greengard, P. (2007). Regulation of Alzheimer's disease amyloid-beta formation by casein kinase I. Proc. Natl. Acad. Sci. U.S.A. 104, 4159-4164. doi: 10.1073/pnas.0611236104

Flament, S., Delacourte, A., and Mann, D. M. (1990). Phosphorylation of Tau proteins: a major event during the process of neurofibrillary degeneration. A comparative study between Alzheimer's disease and Down's syndrome. Brain Res. 516, 15-19. doi: 10.1016/0006-8993(90)90891-E

Freichel, C., Neumann, M., Ballard, T., Muller, V., Woolley, M., Ozmen, L., et al. (2007). Age-dependent cognitive decline and amygdala pathology in alphasynuclein transgenic mice. Neurobiol. Aging 28, 1421-1435. doi: 10.1016/j. neurobiolaging.2006.06.013

Frost, B., and Diamond, M. I. (2010). Prion-like mechanisms in neurodegenerative diseases. Nat. Rev. Neurosci. 11, 155-159. doi: 10.1038/nrn2786

Fujiwara, H., Hasegawa, M., Dohmae, N., Kawashima, A., Masliah, E., Goldberg, M. S., et al. (2002). alpha-Synuclein is phosphorylated in synucleinopathy lesions. Nat. Cell Biol. 4, 160-164. doi: 10.1038/ncb748.

Fuster-Matanzo, A., Llorens-Martin, M., Jurado-Arjona, J., Avila, J., and Hernandez, F. (2012). Tau protein and adult hippocampal neurogenesis. Front. Neurosci. 6:104. doi: 10.3389/fnins.2012.00104

Gauthier-Kemper, A., Weissmann, C., Golovyashkina, N., Sebo-Lemke, Z., Drewes, G., Gerke, V., et al. (2011). The frontotemporal dementia mutation R406W blocks tau's interaction with the membrane in an annexin A2-dependent manner. J. Cell Biol. 192, 647-661. doi: 10.1083/jcb.201007161

Giacobini, E., and Gold, G. (2013). Alzheimer disease therapy-moving from amyloid-beta to tau. Nat. Rev. Neurol. 9, 677-686. doi: 10.1038/nrneurol. 2013.223

Giasson, B. I., Duda, J. E., Murray, I. V., Chen, Q., Souza, J. M., Hurtig, H. I., et al. (2000). Oxidative damage linked to neurodegeneration by selective alpha-synuclein nitration in synucleinopathy lesions. Science 290, 985-989. doi: 10.1126/science.290.5493.985

Giasson, B. I., Forman, M. S., Higuchi, M., Golbe, L. I., Graves, C. L., Kotzbauer, P. T., et al. (2003a). Initiation and synergistic fibrillization of tau and alphasynuclein. Science 300, 636-640. doi: 10.1126/science.1082324

Giasson, B. I., Mabon, M. E., Duda, J. E., Montine, T. J., Robertson, D., Hurtig, H. I., et al. (2003b). Tau and 14-3-3 in glial cytoplasmic inclusions of multiple system atrophy. Acta Neuropathol. 106, 243-250. doi: 10.1007/s00401-003-0726-x

Gillardon, F. (2009). Leucine-rich repeat kinase 2 phosphorylates brain tubulinbeta isoforms and modulates microtubule stability-a point of convergence in parkinsonian neurodegeneration? J. Neurochem. 110, 1514-1522. doi: 10.1111/j.1471-4159.2009.06235.x

Gloeckner, C. J., Schumacher, A., Boldt, K., and Ueffing, M. (2009). The Parkinson disease-associated protein kinase LRRK2 exhibits MAPKKK activity and phosphorylates MKK3/6 and MKK4/7, in vitro. J. Neurochem. 109, 959-968. doi: 10.1111/j.1471-4159.2009.06024.x

Goedert, M. (2001). Alpha-synuclein and neurodegenerative diseases. Nat. Rev. Neurosci. 2, 492-501. doi: 10.1038/35081564

Goedert, M., Wischik, C. M., Crowther, R. A., Walker, J. E., and Klug, A. (1988). Cloning and sequencing of the cDNA encoding a core protein of the paired helical filament of Alzheimer disease: identification as the microtubuleassociated protein tau. Proc. Natl. Acad. Sci. U.S.A. 85, 4051-4055. doi: 10.1073/pnas.85.11.4051

Goers, J., Manning-Bog, A. B., McCormack, A. L., Millett, I. S., Doniach, S., Di Monte, D. A., et al. (2003). Nuclear localization of alpha-synuclein and its interaction with histones. Biochemistry 42, 8465-8471. doi: 10.1021/ bi0341152

Gomez-Isla, T., Hollister, R., West, H., Mui, S., Growdon, J. H., Petersen, R. C., et al. (1997). Neuronal loss correlates with but exceeds neurofibrillary tangles in Alzheimer's disease. Ann. Neurol. 41, 17-24. doi: 10.1002/ana.410410106

Gonçalves, S., and Outeiro, T. F. (2013). Assessing the subcellular dynamics of alpha-synuclein using photoactivation microscopy. Mol. Neurobiol. 47, 1081-1092. doi: 10.1007/s12035-013-8406-x

Gorbatyuk, O. S., Li, S., Sullivan, L. F., Chen, W., Kondrikova, G., Manfredsson, F. P., et al. (2008). The phosphorylation state of Ser-129 in human alpha-synuclein determines neurodegeneration in a rat model of Parkinson disease. Proc. Natl. Acad. Sci. U.S.A. 105, 763-768. doi: 10.1073/pnas.0711053105

Gotz, J., Chen, F., Van Dorpe, J., and Nitsch, R. M. (2001). Formation of neurofibrillary tangles in P301l tau transgenic mice induced by Abeta 42 fibrils. Science 293, 1491-1495. doi: 10.1126/science.1062097

Graham, D. L., Gray, A. J., Joyce, J. A., Yu, D., O’Moore, J., Carlson, G. A., et al. (2013). Increased O-GlcNAcylation reduces pathological tau without affecting its normal phosphorylation in a mouse model of tauopathy. Neuropharmacology 79C, 307-313. doi: 10.1016/j.neuropharm.2013.11.025

Grueninger, F., Bohrmann, B., Czech, C., Ballard, T. M., Frey, J. R., Weidensteiner, C., et al. (2010). Phosphorylation of Tau at S422 is enhanced by Abeta 
in TauPS2APP triple transgenic mice. Neurobiol. Dis. 37, 294-306. doi: 10.1016/j.nbd.2009.09.004

Grunblatt, E., Mandel, S., Jacob-Hirsch, J., Zeligson, S., Amariglo, N., Rechavi, G., et al. (2004). Gene expression profiling of parkinsonian substantia nigra pars compacta; alterations in ubiquitin-proteasome, heat shock protein, iron and oxidative stress regulated proteins, cell adhesion/cellular matrix and vesicle trafficking genes. J. Neural Transm. 111, 1543-1573. doi: 10.1007/s00702-0040212-1

Grundke-Iqbal, I., Iqbal, K., Tung, Y. C., Quinlan, M., Wisniewski, H. M., and Binder, L. I. (1986). Abnormal phosphorylation of the microtubule-associated protein tau (tau) in Alzheimer cytoskeletal pathology. Proc. Natl. Acad. Sci. U.S.A. 83, 4913-4917. doi: 10.1073/pnas.83.13.4913

Gu, G. J., Lund, H., Wu, D., Blokzijl, A., Classon, C., Von Euler, G., et al. (2013a). Role of individual MARK isoforms in phosphorylation of tau at $\operatorname{Ser}(2)(6)(2)$ in Alzheimer's disease. Neuromolecular Med. 15, 458-469. doi: 10.1007/s12017013-8232-3

Gu, J., Congdon, E. E., and Sigurdsson, E. M. (2013b). Two novel Tau antibodies targeting the 396/404 region are primarily taken up by neurons and reduce Tau protein pathology. J. Biol. Chem. 288, 33081-33095. doi: 10.1074/jbc.M113.494922

Guerreiro, P. S., Huang, Y., Gysbers, A., Cheng, D., Gai, W. P., Outeiro, T. F., et al. (2013). LRRK2 interactions with alpha-synuclein in Parkinson's disease brains and in cell models. J. Mol. Med. (Berl.) 91, 513-522. doi: 10.1007/s00109-0120984-y

Guillozet-Bongaarts, A. L., Garcia-Sierra, F., Reynolds, M. R., Horowitz, P. M., Fu, Y., Wang, T., et al. (2005). Tau truncation during neurofibrillary tangle evolution in Alzheimer's disease. Neurobiol. Aging 26, 1015-1022. doi: 10.1016/j.neurobiolaging.2004.09.019

Hamilton, B. A. (2004). alpha-Synuclein A53T substitution associated with Parkinson disease also marks the divergence of Old World and New World primates. Genomics 83, 739-742. doi: 10.1016/j.ygeno.2003.09.016

Han, D., Qureshi, H. Y., Lu, Y., and Paudel, H. K. (2009). Familial FTDP-17 missense mutations inhibit microtubule assembly-promoting activity of tau by increasing phosphorylation at Ser202 in vitro. J. Biol. Chem. 284, 13422-13433. doi: 10.1074/jbc.M901095200

Hanger, D. P., Anderton, B. H., and Noble, W. (2009a). Tau phosphorylation: the therapeutic challenge for neurodegenerative disease. Trends Mol. Med. 15, 112-119. doi: 10.1016/j.molmed.2009.01.003

Hanger, D. P., Byers, H. L., Wray, S., Leung, K. Y., Saxton, M. J., Seereeram, A., et al. (2007). Novel phosphorylation sites in tau from Alzheimer brain support a role for casein kinase 1 in disease pathogenesis. J. Biol. Chem. 282, 23645-23654. doi: 10.1074/jbc.M703269200

Hanger, D. P., Seereeram, A., and Noble, W. (2009b). Mediators of tau phosphorylation in the pathogenesis of Alzheimer's disease. Expert Rev. Neurother. 9, 1647-1666. doi: 10.1586/ern.09.104

Hara, S., Arawaka, S., Sato, H., Machiya, Y., Cui, C., Sasaki, A., et al. (2013). Serine 129 phosphorylation of membrane-associated alpha-synuclein modulates dopamine transporter function in a $G$ protein-coupled receptor kinase-dependent manner. Mol. Biol. Cell 24, 1649-1660, S1641-S1643. doi 10.1091/mbc.E12-12-0903

Hardy, J. A., and Higgins, G. A. (1992). Alzheimer's disease: the amyloid cascade hypothesis. Science 256, 184-185. doi: 10.1126/science.1566067

Hayashi, K., Suzuki, A., and Ohno, S. (2011). A novel function of the cell polarityregulating kinase PAR-1/MARK in dendritic spines. Bioarchitecture 1, 261-266. doi: 10.4161/bioa.1.6.19199

Hebron, M. L., Lonskaya, I., and Moussa, C. E. (2013a). Nilotinib reverses loss of dopamine neurons and improves motor behavior via autophagic degradation of alpha-synuclein in Parkinson's disease models. Hum. Mol. Genet. 22, 3315-3328. doi: $10.1093 / \mathrm{hmg} / \mathrm{ddt} 192$

Hebron, M. L., Lonskaya, I., and Moussa, C. E. (2013b). Tyrosine kinase inhibition facilitates autophagic SNCA/alpha-synuclein clearance. Autophagy 9, 1249-1250. doi: 10.4161/auto.25368

Henkins, K. M., Sokolow, S., Miller, C. A., Vinters, H. V., Poon, W. W., Cornwell, L. B., et al. (2012). Extensive p-tau pathology and SDS-stable p-tau oligomers in Alzheimer's cortical synapses. Brain Pathol 22, 826-833. doi: 10.1111/j.17503639.2012.00598.x

Hensley, K., Floyd, R. A., Zheng, N. Y., Nael, R., Robinson, K. A., Nguyen, X., et al. (1999). p38 kinase is activated in the Alzheimer's disease brain. J. Neurochem. 72, 2053-2058. doi: 10.1046/j.1471-4159.1999.0722053.x
Hernandez, F., Lucas, J. J., and Avila, J. (2013). GSK3 and tau: two convergence points in Alzheimer's disease. J. Alzheimers Dis. 33(Suppl. 1), S141-S144. doi: 10.3233/JAD-2012-129025

Hongo, H., Kihara, T., Kume, T., Izumi, Y., Niidome, T., Sugimoto, H., et al. (2012). Glycogen synthase kinase-3beta activation mediates rotenone-induced cytotoxicity with the involvement of microtubule destabilization. Biochem. Biophys. Res. Commun. 426, 94-99. doi: 10.1016/j.bbrc.2012.08.042

Hooper, C., Killick, R., and Lovestone, S. (2008). The GSK3 hypothesis of Alzheimer's disease. J. Neurochem. 104, 1433-1439. doi: 10.1111/j.14714159.2007.05194.x

Iba, M., Guo, J. L., McBride, J. D., Zhang, B., Trojanowski, J. Q., and Lee, V. M. (2013). Synthetic tau fibrils mediate transmission of neurofibrillary tangles in a transgenic mouse model of Alzheimer's-like tauopathy. J. Neurosci. 33, 1024-1037. doi: 10.1523/JNEUROSCI.2642-12.2013

Iijima-Ando, K., Sekiya, M., Maruko-Otake, A., Ohtake, Y., Suzuki, E., Lu, B., et al. (2012). Loss of axonal mitochondria promotes tau-mediated neurodegeneration and Alzheimer's disease-related tau phosphorylation via PAR-1. PLoS Genet. 8:e1002918. doi: 10.1371/journal.pgen.1002918

Iijima-Ando, K., Zhao, L., Gatt, A., Shenton, C., and Iijima, K. (2010). A DNA damage-activated checkpoint kinase phosphorylates tau and enhances tau-induced neurodegeneration. Hum. Mol. Genet. 19, 1930-1938. doi: 10.1093/hmg/ddq068

Iimoto, D. S., Masliah, E., Deteresa, R., Terry, R. D., and Saitoh, T. (1990). Aberrant casein kinase II in Alzheimer's disease. Brain Res. 507, 273-280. doi: 10.1016/0006-8993(90)90282-G

Illenberger, S., Zheng-Fischhofer, Q., Preuss, U., Stamer, K., Baumann, K., Trinczek, B., et al. (1998). The endogenous and cell cycle-dependent phosphorylation of tau protein in living cells: implications for Alzheimer's disease. Mol. Biol. Cell 9, 1495-1512. doi: 10.1091/mbc.9.6.1495

Imam, S. Z., Trickler, W., Kimura, S., Binienda, Z. K., Paule, M. G., Slikker, W. Jr., et al. (2013). Neuroprotective efficacy of a new brain-penetrating C-Abl inhibitor in a murine Parkinson's disease model. PLoS ONE 8:e65129. doi: 10.1371/journal.pone.0065129

Imam, S. Z., Zhou, Q., Yamamoto, A., Valente, A. J., Ali, S. F., Bains, M., et al. (2011). Novel regulation of parkin function through c-Abl-mediated tyrosine phosphorylation: implications for Parkinson's disease. J. Neurosci. 31, 157-163. doi: 10.1523/JNEUROSCI.1833-10.2011

Inglis, K. J., Chereau, D., Brigham, E. F., Chiou, S. S., Schobel, S., Frigon, N. L., et al. (2009). Polo-like kinase 2 (PLK2) phosphorylates alpha-synuclein at serine 129 in central nervous system. J. Biol. Chem. 284, 2598-2602. doi: 10.1074/jbc.C800206200

Inoue, M., Konno, T., Tainaka, K., Nakata, E., Yoshida, H. O., and Morii, T. (2012). Positional effects of phosphorylation on the stability and morphology of taurelated amyloid fibrils. Biochemistry 51, 1396-1406. doi: 10.1021/bi201451z

Iqbal, K., Gong, C. X., and Liu, F. (2013). Hyperphosphorylation-induced tau oligomers. Front Neurol 4:112. doi: 10.3389/fneur.2013.00112

Irwin, D. J., Cohen, T. J., Grossman, M., Arnold, S. E., McCarty-Wood, E., Van Deerlin, V. M., et al. (2013). Acetylated tau neuropathology in sporadic and hereditary tauopathies. Am. J. Pathol. 183, 344-351. doi: 10.1016/j.ajpath.2013.04.025

Irwin, D. J., Cohen, T. J., Grossman, M., Arnold, S. E., Xie, S. X., Lee, V. M., et al. (2012). Acetylated tau, a novel pathological signature in Alzheimer's disease and other tauopathies. Brain 135, 807-818. doi: 10.1093/brain/aws013

Ishii, A., Nonaka, T., Taniguchi, S., Saito, T., Arai, T., Mann, D., et al. (2007). Casein kinase 2 is the major enzyme in brain that phosphorylates Ser129 of human alpha-synuclein: implication for alpha-synucleinopathies. FEBS Lett. 581, 4711-4717. doi: 10.1016/j.febslet.2007.08.067

Ishizawa, T., Mattila, P., Davies, P., Wang, D., and Dickson, D. W. (2003). Colocalization of tau and alpha-synuclein epitopes in Lewy bodies. J. Neuropathol. Exp. Neurol. 62, 389-397.

Ittner, L. M., Ke, Y. D., Delerue, F., Bi, M., Gladbach, A., Van Eersel, J., et al. (2010). Dendritic function of tau mediates amyloid-beta toxicity in Alzheimer's disease mouse models. Cell 142, 387-397. doi: 10.1016/j.cell.2010.06.036

Jackson, G. R., Wiedau-Pazos, M., Sang, T. K., Wagle, N., Brown, C. A., Massachi, S., et al. (2002). Human wild-type tau interacts with wingless pathway components and produces neurofibrillary pathology in Drosophila. Neuron 34, 509-519. doi: 10.1016/S0896-6273(02)00706-7

Jeganathan, S., Hascher, A., Chinnathambi, S., Biernat, J., Mandelkow, E. M., and Mandelkow, E. (2008). Proline-directed pseudo-phosphorylation at AT8 and 
PHF1 epitopes induces a compaction of the paperclip folding of Tau and generates a pathological (MC-1) conformation. J. Biol. Chem. 283, 32066-32076. doi: 10.1074/jbc.M805300200

Jensen, P. H., Hager, H., Nielsen, M. S., Hojrup, P., Gliemann, J., and Jakes, R. (1999). Alpha-synuclein binds to Tau and stimulates the protein kinase Acatalyzed tau phosphorylation of serine residues 262 and 356. J. Biol. Chem. 274, 25481-25489. doi: 10.1074/jbc.274.36.25481

Jin, Y. N., Chen, P. C., Watson, J. A., Walters, B. J., Phillips, S. E., Green, K., et al. (2012). Usp14 deficiency increases tau phosphorylation without altering tau degradation or causing tau-dependent deficits. PLoS ONE 7:e47884. doi: 10.1371/journal.pone.0047884

Kahle, P. J., Neumann, M., Ozmen, L., Muller, V., Jacobsen, H., Spooren, W., et al. (2002). Hyperphosphorylation and insolubility of alpha-synuclein in transgenic mouse oligodendrocytes. EMBO Rep. 3, 583-588. doi: 10.1093/emboreports/kvf109

Kanaan, N. M., Morfini, G., Pigino, G., Lapointe, N. E., Andreadis, A., Song, Y., et al. (2012). Phosphorylation in the amino terminus of tau prevents inhibition of anterograde axonal transport. Neurobiol. Aging 33, 826.e815-826.e830. doi: 10.1016/j.neurobiolaging.2011.06.006

Kauselmann, G., Weiler, M., Wulff, P., Jessberger, S., Konietzko, U., Scafidi, J., et al. (1999). The polo-like protein kinases Fnk and Snk associate with a $\mathrm{Ca}(2+)$ - and integrin-binding protein and are regulated dynamically with synaptic plasticity. EMBO J. 18, 5528-5539. doi: 10.1093/emboj/18.20.5528

Kawakami, F., Shimada, N., Ohta, E., Kagiya, G., Kawashima, R., Maekawa, T., et al. (2014). Leucine-rich repeat kinase 2 regulates tau phosphorylation through direct activation of glycogen synthase kinase-3beta. FEBS J. 281, 3-13. doi: 10.1111/febs. 12579

Kenessey, A., and Yen, S. H. (1993). The extent of phosphorylation of fetal tau is comparable to that of PHF-tau from Alzheimer paired helical filaments. Brain Res. 629, 40-46. doi: 10.1016/0006-8993(93)90478-6

Kessels, H. W., Nguyen, L. N., Nabavi, S., and Malinow, R. (2010). The prion protein as a receptor for amyloid-beta. Nature 466, E3-E4. discussion: E4-E5. doi: 10.1038 /nature09217

Khatoon, S., Grundke-Iqbal, I., and Iqbal, K. (1992). Brain levels of microtubuleassociated protein tau are elevated in Alzheimer's disease: a radioimmuno-slotblot assay for nanograms of the protein. J. Neurochem. 59, 750-753.

Kickstein, E., Krauss, S., Thornhill, P., Rutschow, D., Zeller, R., Sharkey, J., et al. (2010). Biguanide metformin acts on tau phosphorylation via mTOR/protein phosphatase 2A (PP2A) signaling. Proc. Natl. Acad. Sci. U.S.A. 107, 21830-21835. doi: 10.1073/pnas.0912793107

Kiely, A. P., Asi, Y. T., Kara, E., Limousin, P., Ling, H., Lewis, P., et al. (2013). alpha-Synucleinopathy associated with G51D SNCA mutation: a link between Parkinson's disease and multiple system atrophy? Acta Neuropathol. 125, 753-769. doi: 10.1007/s00401-013-1096-7

Kim, E. J., Sung, J. Y., Lee, H. J., Rhim, H., Hasegawa, M., Iwatsubo, T., et al. (2006). Dyrk1A phosphorylates alpha-synuclein and enhances intracellular inclusion formation. J. Biol. Chem. 281, 33250-33257. doi: 10.1074/jbc.M606147200

Kim, E. K., and Choi, E. J. (2010). Pathological roles of MAPK signaling pathways in human diseases. Biochim. Biophys. Acta 1802, 396-405. doi: 10.1016/j.bbadis.2009.12.009

Kim, S., Nollen, E. A., Kitagawa, K., Bindokas, V. P., and Morimoto, R. I. (2002). Polyglutamine protein aggregates are dynamic. Nat. Cell Biol. 4, 826-831. doi: $10.1038 /$ ncb863

Kimura, T., Ono, T., Takamatsu, J., Yamamoto, H., Ikegami, K., Kondo, A., et al. (1996). Sequential changes of tau-site-specific phosphorylation during development of paired helical filaments. Dementia 7, 177-181. doi: 10.1159/000106875

Kiris, E., Ventimiglia, D., Sargin, M. E., Gaylord, M. R., Altinok, A., Rose, K., et al. (2011). Combinatorial Tau pseudophosphorylation: markedly different regulatory effects on microtubule assembly and dynamic instability than the sum of the individual parts. J. Biol. Chem. 286, 14257-14270. doi: 10.1074/jbc.M111.219311

Ko, H. S., Lee, Y., Shin, J. H., Karuppagounder, S. S., Gadad, B. S., Koleske, A. J., et al. (2010). Phosphorylation by the c-Abl protein tyrosine kinase inhibits parkin's ubiquitination and protective function. Proc. Natl. Acad. Sci. U.S.A. 107, 16691-16696. doi: 10.1073/pnas.1006083107

Kohler, C., Dinekov, M., and Gotz, J. (2013). Active glycogen synthase kinase-3 and tau pathology-related tyrosine phosphorylation in pR5 human tau transgenic mice. Neurobiol. Aging 34, 1369-1379. doi: 10.1016/j.neurobiolaging.2012.11.010
Kontopoulos, E., Parvin, J. D., and Feany, M. B. (2006). Alpha-synuclein acts in the nucleus to inhibit histone acetylation and promote neurotoxicity. Hum. Mol. Genet. 15, 3012-3023. doi: 10.1093/hmg/ddl243

Kosik, K. S., Orecchio, L. D., Binder, L., Trojanowski, J. Q., Lee, V. M., and Lee, G. (1988). Epitopes that span the tau molecule are shared with paired helical filaments. Neuron 1, 817-825. doi: 10.1016/0896-6273(88)90129-8

Kosik, K. S., and Shimura, H. (2005). Phosphorylated tau and the neurodegenerative foldopathies. Biochim. Biophys. Acta 1739, 298-310. doi: 10.1016/j.bbadis.2004.10.011

Kosuga, S., Tashiro, E., Kajioka, T., Ueki, M., Shimizu, Y., and Imoto, M. (2005). GSK-3beta directly phosphorylates and activates MARK2/PAR-1. J. Biol. Chem. 280, 42715-42722. doi: 10.1074/jbc.M507941200

Kragh, C. L., Lund, L. B., Febbraro, F., Hansen, H. D., Gai, W. P., El-Agnaf, O., et al. (2009). Alpha-synuclein aggregation and Ser-129 phosphorylationdependent cell death in oligodendroglial cells. J. Biol. Chem. 284, 10211-10222. doi: 10.1074/jbc.M809671200

Krishnamurthy, P. K., and Johnson, G. V. (2004). Mutant (R406W) human tau is hyperphosphorylated and does not efficiently bind microtubules in a neuronal cortical cell model. J. Biol. Chem. 279, 7893-7900. doi: 10.1074/jbc.M311203200

Kruger, R., Kuhn, W., Muller, T., Woitalla, D., Graeber, M., Kosel, S., et al. (1998). Ala30Pro mutation in the gene encoding alpha-synuclein in Parkinson's disease. Nat. Genet. 18, 106-108. doi: 10.1038/ng0298-106

Kuwahara, T., Tonegawa, R., Ito, G., Mitani, S., and Iwatsubo, T. (2012). Phosphorylation of alpha-synuclein protein at Ser-129 reduces neuronal dysfunction by lowering its membrane binding property in Caenorhabditis elegans. J. Biol. Chem. 287, 7098-7109. doi: 10.1074/jbc.M111.237131

Lasagna-Reeves, C. A., Castillo-Carranza, D. L., Sengupta, U., Sarmiento, J., Troncoso, J., Jackson, G. R., et al. (2012). Identification of oligomers at early stages of tau aggregation in Alzheimer's disease. FASEB J. 26, 1946-1959. doi: 10.1096/fj.11-199851

Lashuel, H. A., Overk, C. R., Oueslati, A., and Masliah, E. (2013). The many faces of alpha-synuclein: from structure and toxicity to therapeutic target. Nat. Rev. Neurosci. 14, 38-48. doi: 10.1038/nrn3406

Lauren, J., Gimbel, D. A., Nygaard, H. B., Gilbert, J. W., and Strittmatter, S. M. (2009). Cellular prion protein mediates impairment of synaptic plasticity by amyloid-beta oligomers. Nature 457, 1128-1132. doi: 10.1038/nature07761

Lee, B. H., Lee, M. J., Park, S., Oh, D. C., Elsasser, S., Chen, P. C., et al. (2010). Enhancement of proteasome activity by a small-molecule inhibitor of USP14. Nature 467, 179-184. doi: 10.1038/nature09299

Lee, G., and Leugers, C. J. (2012). Tau and tauopathies. Prog. Mol. Biol. Transl. Sci. 107, 263-293. doi: 10.1016/B978-0-12-385883-2.00004-7

Lee, G., Tanaka, M., Park, K., Lee, S. S., Kim, Y. M., Junn, E., et al. (2004a). Casein kinase II-mediated phosphorylation regulates alpha-synuclein/synphilin-1 interaction and inclusion body formation. J. Biol. Chem. 279, 6834-6839. doi: 10.1074/jbc.M312760200

Lee, H. J., Khoshaghideh, F., Patel, S., and Lee, S. J. (2004b). Clearance of alphasynuclein oligomeric intermediates via the lysosomal degradation pathway. J. Neurosci. 24, 1888-1896. doi: 10.1523/JNEUROSCI.3809-03.2004.

Lee, K. W., Chen, W., Junn, E., Im, J. Y., Grosso, H., Sonsalla, P. K., et al. (2011). Enhanced phosphatase activity attenuates alpha-synucleinopathy in a mouse model. J. Neurosci. 31, 6963-6971. doi: 10.1523/JNEUROSCI.6513-10.2011

Lee, K. Y., Clark, A. W., Rosales, J. L., Chapman, K., Fung, T., and Johnston, R. N. (1999). Elevated neuronal Cdc2-like kinase activity in the Alzheimer disease brain. Neurosci. Res. 34, 21-29. doi: 10.1016/S0168-0102(99)00026-7

Lee, V. M., and Trojanowski, J. Q. (2006). Mechanisms of Parkinson's disease linked to pathological alpha-synuclein: new targets for drug discovery. Neuron 52, 33-38. doi: 10.1016/j.neuron.2006.09.026

Lesage, S., Anheim, M., Letournel, F., Bousset, L., Honore, A., Rozas, N., et al. (2013). G51D alpha-synuclein mutation causes a novel Parkinsonian-pyramidal syndrome. Ann. Neurol. 73, 459-471. doi: 10.1002/ana.23894

Lesne, S. E. (2013). Breaking the code of amyloid- oligomers. Int. J. Cell Biol. 2013, 950783. doi: 10.1155/2013/950783

Li, L., Sengupta, A., Haque, N., Grundke-Iqbal, I., and Iqbal, K. (2004). Memantine inhibits and reverses the Alzheimer type abnormal hyperphosphorylation of tau and associated neurodegeneration. FEBS Lett. 566, 261-269. doi: 10.1016/j.febslet.2004.04.047

Li, W., West, N., Colla, E., Pletnikova, O., Troncoso, J. C., Marsh, L., et al. (2005). Aggregation promoting C-terminal truncation of alpha-synuclein is a normal cellular process and is enhanced by the familial Parkinson's 
disease-linked mutations. Proc. Natl. Acad. Sci. U.S.A. 102, 2162-2167. doi: 10.1073/pnas.0406976102

Li, X., Patel, J. C., Wang, J., Avshalumov, M. V., Nicholson, C., Buxbaum, J. D., et al. (2010). Enhanced striatal dopamine transmission and motor performance with LRRK2 overexpression in mice is eliminated by familial Parkinson's disease mutation G2019S. J. Neurosci. 30, 1788-1797. doi: 10.1523/JNEUROSCI.560409.2010

Li, Y., Liu, W., Oo, T. F., Wang, L., Tang, Y., Jackson-Lewis, V., et al. (2009). Mutant LRRK2(R1441G) BAC transgenic mice recapitulate cardinal features of Parkinson's disease. Nat. Neurosci. 12, 826-828. doi: 10.1038/nn.2349

Lin, C. H., Tsai, P. I., Wu, R. M., and Chien, C. T. (2010). LRRK2 G2019S mutation induces dendrite degeneration through mislocalization and phosphorylation of tau by recruiting autoactivated GSK3ss. J. Neurosci. 30, 13138-13149. doi: 10.1523/JNEUROSCI.1737-10.2010

Lindersson, E., Beedholm, R., Hojrup, P., Moos, T., Gai, W., Hendil, K. B., et al. (2004). Proteasomal inhibition by alpha-synuclein filaments and oligomers. J. Biol. Chem. 279, 12924-12934. doi: 10.1074/jbc.M306390200

Lindwall, G., and Cole, R. D. (1984). Phosphorylation affects the ability of tau protein to promote microtubule assembly. J. Biol. Chem. 259, 5301-5305.

Liu, P., Wang, X., Gao, N., Zhu, H., Dai, X., Xu, Y., et al. (2010). G protein-coupled receptor kinase 5, overexpressed in the alpha-synuclein up-regulation model of Parkinson's disease, regulates bcl-2 expression. Brain Res. 1307, 134-141. doi: 10.1016/j.brainres.2009.10.036

Liu, S., Breitbart, A., Sun, Y., Mehta, P. D., Boutajangout, A., Scholtzova, H., et al. (2014). Blocking the apolipoprotein E/amyloid beta Interaction in triple transgenic mice ameliorates Alzheimer's disease related amyloid beta and tau pathology. J. Neurochem. 128, 577-591. doi: 10.1111/jnc.12484

Llorens-Martin, M., Lopez-Domenech, G., Soriano, E., and Avila, J. (2011). GSK3beta is involved in the relief of mitochondria pausing in a Tau-dependent manner. PLoS ONE 6:e27686. doi: 10.1371/journal.pone.0027686

Lu, Y., Prudent, M., Fauvet, B., Lashuel, H. A., and Girault, H. H. (2011). Phosphorylation of alpha-Synuclein at Y125 and S129 alters its metal binding properties: implications for understanding the role of alpha-Synuclein in the pathogenesis of Parkinson's Disease and related disorders. ACS Chem. Neurosci. 2, 667-675. doi: 10.1021/cn200074d

Lundblad, M., Decressac, M., Mattsson, B., and Bjorklund, A. (2012). Impaired neurotransmission caused by overexpression of alpha-synuclein in nigral dopamine neurons. Proc. Natl. Acad. Sci. U.S.A. 109, 3213-3219. doi: 10.1073/pnas. 1200575109

Ma, T. (2014). GSK3 in Alzheimer's Disease: mind the isoforms. J. Alzheimers Dis. 39, 707-710. doi: 10.3233/JAD-131661

Mahul-Mellier, A. L., Fauvet, B., Gysbers, A., Dikiy, I., Oueslati, A., Georgeon, S., et al. (2014). c-Abl phosphorylates alpha-syn and regulates its degradation, implication for alpha-syn clearance and contribution to the pathogenesis of Parkinson's Disease. Hum. Mol. Genet. doi: 10.1093/hmg/ddt674. [Epub ahead of print].

Manczak, M., and Reddy, P. H. (2012). Abnormal interaction between the mitochondrial fission protein Drpl and hyperphosphorylated tau in Alzheimer's disease neurons: implications for mitochondrial dysfunction and neuronal damage. Hum. Mol. Genet. 21, 2538-2547. doi: 10.1093/hmg/dds072

Mandelkow, E. M., and Mandelkow, E. (2012). Biochemistry and cell biology of tau protein in neurofibrillary degeneration. Cold Spring Harb. Perspect. Med. 2, a006247. doi: 10.1101/cshperspect.a006247

Mandelkow, E. M., Thies, E., Trinczek, B., Biernat, J., and Mandelkow, E. (2004). MARK/PAR1 kinase is a regulator of microtubule-dependent transport in axons. J. Cell Biol. 167, 99-110. doi: 10.1083/jcb.200401085

Marques, O., and Outeiro, T. F. (2012). Alpha-synuclein: from secretion to dysfunction and death. Cell Death Dis. 3, e350. doi: 10.1038/cddis.2012.94

Martin, L., Latypova, X., Wilson, C. M., Magnaudeix, A., Perrin, M. L., Yardin, C., et al. (2013). Tau protein kinases: involvement in Alzheimer's disease. Ageing Res. Rev. 12, 289-309. doi: 10.1016/j.arr.2012.06.003

Masliah, E., Rockenstein, E., Adame, A., Alford, M., Crews, L., Hashimoto, M., et al. (2005). Effects of alpha-synuclein immunization in a mouse model of Parkinson's disease. Neuron 46, 857-868. doi: 10.1016/j.neuron.2005. 05.010

Masliah, E., Rockenstein, E., Mante, M., Crews, L., Spencer, B., Adame, A., et al. (2011). Passive immunization reduces behavioral and neuropathological deficits in an alpha-synuclein transgenic model of Lewy body disease. PLoS ONE 6:e19338. doi: 10.1371/journal.pone.0019338
Matenia, D., and Mandelkow, E. M. (2009). The tau of MARK: a polarized view of the cytoskeleton. Trends Biochem. Sci. 34, 332-342. doi: 10.1016/j.tibs.2009.03.008

Mawal-Dewan, M., Henley, J., Van De Voorde, A., Trojanowski, J. Q., and Lee, V. M. (1994). The phosphorylation state of tau in the developing rat brain is regulated by phosphoprotein phosphatases. J. Biol. Chem. 269, 30981-30987.

Mazanetz, M. P., and Fischer, P. M. (2007). Untangling tau hyperphosphorylation in drug design for neurodegenerative diseases. Nat. Rev. Drug Discov. 6, 464-479. doi: 10.1038/nrd2111

Mbefo, M. K., Paleologou, K. E., Boucharaba, A., Oueslati, A., Schell, H., Fournier, M., et al. (2010). Phosphorylation of synucleins by members of the Polo-like kinase family. J. Biol. Chem. 285, 2807-2822. doi: 10.1074/jbc.M109.081950

McFarland, M. A., Ellis, C. E., Markey, S. P., and Nussbaum, R. L. (2008). Proteomics analysis identifies phosphorylation-dependent alphasynuclein protein interactions. Mol. Cell. Proteomics 7, 2123-2137. doi: 10.1074/mcp.M800116-MCP200

McMillan, P. J., Kraemer, B. C., Robinson, L., Leverenz, J. B., Raskind, M., and Schellenberg, G. (2011). Truncation of tau at E391 promotes early pathologic changes in transgenic mice. J. Neuropathol. Exp. Neurol. 70, 1006-1019. doi: 10.1097/NEN.0b013e31823557fb

McNaught, K. S., and Jenner, P. (2001). Proteasomal function is impaired in substantia nigra in Parkinson's disease. Neurosci. Lett. 297, 191-194.

Medina, M., and Avila, J. (2014). New insights into the role of glycogen synthase kinase-3 in Alzheimer's disease. Expert. Opin. Ther. Targets 18, 69-77. doi: $10.1517 / 14728222.2013 .843670$

Melov, S., Adlard, P. A., Morten, K., Johnson, F., Golden, T. R., Hinerfeld, D., et al. (2007). Mitochondrial oxidative stress causes hyperphosphorylation of tau. PLoS ONE 2:e536. doi: 10.1371/journal.pone.0000536

Melrose, H. L., Dachsel, J. C., Behrouz, B., Lincoln, S. J., Yue, M., Hinkle, K. M., et al. (2010). Impaired dopaminergic neurotransmission and microtubuleassociated protein tau alterations in human LRRK2 transgenic mice. Neurobiol. Dis. 40, 503-517. doi: 10.1016/j.nbd.2010.07.010

Merino-Serrais, P., Benavides-Piccione, R., Blazquez-Llorca, L., Kastanauskaite, A., Rabano, A., Avila, J., et al. (2013). The influence of phospho-tau on dendritic spines of cortical pyramidal neurons in patients with Alzheimer's disease. Brain 136, 1913-1928. doi: 10.1093/brain/awt088

Michel, C. H., Kumar, S., Pinotsi, D., Tunnacliffe, A., St George-Hyslop, P., Mandelkow, E., et al. (2014). Extracellular monomeric tau protein is sufficient to initiate the spread of tau protein pathology. J. Biol. Chem. 289, 956-967. doi: 10.1074/jbc.M113.515445

Min, S. W., Cho, S. H., Zhou, Y., Schroeder, S., Haroutunian, V., Seeley, W. W., et al. (2010). Acetylation of tau inhibits its degradation and contributes to tauopathy. Neuron 67, 953-966. doi: 10.1016/j.neuron.2010.08.044

Miyasaka, T., Morishima-Kawashima, M., Ravid, R., Heutink, P., Van Swieten, J. C., Nagashima, K., et al. (2001). Molecular analysis of mutant and wild-type tau deposited in the brain affected by the FTDP-17 R406W mutation. Am. J. Pathol. 158, 373-379. doi: 10.1016/S0002-9440(10)63979-X

Mondragon-Rodriguez, S., Perry, G., Luna-Munoz, J., Acevedo-Aquino, M. C., and Williams, S. (2014). Phosphorylation of tau protein at sites Ser(396-404) is one of the earliest events in Alzheimer's disease and Down syndrome. Neuropathol. Appl. Neurobiol. 40, 121-135. doi: 10.1111/nan.12084

Mondragon-Rodriguez, S., Trillaud-Doppia, E., Dudilot, A., Bourgeois, C., Lauzon, M., Leclerc, N., et al. (2012). Interaction of endogenous tau protein with synaptic proteins is regulated by N-methyl-D-aspartate receptor-dependent tau phosphorylation. J. Biol. Chem. 287, 32040-32053. doi: 10.1074/jbc.M112.401240

Monti, B., Gatta, V., Piretti, F., Raffaelli, S. S., Virgili, M., and Contestabile, A. (2010). Valproic acid is neuroprotective in the rotenone rat model of Parkinson's disease: involvement of alpha-synuclein. Neurotox. Res. 17, 130-141. doi: 10.1007/s12640-009-9090-5

Moresco, E. M., and Koleske, A. J. (2003). Regulation of neuronal morphogenesis and synaptic function by Abl family kinases. Curr. Opin. Neurobiol. 13, 535-544. doi: 10.1016/j.conb.2003.08.002

Moresco, E. M., Scheetz, A. J., Bornmann, W. G., Koleske, A. J., and Fitzsimonds, R. M. (2003). Abl family nonreceptor tyrosine kinases modulate shortterm synaptic plasticity. J. Neurophysiol. $89,1678-1687$. doi: 10.1152/jn.08 92.2002

Morfini, G., Pigino, G., Mizuno, N., Kikkawa, M., and Brady, S. T. (2007). Tau binding to microtubules does not directly affect microtubule-based vesicle motility. J. Neurosci. Res. 85, 2620-2630. doi: 10.1002/jnr.21154 
Morishima-Kawashima, M., Hasegawa, M., Takio, K., Suzuki, M., Yoshida, H., Titani, K., et al. (1995a). Proline-directed and non-proline-directed phosphorylation of PHF-tau. J. Biol. Chem. 270, 823-829.

Morishima-Kawashima, M., Hasegawa, M., Takio, K., Suzuki, M., Yoshida, H., Watanabe, A., et al. (1995b). Hyperphosphorylation of tau in PHF. Neurobiol. Aging 16, 365-371. discussion: 371-380. doi: 10.1016/0197-4580(95)00027-C

Morozova, O. A., March, Z. M., Robinson, A. S., and Colby, D. W. (2013). Conformational features of tau fibrils from Alzheimer's disease brain are faithfully propagated by unmodified recombinant protein. Biochemistry 52, 6960-6967. doi: 10.1021/bi400866w

Mudher, A., Shepherd, D., Newman, T. A., Mildren, P., Jukes, J. P., Squire, A., et al. (2004). GSK-3beta inhibition reverses axonal transport defects and behavioural phenotypes in Drosophila. Mol. Psychiatry 9, 522-530. doi: 10.1038/sj.mp.4001483

Muyllaert, D., Terwel, D., Borghgraef, P., Devijver, H., Dewachter, I., and Van Leuven, F. (2006). Transgenic mouse models for Alzheimer's disease: the role of GSK-3B in combined amyloid and tau-pathology. Rev. Neurol. (Paris) 162, 903-907. doi: 10.1016/S0035-3787(06)75098-6

Nakamura, T., Yamashita, H., Takahashi, T., and Nakamura, S. (2001). Activated Fyn phosphorylates alpha-synuclein at tyrosine residue 125. Biochem. Biophys. Res. Commun. 280, 1085-1092. doi: 10.1006/bbrc.2000.4253

Nakashima, H., Ishihara, T., Suguimoto, P., Yokota, O., Oshima, E., Kugo, A., et al. (2005). Chronic lithium treatment decreases tau lesions by promoting ubiquitination in a mouse model of tauopathies. Acta Neuropathol. 110, 547-556. doi: 10.1007/s00401-005-1087-4

Negro, A., Brunati, A. M., Donella-Deana, A., Massimino, M. L., and Pinna, L. A. (2002). Multiple phosphorylation of alpha-synuclein by protein tyrosine kinase Syk prevents eosin-induced aggregation. FASEB J. 16, 210-212. doi: 10.1096/fj.01-0517fje

Netzer, W. J., Dou, F., Cai, D., Veach, D., Jean, S., Li, Y., et al. (2003). Gleevec inhibits beta-amyloid production but not Notch cleavage. Proc. Natl. Acad. Sci. U.S.A. 100, 12444-12449. doi: 10.1073/pnas.1534745100

Ng, S. S., Papadopoulou, K., and McInerny, C. J. (2006). Regulation of gene expression and cell division by Polo-like kinases. Curr. Genet. 50, 73-80. doi: 10.1007/s00294-006-0077-y

Niewiadomska, G., Baksalerska-Pazera, M., and Riedel, G. (2005). Altered cellular distribution of phospho-tau proteins coincides with impaired retrograde axonal transport in neurons of aged rats. Ann. N.Y. Acad. Sci. 1048, 287-295. doi: 10.1196/annals.1342.026

Nilsen, L. H., Rae, C., Ittner, L. M., Gotz, J., and Sonnewald, U. (2013). Glutamate metabolism is impaired in transgenic mice with tau hyperphosphorylation. J. Cereb. Blood Flow Metab. 33, 684-691. doi: 10.1038/jcbfm.2012.212

Nishie, M., Mori, F., Fujiwara, H., Hasegawa, M., Yoshimoto, M., Iwatsubo, T., et al. (2004). Accumulation of phosphorylated alpha-synuclein in the brain and peripheral ganglia of patients with multiple system atrophy. Acta Neuropathol. 107, 292-298. doi: 10.1007/s00401-003-0811-1

Nishimura, I., Yang, Y., and Lu, B. (2004). PAR-1 kinase plays an initiator role in a temporally ordered phosphorylation process that confers tau toxicity in Drosophila. Cell 116, 671-682. doi: 10.1016/S0092-8674(04)00170-9

Noble, W., Hanger, D. P., Miller, C. C., and Lovestone, S. (2013). The importance of tau phosphorylation for neurodegenerative diseases. Front. Neurol. 4:83. doi: 10.3389/fneur.2013.00083

Noble, W., Olm, V., Takata, K., Casey, E., Mary, O., Meyerson, J., et al. (2003). Cdk5 is a key factor in tau aggregation and tangle formation in vivo. Neuron 38, 555-565. doi: 10.1016/S0896-6273(03)00259-9

Noh, M. Y., Chun, K., Kang, B. Y., Kim, H., Park, J. S., Lee, H. C., et al. (2013). Newly developed glycogen synthase kinase-3 (GSK-3) inhibitors protect neuronal cells death in amyloid-beta induced cell model and in a transgenic mouse model of Alzheimer's disease. Biochem. Biophys. Res. Commun. 435, 274-281. doi: 10.1016/j.bbrc.2013.04.065

Oddo, S., Caccamo, A., Shepherd, J. D., Murphy, M. P., Golde, T. E., Kayed, R., et al. (2003). Triple-transgenic model of Alzheimer's disease with plaques and tangles: intracellular Abeta and synaptic dysfunction. Neuron 39, 409-421. doi: 10.1016/S0896-6273(03)00434-3

Okochi, M., Walter, J., Koyama, A., Nakajo, S., Baba, M., Iwatsubo, T., et al. (2000). Constitutive phosphorylation of the Parkinson's disease associated alpha-synuclein. J. Biol. Chem. 275, 390-397. doi: 10.1074/jbc.275.1.390

Onishi, T., Matsumoto, Y., Hattori, M., Obayashi, Y., Nakamura, K., Yano, T., et al. (2014). Early-onset cognitive deficits and axonal transport dysfunction in P301S mutant tau transgenic mice. Neurosci. Res. 80, 76-85. doi: 10.1016/j.neures. 2013.12.006

Otth, C., Concha, Ii, Arendt, T., Stieler, J., Schliebs, R., Gonzalez-Billault, C., et al. (2002). AbetaPP induces cdk5-dependent tau hyperphosphorylation in transgenic mice Tg2576. J. Alzheimers Dis. 4, 417-430.

Oueslati, A., Paleologou, K. E., Schneider, B. L., Aebischer, P., and Lashuel, H. A. (2012). Mimicking phosphorylation at serine 87 inhibits the aggregation of human alpha-synuclein and protects against its toxicity in a rat model of Parkinson's disease. J. Neurosci. 32, 1536-1544. doi: 10.1523/JNEUROSCI.378411.2012

Oueslati, A., Schneider, B. L., Aebischer, P., and Lashuel, H. A. (2013). Polo-like kinase 2 regulates selective autophagic alpha-synuclein clearance and suppresses its toxicity in vivo. Proc. Natl. Acad. Sci. U.S.A. 110, E3945-E3954. doi: $10.1073 /$ pnas. 1309991110

Outeiro, T. F., Kontopoulos, E., Altmann, S. M., Kufareva, I., Strathearn, K. E., Amore, A. M., et al. (2007). Sirtuin 2 inhibitors rescue alpha-synucleinmediated toxicity in models of Parkinson's disease. Science 317, 516-519. doi: 10.1126/science. 1143780

Outeiro, T. F., and Lindquist, S. (2003). Yeast cells provide insight into alphasynuclein biology and pathobiology. Science 302, 1772-1775. doi: 10.1126/science. 1090439

Paik, S. R., Shin, H. J., Lee, J. H., Chang, C. S., and Kim, J. (1999). Copper(II)-induced self-oligomerization of alpha-synuclein. Biochem. J. 340(Pt 3), 821-828. doi: 10.1042/0264-6021:3400821

Paleologou, K. E., Oueslati, A., Shakked, G., Rospigliosi, C. C., Kim, H. Y., Lamberto, G. R., et al. (2010). Phosphorylation at S87 is enhanced in synucleinopathies, inhibits alpha-synuclein oligomerization, and influences synuclein-membrane interactions. J. Neurosci. 30, 3184-3198. doi: 10.1523/JNEUROSCI.5922-09.2010

Paleologou, K. E., Schmid, A. W., Rospigliosi, C. C., Kim, H. Y., Lamberto, G. R., Fredenburg, R. A., et al. (2008). Phosphorylation at Ser-129 but not the phosphomimics S129E/D inhibits the fibrillation of alpha-synuclein. J. Biol. Chem. 283, 16895-16905. doi: 10.1074/jbc.M800747200

Papanikolopoulou, K., Kosmidis, S., Grammenoudi, S., and Skoulakis, E. M. (2010). Phosphorylation differentiates tau-dependent neuronal toxicity and dysfunction. Biochem. Soc. Trans. 38, 981-987. doi: 10.1042/BST0 380981

Patrick, G. N., Zukerberg, L., Nikolic, M., De La Monte, S., Dikkes, P., and Tsai, L. H. (1999). Conversion of p35 to p25 deregulates Cdk5 activity and promotes neurodegeneration. Nature 402, 615-622. doi: 10.1038/45159

Payton, J. E., Perrin, R. J., Woods, W. S., and George, J. M. (2004). Structural determinants of PLD2 inhibition by alpha-synuclein. J. Mol. Biol. 337, 1001-1009. doi: 10.1016/j.jmb.2004.02.014

Pei, J. J., Braak, E., Braak, H., Grundke-Iqbal, I., Iqbal, K., Winblad, B., et al. (1999). Distribution of active glycogen synthase kinase 3beta (GSK-3beta) in brains staged for Alzheimer disease neurofibrillary changes. J. Neuropathol. Exp. Neurol. 58, 1010-1019. doi: 10.1097/00005072-199909000-00011

Pei, J. J., Braak, E., Braak, H., Grundke-Iqbal, I., Iqbal, K., Winblad, B., et al. (2001). Localization of active forms of C-jun kinase (JNK) and p38 kinase in Alzheimer's disease brains at different stages of neurofibrillary degeneration. J. Alzheimers Dis. 3, 41-48.

Pei, J. J., Grundke-Iqbal, I., Iqbal, K., Bogdanovic, N., Winblad, B., and Cowburn, R. F. (1998). Accumulation of cyclin-dependent kinase 5 (cdk5) in neurons with early stages of Alzheimer's disease neurofibrillary degeneration. Brain Res. 797, 267-277.

Pinsetta, F. R., Taft, C. A., and De Paula Da Silva, C. H. (2014). Structure- and ligand-based drug design of novel p38-alpha MAPK inhibitors in the fight against the Alzheimer's disease. J. Biomol. Struct. Dyn. 32, 1047-1063. doi: 10.1080/07391102.2013.803441

Plouffe, V., Mohamed, N. V., Rivest-McGraw, J., Bertrand, J., Lauzon, M., and Leclerc, N. (2012). Hyperphosphorylation and cleavage at D421 enhance tau secretion. PLOS ONE 7:e36873. doi: 10.1371/journal.pone. 0036873

Polymeropoulos, M. H., Lavedan, C., Leroy, E., Ide, S. E., Dehejia, A., Dutra, A., et al. (1997). Mutation in the alpha-synuclein gene identified in families with Parkinson's disease. Science 276, 2045-2047.

Pronin, A. N., Morris, A. J., Surguchov, A., and Benovic, J. L. (2000). Synucleins are a novel class of substrates for $\mathrm{G}$ protein-coupled receptor kinases. J. Biol. Chem. 275, 26515-26522. doi: 10.1074/jbc.M003542200 
Qian, W., Jin, N., Shi, J., Yin, X., Jin, X., Wang, S., et al. (2013). Dual-specificity tyrosine phosphorylation-regulated kinase 1A (Dyrk1A) enhances tau expression. J. Alzheimers Dis. 37, 529-538. doi: 10.3233/JAD-130824

Qing, H., Wong, W., McGeer, E. G., and McGeer, P. L. (2009). Lrrk2 phosphorylates alpha synuclein at serine 129: Parkinson disease implications. Biochem. Biophys. Res. Commun. 387, 149-152. doi: 10.1016/j.bbrc.2009.06.142

Qureshi, H. Y., Han, D., Macdonald, R., and Paudel, H. K. (2013). Overexpression of 14-3-3z promotes tau phosphorylation at ser(262) and accelerates proteosomal degradation of synaptophysin in rat primary hippocampal neurons. PLoS ONE 8:e84615. doi: 10.1371/journal.pone.0084615

Rajput, A., Dickson, D. W., Robinson, C. A., Ross, O. A., Dachsel, J. C., Lincoln, S. J., et al. (2006). Parkinsonism, Lrrk2 G2019S, and tau neuropathology. Neurology 67, 1506-1508. doi: 10.1212/01.wnl.0000240220.33950.0c

Rametti, A., Esclaire, F., Yardin, C., Cogne, N., and Terro, F. (2008). Lithium down-regulates tau in cultured cortical neurons: a possible mechanism of neuroprotection. Neurosci. Lett. 434, 93-98. doi: 10.1016/j.neulet.2008.01.034

Rankin, C. A., Sun, Q., and Gamblin, T. C. (2008). Pre-assembled tau filaments phosphorylated by GSK-3b form large tangle-like structures. Neurobiol. Dis. 31, 368-377. doi: 10.1016/j.nbd.2008.05.011

Reiner, O., and Sapir, T. (2014). Mark/Par-1 marking the polarity of migrating neurons. Adv. Exp. Med. Biol. 800, 97-111. doi: 10.1007/978-94-007-7687-6_6

Rhein, V., Song, X., Wiesner, A., Ittner, L. M., Baysang, G., Meier, F., et al. (2009). Amyloid-beta and tau synergistically impair the oxidative phosphorylation system in triple transgenic Alzheimer's disease mice. Proc. Natl. Acad. Sci. U.S.A. 106, 20057-20062. doi: 10.1073/pnas.0905529106

Ribeiro, F. M., Camargos, E. R., De Souza, L. C., and Teixeira, A. L. (2013). Animal models of neurodegenerative diseases. Rev. Bras. Psiquiatr. 35(Suppl. 2), S82-S91. doi: 10.1590/1516-4446-2013-1157

Rochet, J. C., Conway, K. A., and Lansbury, P. T. Jr. (2000). Inhibition of fibrillization and accumulation of prefibrillar oligomers in mixtures of human and mouse alpha-synuclein. Biochemistry 39, 10619-10626. doi: 10.1021/bi001315u

Rodriguez-Martin, T., Cuchillo-Ibanez, I., Noble, W., Nyenya, F., Anderton, B. H., and Hanger, D. P. (2013). Tau phosphorylation affects its axonal transport and degradation. Neurobiol. Aging 34, 2146-2157. doi: 10.1016/j.neurobiolaging.2013.03.015

Rosenmann, H., Grigoriadis, N., Karussis, D., Boimel, M., Touloumi, O., Ovadia, H., et al. (2006). Tauopathy-like abnormalities and neurologic deficits in mice immunized with neuronal tau protein. Arch. Neurol. 63, 1459-1467. doi: 10.1001/archneur.63.10.1459

Rozenstein-Tsalkovich, L., Grigoriadis, N., Lourbopoulos, A., Nousiopoulou, E., Kassis, I., Abramsky, O., et al. (2013). Repeated immunization of mice with phosphorylated-tau peptides causes neuroinflammation. Exp. Neurol. 248, 451-456. doi: 10.1016/j.expneurol.2013.07.006

Ryu, M. Y., Kim, D. W., Arima, K., Mouradian, M. M., Kim, S. U., and Lee, G. (2008). Localization of CKII beta subunits in Lewy bodies of Parkinson's disease. J. Neurol. Sci. 266, 9-12. doi: 10.1016/j.jns.2007.08.027

Saha, A. R., Hill, J., Utton, M. A., Asuni, A. A., Ackerley, S., Grierson, A. J., et al. (2004). Parkinson's disease alpha-synuclein mutations exhibit defective axonal transport in cultured neurons. J. Cell Sci. 117, 1017-1024. doi: 10.1242/jcs.00967

Sahara, N., and Avila, J. (2014). “Tau oligomers," what we know and what we don't know. Front. Neurol. 5:1. doi: 10.3389/fneur.2014.00001

Sahara, N., Deture, M., Ren, Y., Ebrahim, A. S., Kang, D., Knight, J., et al. (2013). Characteristics of TBS-extractable hyperphosphorylated tau species: aggregation intermediates in rTg4510 mouse brain. J. Alzheimers Dis. 33, 249-263. doi: 10.3233/JAD-2012-121093

Saito, Y., Kawashima, A., Ruberu, N. N., Fujiwara, H., Koyama, S., Sawabe, M., et al. (2003). Accumulation of phosphorylated alpha-synuclein in aging human brain. J. Neuropathol. Exp. Neurol. 62, 644-654.

Sakamoto, M., Arawaka, S., Hara, S., Sato, H., Cui, C., Machiya, Y., et al. (2009). Contribution of endogenous G-protein-coupled receptor kinases to Ser129 phosphorylation of alpha-synuclein in HEK293 cells. Biochem. Biophys. Res. Commun. 384, 378-382. doi: 10.1016/j.bbrc.2009.04.130

Salazar, C., and Hofer, T. (2009). Multisite protein phosphorylation-from molecular mechanisms to kinetic models. FEBS J. 276, 3177-3198. doi: 10.1111/j.17424658.2009.07027.x

Sancenon, V., Lee, S. A., Patrick, C., Griffith, J., Paulino, A., Outeiro, T. F., et al. (2012). Suppression of alpha-synuclein toxicity and vesicle trafficking defects by phosphorylation at S129 in yeast depends on genetic context. Hum. Mol. Genet. 21, 2432-2449. doi: 10.1093/hmg/dds058
Sato-Harada, R., Okabe, S., Umeyama, T., Kanai, Y., and Hirokawa, N. (1996). Microtubule-associated proteins regulate microtubule function as the track for intracellular membrane organelle transports. Cell Struct. Funct. 21, 283-295. doi: $10.1247 /$ csf.21.283

Sayas, C. L., Avila, J., and Wandosell, F. (2002). Regulation of neuronal cytoskeleton by lysophosphatidic acid: role of GSK-3. Biochim. Biophys. Acta 1582, 144-153. doi: 10.1016/S1388-1981(02)00149-X

Schlatterer, S. D., Acker, C. M., and Davies, P. (2011). c-Abl in neurodegenerative disease. J. Mol. Neurosci. 45, 445-452. doi: 10.1007/s12031-011-9588-1

Schneider, A., Biernat, J., Von Bergen, M., Mandelkow, E., and Mandelkow, E. M. (1999). Phosphorylation that detaches tau protein from microtubules (Ser262, Ser214) also protects it against aggregation into Alzheimer paired helical filaments. Biochemistry 38, 3549-3558. doi: 10.1021/bi981874p

Schreurs, S., Gerard, M., Derua, R., Waelkens, E., Taymans, J. M., Baekelandt, V., et al. (2014). In vitro phosphorylation does not influence the aggregation kinetics of WT alpha-synuclein in contrast to its phosphorylation mutants. Int. J. Mol. Sci. 15, 1040-1067. doi: 10.3390/ijms15011040

Schwalbe, M., Biernat, J., Bibow, S., Ozenne, V., Jensen, M. R., Kadavath, H., et al. (2013). Phosphorylation of human tau protein by microtubule affinityregulating kinase 2. Biochemistry 52, 9068-9079. doi: 10.1021/bi401266n

Scott, D., and Roy, S. (2012). alpha-Synuclein inhibits intersynaptic vesicle mobility and maintains recycling-pool homeostasis. J. Neurosci. 32, 10129-10135. doi: 10.1523/JNEUROSCI.0535-12.2012

Seeburg, D. P., Feliu-Mojer, M., Gaiottino, J., Pak, D. T., and Sheng, M. (2008). Critical role of CDK5 and Polo-like kinase 2 in homeostatic synaptic plasticity during elevated activity. Neuron 58, 571-583. doi: 10.1016/j.neuron.2008.03.021

Seeburg, D. P., Pak, D., and Sheng, M. (2005). Polo-like kinases in the nervous system. Oncogene 24, 292-298. doi: 10.1038/sj.onc.1208277

Selenica, M. L., Brownlow, M., Jimenez, J. P., Lee, D. C., Pena, G., Dickey, C. A., et al. (2013). Amyloid oligomers exacerbate tau pathology in a mouse model of tauopathy. Neurodegener. Dis. 11, 165-181. doi: 10.1159/000337230

Selvatici, R., Marani, L., Marino, S., and Siniscalchi, A. (2013). In vitro mitochondrial failure and oxidative stress mimic biochemical features of Alzheimer disease. Neurochem. Int. 63, 112-120. doi: 10.1016/j.neuint.2013. 05.005

Sengupta, A., Kabat, J., Novak, M., Wu, Q., Grundke-Iqbal, I., and Iqbal, K. (1998). Phosphorylation of tau at both Thr 231 and Ser 262 is required for maximal inhibition of its binding to microtubules. Arch. Biochem. Biophys. 357, 299-309. doi: 10.1006/abbi.1998.0813

Shahpasand, K., Uemura, I., Saito, T., Asano, T., Hata, K., Shibata, K., et al. (2012). Regulation of mitochondrial transport and inter-microtubule spacing by tau phosphorylation at the sites hyperphosphorylated in Alzheimer's disease. J. Neurosci. 32, 2430-2441. doi: 10.1523/JNEUROSCI.5927-11.2012

Sharma, P., Veeranna, Sharma, M., Amin, N. D., Sihag, R. K., Grant, P., et al. (2002). Phosphorylation of MEK1 by cdk5/p35 down-regulates the mitogen-activated protein kinase pathway. J. Biol. Chem. 277, 528-534. doi: 10.1074/jbc.M109324200

Shimura, H., Schlossmacher, M. G., Hattori, N., Frosch, M. P., Trockenbacher, A., Schneider, R., et al. (2001). Ubiquitination of a new form of alpha-synuclein by parkin from human brain: implications for Parkinson's disease. Science 293, 263-269. doi: 10.1126/science.1060627

Shimura, H., Schwartz, D., Gygi, S. P., and Kosik, K. S. (2004). CHIP-Hsc70 complex ubiquitinates phosphorylated tau and enhances cell survival. J. Biol. Chem. 279, 4869-4876. doi: 10.1074/jbc.M305838200

Shukla, V., Skuntz, S., and Pant, H. C. (2012). Deregulated Cdk5 activity is involved in inducing Alzheimer's disease. Arch. Med. Res. 43, 655-662. doi: 10.1016/j.arcmed.2012.10.015

Sibille, N., Huvent, I., Fauquant, C., Verdegem, D., Amniai, L., Leroy, A., et al. (2011). Structural characterization by nuclear magnetic resonance of the impact of phosphorylation in the proline-rich region of the disordered Tau protein. Proteins. doi: 10.1002/prot.23210. [Epub ahead of print].

Siddiqui, A., Chinta, S. J., Mallajosyula, J. K., Rajagopolan, S., Hanson, I., Rane, A., et al. (2012). Selective binding of nuclear alpha-synuclein to the PGClalpha promoter under conditions of oxidative stress may contribute to losses in mitochondrial function: implications for Parkinson's disease. Free Radic. Biol. Med. 53, 993-1003. doi: 10.1016/j.freeradbiomed.2012.05.024

Singleton, A. B., Farrer, M., Johnson, J., Singleton, A., Hague, S., Kachergus, J., et al. (2003). alpha-Synuclein locus triplication causes Parkinson's disease. Science 302, 841. doi: 10.1126/science.1090278 
Smet-Nocca, C., Broncel, M., Wieruszeski, J. M., Tokarski, C., Hanoulle, X., Leroy, A., et al. (2011). Identification of O-GlcNAc sites within peptides of the Tau protein and their impact on phosphorylation. Mol. Biosyst. 7, 1420-1429. doi: 10.1039/c0mb00337a

Smith, W. W., Margolis, R. L., Li, X., Troncoso, J. C., Lee, M. K., Dawson, V. L., et al. (2005). Alpha-synuclein phosphorylation enhances eosinophilic cytoplasmic inclusion formation in SH-SY5Y cells. J. Neurosci. 25, 5544-5552. doi: 10.1523/JNEUROSCI.0482-05.2005

Snyder, H., Mensah, K., Theisler, C., Lee, J., Matouschek, A., and Wolozin, B. (2003). Aggregated and monomeric alpha-synuclein bind to the S6' proteasomal protein and inhibit proteasomal function. J. Biol. Chem. 278, 11753-11759. doi: 10.1074/jbc.M208641200

Spillantini, M. G., Schmidt, M. L., Lee, V. M., Trojanowski, J. Q., Jakes, R., and Goedert, M. (1997). Alpha-synuclein in Lewy bodies. Nature 388, 839-840. doi: $10.1038 / 42166$.

Spilman, P., Descamps, O., Gorostiza, O., Peters-Libeu, C., Poksay, K. S., Matalis, A., et al. (2013). The multi-functional drug tropisetron binds APP and normalizes cognition in a murine Alzheimer's model. Brain Res. 1551, 25-44. doi: 10.1016/ j.brainres.2013.12.029

Spires-Jones, T. L., Friedman, T., Pitstick, R., Polydoro, M., Roe, A., Carlson, G. A., et al. (2014). Methylene blue does not reverse existing neurofibrillary tangle pathology in the rTg4510 mouse model of tauopathy. Neurosci. Lett. 562, 63-68. doi: 10.1016/j.neulet.2014.01.013

Steinhilb, M. L., Dias-Santagata, D., Mulkearns, E. E., Shulman, J. M., Biernat, J., Mandelkow, E. M., et al. (2007). S/P and T/P phosphorylation is critical for tau neurotoxicity in Drosophila. J. Neurosci. Res. 85, 1271-1278. doi: 10.1002/jnr.21232

Sun, Q., and Gamblin, T. C. (2009). Pseudohyperphosphorylation causing AD-like changes in tau has significant effects on its polymerization. Biochemistry 48 , 6002-6011. doi: 10.1021/bi900602h

Tackenberg, C., and Brandt, R. (2009). Divergent pathways mediate spine alterations and cell death induced by amyloid-beta, wild-type tau, and R406W tau. J. Neurosci. 29, 14439-14450. doi: 10.1523/JNEUROSCI.3590-09.2009

Tai, H. C., Serrano-Pozo, A., Hashimoto, T., Frosch, M. P., Spires-Jones, T. L., and Hyman, B. T. (2012). The synaptic accumulation of hyperphosphorylated tau oligomers in Alzheimer disease is associated with dysfunction of the ubiquitin-proteasome system. Am. J. Pathol. 181, 1426-1435. doi: 10.1016/j.ajpath.2012.06.033

Takahashi, M., Ko, L. W., Kulathingal, J., Jiang, P., Sevlever, D., and Yen, S. H. (2007). Oxidative stress-induced phosphorylation, degradation and aggregation of alpha-synuclein are linked to upregulated CK2 and cathepsin D. Eur J. Neurosci. 26, 863-874. doi: 10.1111/j.1460-9568.2007.05736.x

Tanaka, M., Kim, Y. M., Lee, G., Junn, E., Iwatsubo, T., and Mouradian, M. M. (2004). Aggresomes formed by alpha-synuclein and synphilin-1 are cytoprotective. J. Biol. Chem. 279, 4625-4631. doi: 10.1074/jbc.M310994200

Tanaka, Y., Engelender, S., Igarashi, S., Rao, R. K., Wanner, T., Tanzi, R. E., et al. (2001). Inducible expression of mutant alpha-synuclein decreases proteasome activity and increases sensitivity to mitochondria-dependent apoptosis. Hum. Mol. Genet. 10, 919-926. doi: 10.1093/hmg/10.9.919

Tarantino, P., De Marco, E. V., Annesi, G., Rocca, F. E., Annesi, F., Civitelli, D., et al. (2011). Lack of association between G-protein coupled receptor kinase 5 gene and Parkinson's disease. Am. J. Med. Genet. B Neuropsychiatr. Genet. 156B, 104-107. doi: 10.1002/ajmg.b.31129

Tatebayashi, Y., Haque, N., Tung, Y. C., Iqbal, K., and Grundke-Iqbal, I. (2004). Role of tau phosphorylation by glycogen synthase kinase-3beta in the regulation of organelle transport. J. Cell Sci. 117, 1653-1663. doi: 10.1242/jcs.01018

Tell, V., and Hilgeroth, A. (2013). Recent developments of protein kinase inhibitors as potential AD therapeutics. Front Cell. Neurosci. 7:189. doi: 10.3389/fncel.2013.00189

Tenreiro, S., Reimão-Pinto, M. M., Antas, P., Rino, J., Wawrzycka, D., Macedo, D., et al. (2014). Phosphorylation modulates clearance of alpha-synuclein inclusions in a yeast model of Parkinson's disease. PLoS Genet. 10:e1004302. doi: 10.1371/journal.pgen.1004302

Terwel, D., Muyllaert, D., Dewachter, I., Borghgraef, P., Croes, S., Devijver, H., et al. (2008). Amyloid activates GSK-3beta to aggravate neuronal tauopathy in bigenic mice. Am. J. Pathol. 172, 786-798. doi: 10.2353/ajpath.2008.070904

Thies, E., and Mandelkow, E. M. (2007). Missorting of tau in neurons causes degeneration of synapses that can be rescued by the kinase MARK2/Par-1. J. Neurosci. 27, 2896-2907. doi: 10.1523/JNEUROSCI.4674-06.2007
Timm, T., Balusamy, K., Li, X., Biernat, J., Mandelkow, E., and Mandelkow, E. M. (2008). Glycogen synthase kinase (GSK) 3beta directly phosphorylates Serine 212 in the regulatory loop and inhibits microtubule affinityregulating kinase (MARK) 2. J. Biol. Chem. 283, 18873-18882. doi: 10.1074/jbc. M706596200

Trinczek, B., Ebneth, A., Mandelkow, E. M., and Mandelkow, E. (1999). Tau regulates the attachment/detachment but not the speed of motors in microtubuledependent transport of single vesicles and organelles. J. Cell Sci. 112(Pt 14), 2355-2367.

Troquier, L., Caillierez, R., Burnouf, S., Fernandez-Gomez, F. J., Grosjean, M. E., Zommer, N., et al. (2012). Targeting phospho-Ser422 by active Tau Immunotherapy in the THYTau22 mouse model: a suitable therapeutic approach. Curr. Alzheimer Res. 9, 397-405. doi: 10.2174/156720512800492503

Ujiie, S., Hatano, T., Kubo, S., Imai, S., Sato, S., Uchihara, T., et al. (2012). LRRK2 I2020T mutation is associated with tau pathology. Parkinsonism Relat. Disord. 18, 819-823. doi: 10.1016/j.parkreldis.2012.03.024

Um, J. W., Nygaard, H. B., Heiss, J. K., Kostylev, M. A., Stagi, M., Vortmeyer, A., et al. (2012). Alzheimer amyloid-beta oligomer bound to postsynaptic prion protein activates Fyn to impair neurons. Nat. Neurosci. 15, 1227-1235. doi: 10.1038/nn.3178

Von Bergen, M., Friedhoff, P., Biernat, J., Heberle, J., Mandelkow, E. M., and Mandelkow, E. (2000). Assembly of tau protein into Alzheimer paired helical filaments depends on a local sequence motif ((306)VQIVYK(311)) forming beta structure. Proc. Natl. Acad. Sci. U.S.A. 97, 5129-5134. doi: 10.1073/pnas.97.10. 5129

Wakamatsu, M., Ishii, A., Ukai, Y., Sakagami, J., Iwata, S., Ono, M., et al. (2007). Accumulation of phosphorylated alpha-synuclein in dopaminergic neurons of transgenic mice that express human alpha-synuclein. J. Neurosci. Res. 85, 1819-1825. doi: 10.1002/jnr.21310

Wang, H. H., Li, H. L., Liu, R., Zhang, Y., Liao, K., Wang, Q., et al. (2010). Tau overexpression inhibits cell apoptosis with the mechanisms involving multiple viability-related factors. J. Alzheimers Dis. 21, 167-179. doi: 10.3233/JAD-2010091279

Waxman, E. A., and Giasson, B. I. (2008). Specificity and regulation of casein kinase-mediated phosphorylation of alpha-synuclein. J. Neuropathol. Exp. Neurol. 67, 402-416. doi: 10.1097/NEN.0b013e3186fc995

Waxman, E. A., and Giasson, B. I. (2011). Characterization of kinases involved in the phosphorylation of aggregated alpha-synuclein. J. Neurosci. Res. 89, 231-247. doi: 10.1002/jnr.22537

Wegiel, J., Dowjat, K., Kaczmarski, W., Kuchna, I., Nowicki, K., Frackowiak, J., et al. (2008). The role of overexpressed DYRK1A protein in the early onset of neurofibrillary degeneration in Down syndrome. Acta Neuropathol. 116, 391-407. doi: 10.1007/s00401-008-0419-6

Wen, Y., Planel, E., Herman, M., Figueroa, H. Y., Wang, L., Liu, L., et al. (2008). Interplay between cyclin-dependent kinase 5 and glycogen synthase kinase 3 beta mediated by neuregulin signaling leads to differential effects on tau phosphorylation and amyloid precursor protein processing. J. Neurosci. 28, 2624-2632. doi: 10.1523/JNEUROSCI.5245-07.2008

Wischik, C. M., Harrington, C. R., and Storey, J. M. (2013). Tau-aggregation inhibitor therapy for Alzheimer's disease. Biochem. Pharmacol. 88, 529-539. doi: 10.1016/j.bcp.2013.12.008

Wischik, C. M., Novak, M., Thogersen, H. C., Edwards, P. C., Runswick, M. J., Jakes, R., et al. (1988). Isolation of a fragment of tau derived from the core of the paired helical filament of Alzheimer disease. Proc. Natl. Acad. Sci. U.S.A. 85, 4506-4510. doi: 10.1073/pnas.85.12.4506

Wright, J. A., Wang, X., and Brown, D. R. (2009). Unique copper-induced oligomers mediate alpha-synuclein toxicity. FASEB J. 23, 2384-2393. doi: 10.1096/fj.09130039

Wu, B., Liu, Q., Duan, C., Li, Y., Yu, S., Chan, P., et al. (2011a). Phosphorylation of alpha-synuclein upregulates tyrosine hydroxylase activity in MN9D cells. Acta Histochem. 113, 32-35. doi: 10.1016/j.acthis.2009.07.007

Wu, P. R., Tsai, P. I., Chen, G. C., Chou, H. J., Huang, Y. P., Chen, Y. H., et al. (2011b). DAPK activates MARK1/2 to regulate microtubule assembly, neuronal differentiation, and tau toxicity. Cell Death Differ. 18, 1507-1520. doi: 10.1038/cdd.2011.2.

Xu, S., Zhou, M., Yu, S., Cai, Y., Zhang, A., Ueda, K., et al. (2006). Oxidative stress induces nuclear translocation of C-terminus of alpha-synuclein in dopaminergic cells. Biochem. Biophys. Res. Commun. 342, 330-335. doi: 10.1016/j.bbrc.2006.01.148 
Yamada, M., Iwatsubo, T., Mizuno, Y., and Mochizuki, H. (2004). Overexpression of alpha-synuclein in rat substantia nigra results in loss of dopaminergic neurons, phosphorylation of alpha-synuclein and activation of caspase-9: resemblance to pathogenetic changes in Parkinson's disease. J. Neurochem. 91, 451-461. doi: 10.1111/j.1471-4159.2004.02728.X

Yang, X., Yang, Y., Fu, Z., Li, Y., Feng, J., Luo, J., et al. (2011). Melatonin ameliorates Alzheimer-like pathological changes and spatial memory retention impairment induced by calyculin A. J. Psychopharmacol. 25, 1118-1125. doi: 10.1177/0269881110367723

Yasojima, K., Kuret, J., Demaggio, A. J., McGeer, E., and McGeer, P. L. (2000). Casein kinase 1 delta mRNA is upregulated in Alzheimer disease brain. Brain Res. 865, 116-120. doi: 10.1016/S0006-8993(00)02200-9

Ye, Q., Shen, Y., Zhou, Y., Lv, D., Gao, J., Li, J., et al. (2013). Design, synthesis and evaluation of 7-azaindazolyl-indolyl-maleimides as glycogen synthase kinase-3beta (GSK-3beta) inhibitors. Eur J. Med. Chem. 68, 361-371. doi: 10.1016/j.ejmech.2013.07.046

Yu, W., Polepalli, J., Wagh, D., Rajadas, J., Malenka, R., and Lu, B. (2012). A critical role for the PAR-1/MARK-tau axis in mediating the toxic effects of Abeta on synapses and dendritic spines. Hum. Mol. Genet. 21, 1384-1390. doi: 10.1093/hmg/ddr576

Yuzwa, S. A., Shan, X., Macauley, M. S., Clark, T., Skorobogatko, Y., Vosseller, K., et al. (2012). Increasing O-GlcNAc slows neurodegeneration and stabilizes tau against aggregation. Nat. Chem. Biol. 8, 393-399. doi: 10.1038/ nchembio.797

Zabrocki, P., Bastiaens, I., Delay, C., Bammens, T., Ghillebert, R., Pellens, K., et al. (2008). Phosphorylation, lipid raft interaction and traffic of alpha-synuclein in a yeast model for Parkinson. Biochim. Biophys. Acta 1783, 1767-1780. doi: 10.1016/j.bbamcr.2008.06.010

Zarranz, J. J., Alegre, J., Gomez-Esteban, J. C., Lezcano, E., Ros, R., Ampuero, I., et al. (2004). The new mutation, E46K, of alpha-synuclein causes Parkinson and Lewy body dementia. Ann. Neurol. 55, 164-173. doi: 10.1002/ana.10795

Zempel, H., Thies, E., Mandelkow, E., and Mandelkow, E. M. (2010). Abeta oligomers cause localized $\mathrm{Ca}(2+)$ elevation, missorting of endogenous Tau into dendrites, Tau phosphorylation, and destruction of microtubules and spines. J. Neurosci. 30, 11938-11950. doi: 10.1523/JNEUROSCI.2357-10.2010

Zhao, W., Cavallaro, S., Gusev, P., and Alkon, D. L. (2000). Nonreceptor tyrosine protein kinase pp60c-src in spatial learning: synapse-specific changes in its gene expression, tyrosine phosphorylation, and protein-protein interactions. Proc. Natl. Acad. Sci. U.S.A. 97, 8098-8103. doi: 10.1073/pnas.97.14.8098

Zhao, Y., Ho, P., Yih, Y., Chen, C., Lee, W. L., and Tan, E. K. (2011). LRRK2 variant associated with Alzheimer's disease. Neurobiol. Aging 32, 1990-1993. doi: 10.1016/j.neurobiolaging.2009.11.019

Zheng, Y. L., Li, B. S., Kanungo, J., Kesavapany, S., Amin, N., Grant, P., et al. (2007). Cdk5 Modulation of mitogen-activated protein kinase signaling regulates neuronal survival. Mol. Biol. Cell 18, 404-413. doi: 10.1091/mbc.E06-09-0851

Zhu, X., Castellani, R. J., Takeda, A., Nunomura, A., Atwood, C. S., Perry, G., et al. (2001). Differential activation of neuronal ERK, JNK/SAPK and p38 in Alzheimer disease: the 'two hit' hypothesis. Mech. Ageing Dev. 123, 39-46. doi: 10.1016/S0047-6374(01)00342-6

Conflict of Interest Statement: The authors declare that the research was conducted in the absence of any commercial or financial relationships that could be construed as a potential conflict of interest.

Received: 25 February 2014; paper pending published: 18 March 2014; accepted: 22 April 2014; published online: 13 May 2014

Citation: Tenreiro S, Eckermann K and Outeiro TF (2014) Protein phosphorylation in neurodegeneration: friend or foe? Front. Mol. Neurosci. 7:42. doi: 10.3389/fnmol. 2014.00042

This article was submitted to the journal Frontiers in Molecular Neuroscience.

Copyright (c) 2014 Tenreiro, Eckermann and Outeiro. This is an open-access article distributed under the terms of the Creative Commons Attribution License (CC BY). The use, distribution or reproduction in other forums is permitted, provided the original author(s) or licensor are credited and that the original publication in this journal is cited, in accordance with accepted academic practice. No use, distribution or reproduction is permitted which does not comply with these terms. 